\title{
Standardized assessment of ill-defined clinical problems : the script concordance test
}

Citation for published version (APA):

Charlin, B. (2002). Standardized assessment of ill-defined clinical problems : the script concordance test. [Doctoral Thesis, Maastricht University]. Datawyse / Universitaire Pers Maastricht. https://doi.org/10.26481/dis.20021129bc

Document status and date:

Published: 01/01/2002

DOI:

$10.26481 /$ dis.20021129bc

Document Version:

Publisher's PDF, also known as Version of record

\section{Please check the document version of this publication:}

- A submitted manuscript is the version of the article upon submission and before peer-review. There can be important differences between the submitted version and the official published version of record.

People interested in the research are advised to contact the author for the final version of the publication, or visit the DOI to the publisher's website.

- The final author version and the galley proof are versions of the publication after peer review.

- The final published version features the final layout of the paper including the volume, issue and page numbers.

Link to publication

\footnotetext{
General rights rights.

- You may freely distribute the URL identifying the publication in the public portal. please follow below link for the End User Agreement:

www.umlib.nl/taverne-license

Take down policy

If you believe that this document breaches copyright please contact us at:

repository@maastrichtuniversity.nl

providing details and we will investigate your claim.
}

Copyright and moral rights for the publications made accessible in the public portal are retained by the authors and/or other copyright owners and it is a condition of accessing publications that users recognise and abide by the legal requirements associated with these

- Users may download and print one copy of any publication from the public portal for the purpose of private study or research.

- You may not further distribute the material or use it for any profit-making activity or commercial gain

If the publication is distributed under the terms of Article $25 \mathrm{fa}$ of the Dutch Copyright Act, indicated by the "Taverne" license above, 
Standardized assessment of ill-defined clinical problems 
B Charlin, Montreal 2002

ISBN 9052783624

Datawyse / Umiversitaire Pers Maastricht 


\title{
Standardized assessment of ill-defined clinical problems The script concordance test
}

\author{
PROEFSCHRIFT \\ ter verkrijging van de graad van doctor \\ aan de Universiteit Maastricht, op gezag van \\ de Rector Magnificus Prof. Dr. A.C. Nieuwenhuijzen Kruseman, \\ volgens het besluit van het College van Decanen, \\ in het opembaar te verdedigen \\ op vrijdag 29 november 2002 om 10.00 uur \\ door
}

Bernard Charlin

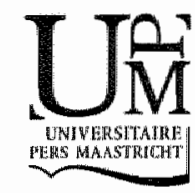


PROMOTOR

Prof. dr. C.P.M. van der Vleuten

BEOORDELINGSCOMMISSIE

Prof.dr. A.J.J.A. Scherpbier (voorzitter)

Prof.dr. D. Dauphinee (Medical Council of Canada)

Prof.dr. E. Heineman

Prof.dr. H.G. Schmidt (Erasmus Universiteit Rotterdam)

Dr. L.W.T. Schuwirth 
To Françoise and Andre with whom everything began. to Andrée who illuminates everything, to Stéphanie and Laurent who are joy and hope. 


\section{Table of contents}

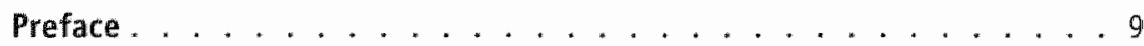

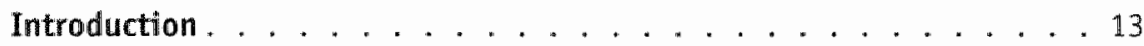

Chapter one: A theory of clinical knowledge organization

Scripts and Medical Diagnostic Knowledge: Theory and Applications for Clinical Reasoning Instruction and Research (in collaboration with J. Tardif and H.P.A. Boshuizen) . . . . . . . . . . . . . . 23

Published in Academic Medicine 2000, 75: 182-190

Chapter two: From theory to clinical reasoning assessment

The Script Concordance Test, a Tool to Assess the Reflective Clinician (in collaboration with L. Roy, C. Brailowsky and C. van der Vleuten) . . . . . . 39 Published in Teaching and Learning in Medicine 2000, 12: 189-195

Chapter three: Overcoming the intermediate effect

The Diagnostic Script Questionnaire: A New Tool to Assess a Specific Dimension of Clinical Competence (in collaboration with C. Brailovsky, C. Leduc and D. Blouin) . . . . . . . . . . . . . . . 51 Published in Advances in Heath Sciences Education, 1998, 3:51-58

Chapter four: A comparison between the aggregate and the consensus method

Comparison of an aggregate scoring method with a consensus scoring method in a measure of clinical reasoning capacity (in collaboration with M. Desaulniers, R. Gagnon, D. Blouin and C. van der Vleuten) . . . . . . 61 Published in Teaching and Learning in Medicine, 2002, 14: 148-154

Chapter five: Stability of the tool across cultures

Stability of clinical reasoning assessment results with the script concordance test across two different linguistic, cultural and learning environments (in collaboration with L. Sibert, J. Corcos, R. Gagnon, P. Grise

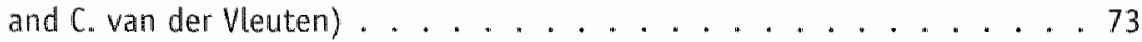
Published in Medical Teacher, 2002, 24:537-542 
Chapter six: The growth of interpretation skill measured with the SCT: A study in radiology Measurement of competence in radiology: Evolution of knowledge elaboration and perception skill scores along training (in collaboration with L. Brazeau-Lamontagne, R. Gagnon, L. Samson, C. Van der Vleuten) . . . 85 Submitted to Radiology, August 2002

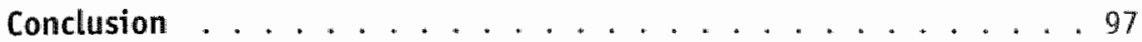

Summary . . . . . . . . . . . . . 107

Samenvatting. ......................... 111

Curriculum Vitae . . . . . . . . . . . 115 



\section{PREFACE}

This Ph.D. dissertation, as any piece of work obtained through sustained effort, is the result of a personal odyssey. In its preface, I will briefly describe a twelve-year journey in which, from an onset characterized by unclear and fuzzy goals, something significant with many potential developments progressively emerged and took place in front of my eyes. Over this long period the feeling was close to the shorter one I frequently savor in analyses of data sets where a precise meaning progressively emerges from the mass of initial data. It is something that is each time very gratifying and represents one of the great joys of research. During this description, I will pay tribute to a few persons who were my masters. In France, my country of origin, we call «my mastern a teacher with a lot of clinical experience and insight who, through years of professional contact, help you to acquire the tacit knowledge, skills and values of your discipline and shape the way you practice. I had the chance to have several masters in medicine and in education. In this text I will talk of those met in education.

The description of this several-year journey might seem pretentious, since it implies that I have produced something valuable for the community. In fact, I hope I have. It would be sad if twelve years of work had produced nothing of interest. But my main goal is to share with younger colleagues the way taken. At a time where education leaders such as Richard Reznick in Canada, or Jacques. Barrier in France, insist on the importance for medical educators to professionalize the education part of their academic career, the description of the path followed by one of them might be useful. It may help these colleagues to skip over some difficulties and get quicker to their goal achievements.

The adventure began at the end of the 1980s. I was practicing as head and neck oncology surgeon and was beginning to get more and more involved as educator. After having taken a year-long course on principles of teaching and learning in medical education, I assumed for a few years the position of director of the specialty program of ear, nose and throat. A few years later, I became responsible of 
the clinical part of the pre-graduate curriculum, with the mission of adapting it to the principles of our new problem-based curriculum.

In that task, I had frequent encounters with my first «masters in education, also a surgeon, Jacques DesMarchais. He deeply influenced my education practice. He has a deep knowledge of the literature of the field and a strong sense of where education should go. He also regularly submitted educational innovation introduced in the school curriculum to the judgment of the international community of medical educators either by podium presentations or by papers in scientific journals. Among many things, he taught me not to fear what keeps many from pursuing their publication endeavor, the rejection-resubmission process. Refusal of a paper is not a rejection of your work. It is a feedback on your work stating that in its present state the paper is not yet publishable. Most of the time, if you use advice provided, and you resubmit, you end up with the satisfaction of a published paper. With such a model of career, and with his strong support, I begam a master degree in education in sherbrooke, to get a formal education in research.

At that time, I was already convinced that a career in education, even for those who have significant clinical activities, should rest on scientific knowledge production. Innovation should come from observation of practice and detection of area in need of improvement. Innovation should be based on theory and on a thorough reading of the important body of medical education literature. Innovation when implanted should then be observed in scientific manner and be submitted to the judgment of peers through the publication process. If this is not undertaken, it is easy to work in small group of educators who share the same beliefs and educational background and build systems that have face value but do not stand critical scrutiny. These feelings were later strongly reinforced by «a master» I had in my courses toward the master degree, Georges Bordage. He too had and still has a strong influence on my endeavor. Besides a role model such as Georges, I also had the surprise to discover that not all share the scientific approach in ed. ucation. The road is therefore sometime scattered with obstacles. A Dean, Michel Bureau, told me once that to become a researcher one has to be stubborn. This took place in my mind; friends may add this has not improved my temper!

At that time I also had a uéfaut de jeunesse» that caused trouble to another «mastery I had the chance to meet, Jacques Tardif, who was my thesis director for the master degree. I told him that I wanted to find a theme on which I could work for ten years. The trouble came from the enthusiasm novices ofter have when they discover the richness of education literature. They fall in love with many themes. It may have been worst in my case, because of a facility to write. I brought him almost each month a new twenty-page set covering another wonderful research theme! This lasted up to the moment he wrote an almost desperate letter asking me to make a choice and deepen my reflection. Jacques is an extraordinary teacher and writer on cognitive psychology. With his help I discovered a wonderful trend of science that is profoundly influencing medical education. 
Then, within that discovery process, one of my readings on categorization stroked me. Edward Smith's script-based categorization model depicted exactly the manner I processed data in clinical situations. I began to ask colleagues around me, all had the same feeling. The model had strong face validity! At the same time Michel Fayol, a French friend and a very respected researcher in cognitive psychology, published an article in the international psychology literature explaining the importance of the script concept. I had found my research theme! It would be the transfer of the cognitive psychology script concept to the clinical reasoning field, and its use to better understand this reasoning process with the goal of improving its acquisition and development by health professionals.

Adapting the script theory to clinical reasoning implied several steps, the first being a thorough reading of clinical reasoning research literature. The second was to conceptualize a model of how scripts may be organized to explain the performance cognition in clinical settings represents. The third was to choose one of the research-based models proposed in the literature (I took Barrows one) and describe how the script theory explained performance at each stage of the process. The final step was to define how the theory could be articulated with competing theories of clinical reasoning proposed by such prominent authors such as Barrows, Bordage, Boshuizen, Elstein, Grant, Norman, Schmidt or Patel, to cite only a few. While working on the script concept with the help of Els Boshuizen and Jacques Tardif, I became convinced that the script concept was not a competitor of the other models. It was rather gathering apparently dissimilar theoretical stands and able to explain several research data obtained by other researchers. This work ended up in a 130-page thesis. I tried then to transform it into a paper aimed to a major medical education journal. The paper was refused by two journals. This showed me the limits of the practice of writing traditional theses to obtain degrees in Education. With a traditional thesis, you have no length limit, and you don't have to keep in mind the characteristics of readers from your own profession that are not familiar with jargon and technical concepts that are far from practice. This gave me a lesson for the future. When I would undertake a Ph.D., I would choose a University and a mentor that would accept dissertation by articles. Concerning the paper on the script theory, I had to place it aside for a few years, forget non useful details and adjust the concepts to the sensibility of my profession. Academic Medicine then accepted the paper without difficulty.

Toward the end of the master Degree, I felt I still not had all skills needed to become an efficient researcher. I was not clever enough in research design, quantitative or qualitative analysis methods, and use of statistical tools. I therefore registered as a student at Harvard Graduate School of Education and took a one year long Certificate of Advanced Studies in Human Development and Psychology, with a concentration in research methodology. A very demanding year begar. The encounter of another «master», $a$ teacher of statistics and methodology, named John B. Willet rewarded it. Besides his extraordinary skill to teach difficult concepts and make them clear to audiences without much mathematicat background, 
he used evaluation as an intrinsic part of the educational process. We were placed in authentic researcher situations and had to answer clear research questions. We were provided real life contexts and large data sets and had to make data analyses (that took weeks to complete), and present results exactly as a scientific paper has to be. I discovered there the joy of data analysis that I referred to at the beginning of the preface.

Very early in the process of writing the adaptation of script theory to clinical reasoning, I realized its potential for assessment. Some principles soon emerged. (1) It should be based on authentic problematic situations. (2) Items should be made with options experts have in mind and actions they take in these situations. (3) Responses should be captured in a manner that reflects real reasoning processes. (4) The scoring method should reflect the variability-of-thinking experts demonstrate in these situations. I thought that transforming these ideas into an assessment tool would constitute a good Ph.D. theme. I began to consider that possibility, but it appeared soon that. it is not easy to find a mentor when you want to work on something as precise as that. I let things run in my mind for several months. Then through readings and discussions, it became evident I should propose this to Cees van der Vleuten, a prominent leader of health profession assessment. He accepted. Then began a wonderful work relationship with another «master». With his deep knowledge of the field literature, an extraordinary ability to discern the key issues, and a sharp mind able to see in an instant the weak points in the draft of an article or in a research proposal, he directed my reflection about the steps needed to build and validate what became the Script Concordance Test. His direction is made of subtle but firm authority, without any limitation for creativity and thinking. There is sadness in completing a degree when directed under such a quality person. Cees I do hope we will pursue collaboration in the future.

During these journey years, I received help of many other persons. I want to thark particularly the early adopters of the test, and among them Lucie BrazeauLamontagne, Carlos Brailovsky, Jean Jacques Moreau and Louis Sibert. I express gratitude to my colleague Robert Gagnon with whom I work very closely to develop the SCT. Finally I would like to thanks all the people from Canada, France and the USA that are working on their own SCT projects. With their help I am confidant SCT will become a valuable adjunction to existing assessment tools and contribute to better health science education. 


\section{Introduction}

Newble, Norman and van der Vleuten ${ }^{1}$ have recently conducted an extensive review of the state of the art of clinical reasoning assessment. They conclude that success in developing valid measures of clinical reasoning has been limited, that no method of assessing clinical reasoning really stands up to critical scrutiny. This dissertation is about a new tool that may represent an improvement of clinical reasoning assessment, the Script Concordance Test. The dissertation introduction will first discuss theoretical and empirical data regarding clinical reasoning. Then it will explain the evolution that assessment of clinical reasoning has followed in the last decades. From there it will state the research questions that have directed the six studies that make the main body of the dissertation.

\section{Clinical reasoning}

Clinical reasoning refers to the thinking and decision making processes that are directed towards enabling the clinician to take the best judged action in a specific context. ${ }^{2,3}$ It can be considered as the intellectual activity that synthesizes information obtained from the clinical situation, integrates it with previous knowledge and experience, and uses it for making diagnostic and management decisions. ${ }^{1}$ It is often referred to as clinical problem solving.

This skill, which is critical and central to practice, is a highly complex phenomenon that has no accepted theoretical or research based model. ${ }^{2}$ The clinical reasoning literature contains several competing theories. Elstein and colleagues ${ }^{4}$ have pointed out that representing a problem through hypotheses generation is a psychological necessity due to the complexity of clinical situations, the enormous amount of data that is potentially available, and the limited capacity of working memory. Hypotheses are then used in an active and conscious way to do an 
oriented data collection aimed at confirming or refuting the corresponding hypotheses. Patel and Groen ${ }^{5}$ argue that all clinicians do not use this hypothetico-deductive process, that experts reason forward, from data to diagnosis, while novices reason backward, from hypotheses to data. Grant and Marsden ${ }^{6,7}$ have confirmed that clinicians actively process clinical information, recognizing items of information that act as keys to particular memory structures. These structures, in turn, dictate particular interpretations. From these interpretations then begins a search for confirming or excluding features. The precise contents and organization of knowledge in memory govern the search.

In Bordage's studies of diagnostic thinking, ${ }^{8,9}$ the more astute diagnosticians are those who build a global representation of the case based on the relational structure of their medical knowledge in long-term memory. Their knowledge is organized not only as simple lists of signs, symptoms, and rules, but as a rich network of knowledge held together by abstract relationships. These relationships are used to interpret similar and opposing bits of information in memory. In contrast, weaker students operate from disjointed lists of signs and symptoms, where the basic diagnostic strategy is to include or exclude disorders as signs and symptoms come and go. Hence the major determinant of diagnostic competence is the capacity to compare and contrast the signs and symptoms presented, transferring the patient's findings into abstract qualities that relate to stored memory structures.

Patel ${ }^{10}$ and Schmidt ${ }^{11}$ have shown that, when medical students start to solve clinical problems, they use causal reasoning based on their biomedical knowledge. During their pre-clinical studies, they progressively build rich and elaborated networks explaining the causes and consequences of disease in terms of general underlying patho-physiological processes. These studies have also shown that the explicit use of biomedical knowledge in clinical problem solving decreases with expertise. Boshuizen and Schmidt ${ }^{12}$ explain this phenomenon as experts encapsulating biomedical knowledge by subsuming low-level, detailed biomedical knowledge into high-level, simplified causal models.

Thinking causally to carry out a diagnostic task is cognitively demanding. ${ }^{13}$ It is more efficient to use known associations between clinical features and illnesses. Hence, when students begin to see patients and are confronted with constraints of time and efficiency, they progressively acquire illness scripts. According to Schmidt, Norman, and Boshuizen, ${ }^{1 / 4}$ these structures encode the signs and symptoms of illnesses, with their relationships, their range of variation, and the enabling conditions. These structures are activated in clinical situations and are used in a conscious and strategic way to confirm or refute the corresponding hypotheses. Biomedical knowledge remains, nevertheless, present and accessible. It is used in situations where scripts are not found. In such cases, clinicians use their biomedical knowledge to understand the situation and to find pertinent hypotheses through a chain of causal reasoning. ${ }^{15}$ Physicians store memories of pre- 
vious patients and, according to Schmidt, Norman, and Boshuizen expert clinical reasoning is, to a large extent, the comparison of the current patient to a previous patient-and the recognition of similarities. Brooks, Norman, and Allen ${ }^{16}$ have provided empirical evidence on the importance of similarity in clinical reasoning.

Problems faced by professional in their practice are of two kinds, those that can be solved through "technical rationality," and those that require "professional knowledge." ${ }^{17}$ Problems that are well defined can be solved using knowledge and skills that Schön considers as belonging to the domain of technical rationality. ${ }^{17}$ These problems can be solved by applying solutions derived from basic and applied sciences, in defined and stable contexts, for clear and predicable goals. These kinds of problems are called well-defined problems, but in practice, each patient is a particular individual, pathologies are sometimes multisystemic and the treatment or management goals to be attained are not always obvious. Clinical problems can be confusing and contradictory, and are characterized by imperfect, inconsistent, or even inaccurate information. ${ }^{18}$ Furthermore, at the beginning of a clinical encounter, not all the data necessary to solve a problem are available. These data must be gathered in order to formulate the problem and then solve it. Hence, clinicians are often confronted by what are called ill-defined problems. ${ }^{3}$ According to Schön ${ }^{17}$ the knowledge and skills that are necessary to solve these kind of problems is different from the technical knowledge needed to solve well-defined problems. The author calls it professional knowledge and he states that professional schools put too much emphasis on learning and assessment of technical knowledge and often neglect what makes the essence of the professions i.e., professional knowledge. Professional judgment and decision making require reflective practice and excellent skills in reasoning. ${ }^{17}$ All these elements contribute to the complexity of clinical reasoning assessment.

Clinical reasoning is one of the three components of clinical competence, the other being relevant knowledge (basic and clinical sciences) and relevant skills (interpersonal, clinical and technical). ${ }^{1}$ For assessment and test development purposes, the three components are often considered separately, so that specific tests are devised to assess relevant knowledge, (e.g. multiple choice tests), relevant skills (e.g. an objective structured clinical examination) and clinical reasoning (e.g. patient management problems). In fact, these components are highly inter-related. A range of attitudinal aspects that are difficult to define and to assess influences each of these components. ${ }^{1}$

For decades medical educators and researchers have been very creative in their search for an assessment tool that would efficiently assess clinical reasoning. We will now describe this search. 


\title{
The evolution of clinical reasoning assessment
}

\author{
Objective tests
}

The 1950 s were characterized by a marked increase in higher education student enrolments and, perhaps for that reason, by the introduction of "objective" tests e.g. multiple-choice questions (MCOs). In many institutions such tests rapidly became the predominant method of assessment, often replacing the traditional essay test, and even bedside oral examinations. ${ }^{19}$ Nevertheless a concern soon emerged that such tests tended to measure merely rote-Learned knowledge and, hence, were inappropriate approaches to the assessment of clinical reasoning and of active application of knowledge. The Mca format was thought to offer, with its limited selection of answers, recognition of the correct answer among distractors. and so to artificially improve performance and to distort clinical problem-solving behavior. ${ }^{20,21}$ This effect, named cueing, and the low fidelity of MCQ format tests, lead to the consideration of MCQs as less suitable for use in tests of clinical reasoning.

\section{Simulations}

In the 1960 s and 1970 s, the focus of interest became the application of knowledge in the clinical context, with use of simulation of reality to enhance fidelity. Examinees were confronted with practical situations, usually a patient-case. ${ }^{19}$ The best-known instrument following this approach is the Patient Management Problem (PMP). ${ }^{22}$ A typical PMP begins with a description of a clinical situation. The examinee is then requested to collect further data that are masked by a variety of technical devices until selected. After collecting history and examination data, ostensibly in the manner and order that would have pertained in the live patient situation, the examinee may be allowed to select investigation and/or make diagnostic and management decisions. The route taken and the decisions made are used to quantify the examinees ${ }^{*}$ problem-solving ability. ${ }^{1}$

This examination method initially provoked great interest and became widely used for certification purposes, being perceived as a valid measure of problem solving ability and of being objectively scored, with the advantages of perceived fidelity to real life situation. However, some growing concerns appeared, related to both psychometric limitations and research findings that brought doubts as to whether that method truly measured clinical reasoning. ${ }^{1}$ One of the major disadvantages has been the scoring of examinees" performance. Problems included the weighting of choices, the scoring of sequences and the value to be accorded to comprehensiveness as opposed to efficiency.

In the 1980s, anather major disadvantage became apparent. The results of research indicated consistently that performance on one simulation was a very poor predictor of performance on another simulation. ${ }^{15}$ This phenomenon, called con- 
tent specificity ${ }^{23}$ undermined the philosophy that was belind simulation i.e., the development of methods that would assess problem-5olving ability as a generic trait. Such a trait would be a separate and stable entity, a strategy that, once mastered, could be applied to any applicable situation. ${ }^{24}$ The research showed that competence at problem solving is highly dependent on the content of the particular case and a change in case content, sometimes even a minimal change, yielded a totally different performance. Consequently to achineve a reliable assessment of clinical reasoning many simulations or cases are required. This finding has major implications for simulation, since most are complex and time consuming. 19

\section{Scoring difficulties}

It was initially assumed that experts solved patient problems using optimal reasoning pathways, sometime even fixed algorithms. Measuring expertise would therefore be based on assessing to what extent the examinee follows an optimal pathway. ${ }^{24}$ The development of a scoring system usually involved a panel of experts who decided, by consensus, on the acceptable pathways through the problem. In those panels it proved to be difficult to reach consensus about optimal pathways or solution to a case, thereby actually challenging the use of fixed pathways by experts. ${ }^{25}$ Panel experts were also asked to decide on the weights (positive and negative), which should be given to the options in each section of the simulation. The weighting of all possible decisions in the case was subject to considerable debate and biases. ${ }^{25}$ Many forms of weighting scheme system of varying complexity have been developed. However, correlation between methods is high. ${ }^{26}$ This confirms the findings of numerous research studies in different domains that have shown that virtually all weighting schemes, regardless of complexity have high correlations with simple counts of items. ${ }^{27}$ As a solution to these scoring difficulties, Norman, ${ }^{28}$ then Norcini ${ }^{29}$ proposed the aggregate scoring method. Its principle is that each possible answer to an item receives a credit that reflects the number of experts answering that way.

\section{The intermediate effect}

In the late $1980 s^{7,14}$ several studies showed that expert dinicians often performed little better, and sometime worse than clinicians with intermediate levels of experience on simulations of clinical problem solving. This phenomenon, called the intermediate effect, came along with results showing that simulations correlated very highly with MCQ examination. This indicates that simulations gather relatively little unique information, and it is at the expense of longer testing time and high test-development costs.

\section{The search for more efficient testing methods}

The scoring difficulties, the intermediate and content validity effects, the length and cost of simulations in which examinees were asked to work througl the com- 
plete patient problem chronologically brought a search for more efficient testing methods. It was then suggested that testing should focus on the components critical to the solution of the problem, which could be within the history taking, the physical exam, the investigation or the management. This approach became known as the "key-feature" approach. ${ }^{30}$ The format of the test is a case description followed by MCQ or free-response-type questions.

\section{The findings of cognitive psychology}

Other developments came in the 1990 s from cognitive psychology research, with concepts bearing on the nature of problem-solving and expert-novice differences. First, it has already been mentioned that problem solving is not, as previously thought, a stable and measurable trait (like a personality trait). Research has repeatedly shown that problem-solving competence is content dependent. To be efficient in solving problems in a domain, it is necessary to possess a strong knowledge base in that domain. Second, knowledge is important in all stages of expertise but the way it is stored and retrieved changes with growing expertise. ${ }^{31-33}$ Third, expertise develops as a transition ${ }^{34,14}$ from a conceptually rich and rational knowledge base to a knowledge base made of knowledge structures constructed to recognize and handle situations effectively and efficiently. Those knowledge structures are acquired from extensive clinical experience. These cognitive psychology concepts have produced a new orientation in clinical reasoning assessment. To measure clinical reasoning competence it appeared important to test knowledge organization, with knowledge being assessed within very realistic contexts. ${ }^{19}$ The work described in this dissertation reflects this orientation. It represents a significant shift in the strategy of clinical reasoning assessment. In the last decades it has been tried to assess clinical reasoning through simulations of clinical encounters, and appreciation of the quality of the options taken in the simulation. Each of these options constitutes the outcome of a decision taken within the reasoning process. Instead of trying to simulate the encounter, SCT has been built from clinical reasoning theory. It places examinees in a specific context and probes cognition, not its outcomes.

\section{Assessment of cognition versus performance-based assessment}

Beside these developments about clinical reasoning assessment, major changes appeared in the assessment of clinical skills. Concerns about their reliability voiced in the 1960s led to attempt to standardize the conditions under which such examinations were conducted. ${ }^{19}$ The development of the objective structured clinical examination (OSCE) in the 1970 s by Harden and Gleeson ${ }^{35}$ and then other variants of the multiple station approach brought a movement that has still an enormous impact: performance-based assessment. ${ }^{36}$ The idea is to simulate clinical encounters in order to achieve standardization of the task that examinees have to perform and to increase objectivity (measures are taken to remove as much as possible of observer subjectivity). In this dissertation, we take the stand 
that performance-based assessment is an excellent approach to evaluate all observable behaviors, but cannot optimally assess the cognitive aspects of clinical reasoning.

\section{Research questions}

This dissertation is build around a general research question:

Is it possible to conceive a clinical reasoning assessment tool that may be congruent with recent developments in cognitive psychology and assessment sciences?

Several sub-questions stem from the general research question:

1 What is the theoretical validity of the tool? In what way can we corroborate the choices that were made in the design of the tool with theoretical considerations and research outcomes in assessment?

2 What is the construct validity of the SCT? The SCT is aimed at assessing the quality of scripts i.e., knowledge structures that theory purports to develop with cinical experience. Is the SCT able to discriminate among examinees across differing levels of experience? Furthermore, does the SCT allow us to overcome the intermediate effect described as a limitation of current clinical reasoning assessment methods?

3. What are SCT reliability and feasibility?

4 What is the validity of it's the scoring method used in the SCT? The aggregate method has been proposed by Norman and by Norcini in the late 1980s, but has hardly been used and studied in the literature. In what way is this method superior to conventional methods?

5 What is the applicability of the SCT in different clinical contexts? Is it useful at all different levels of medical clinical training (clerkship, residency, and physicians in practice)? Is the tool useful in different disciplines? Does the tool keep its psychometric qualities when applied in different cultural and leaming environments? Does the tool help to detect the growth of essential components of clinical competence?

\section{Structure of the dissertation}

The dissertation is made of six chapters.

- Chapter 1 presents a theory of clinical knowledge organization: the script theory.

- Chapter 2 presents the Script Concordance Test, a tool derived from the Script theory.

- Chapter 3 presents a study on the intermediate effect and SCT

- Chapter 4 presents a comparison of the aggregate and the consensus scoring methods. 
- Chopter 5 presents a study about the stability of the SCT concept in different Learning and practice enviromments.

- Chapter 6 presents the use of the SCT to detect the growth of an essential skill. of radiology: film interpretation.

The first research question is addressed in Chapters 1 and 2 . The second, third and fifth research questions are the focus of chapters 3 to 6 . Chapter 4 deals with the fourth research question.

\section{References}

1 Newble D. Norman G. Van der Vleuten C. Assessing Clinical Reasoning. In: Higgs J and Jones M (Eds..). Clinical Reasoning in the Health Professions,. Butterworth-Heinemann Ltd: Oxford, 2000 ( $2^{\text {nd }}$ edition): $156-16$.

2 Higgs $J_{8}$ and Jones M. Clinical reasoning in the health professions. In 3 Higgs \& M Jones, Clinical Reasoning in the Health Professions. Butterworth Heinemann: Oxford, 2000 ( $2^{\text {ndd }}$ edition): 3-14.

3 Harris I. New Expectations for Professional Competence. In L Curry \& JF Wegin (eds), Educating Professionals. Responding to new expectations for competence and accountability. Sam Francisco: Jossey-Bath Publishers, 1993: 17-52.

4 Elstein, A.S., Shuiman, L.S., Sprafka, S.A. Medical Problem Solving: An Analysis of Clinica! Reasoning. Cambridge, MA: Harvard University Press, 1978.

5 Patel VL, Groen GJ. Knowledge based solution strategies in medical reasoning. Cogn 5ci. 1986; 10: $91-116$

6 Grant J, Marsden P. The structure of memorized knowledge in students and clinicians: an explanation for diagnastic expertise. Med Educ. 1987; 21: 92-8.

7 Grant J, Marsden P. Primary knowledge, medical education and consultant expertise. Med Educ. 1988; $22: 173-9$.

8 Bordage $G$ and Lemieux M. Some cognitive characteristics of students with and without diagnostic reasoning difficulties. Pnoceedings of the $21^{\text {sit }}$ Annual Conference on Research in Medical Education of the American Association of Medical Colleges: Washington, DC., 1986: 171-6.

9 Bordage G, Lemieux M. Structuralism and medical problem solving. Int Serniotic Spectrum. 1987; $7: 3-4$

10 Patel VL, Evans QA, Groen GJ. Biomedical knowledge and clinical reasoning. In: Ewans D.A., Patel V.L. (eds). Cognitive Science in Medicine: Bionedical Modeling. Cambridge, MA: MIT Press, 1989.

11. Schmidt HG, Boshuizen HPA., Hobus PPM. Transitory stages in the development of medicall expertise: the "internediate effect" in clinical case representation studies. In: Proceedings of the 10th Annual Conference of the Cognitive Science Society. Hillsdale, NJ: Ertbaum, 1988.

12 Boshuizen HPA. and Schmidt HG. On the role of biomedical knowledge in clinical reasoning by experts, intermediates and novices. Cogn Sci. $1992 ; 16: 153-84$.

13 Custers E. The Development and Function of Illmess 5 cripts: Studies on the Structure of Medical Diagnostic Knowledge. University of Maastricht: PhD Thesis, 1995.

14 Schmidt HG. Norman GR, Boshuizen HPA. A cognitive perspective on medical expertise: theory and implications. Acad Med. $1990 ; 65: 611-21$.

15 Kassiver JP. Diagnostic reasoning. Ann Intern Med. 1989; 110: 893-900.

16 Brooks LR, Norman GR, Allen SW. Role of specific similarity in a medical diagnostic task. I Exp Psychol: General. 1991;120:278-87.

17 Schön, DA. The reflective Practicioner: How Professionals Think in Action. New York: Basic Books, 1983.

18 Kassirer JP, Kopelman RI. Leaming Clinical Reasoning. Baitimore, MD: Willianms \& Wilkins Co, 1991. 
19 Wan der Veuten, C.P.阴. and Hewble D. Methods of assessment in certification. In D. Newble, B. Jolly and $R$. Wakeford (eds.). The certification and recertification of doctors. Issues in the assessment of clinicat competence. Cambridge: University Press, 1996, pp. $105-125$.

20 Norman, G.R. and Feightmer, JW. A comparison of behaviour on shmulated patients and patient: management problems. Joumal of Medical Education, 1981, 55:529-537.

21 Newble, D.I., Hoare, J. \& Bater, A. Patient Management Problems: Issues of Validity. Medical Education, 1982, 16:137-142.

22 McGuire, C. H. and Babbott, D. Simulation techniques in the measurement of problen solving skils. Journal of Educational Measurement, 1967, 4: 1-10,

23 Norman, G.R., Tugwell, P., Feightrer, J.W., Muzzin, L.J. \& Jacoby, L.L.. Knowledge and Cinical Problem Solving. Medical Education, 1985, 19: 344-356.

2.4 Schuwirth L. An approach to the assessment of medical problent solving: Computenized Case-based Testing. Ph D thesis. Maastricht, The Netherlands, 1998.

25 Swanson, D.B., Norcini, J.J., Grosso, L.J. Assessment of Clinical Competence Written and Computer-Biased Simulations. Assessment and Evaluation in higher Education, 1987, 12: 220-246.

26 Norcini, J.J., Swanson, D.B. Whetster, 6.D. and Grosso, L.J. A companson of seweral methods of scoring patient management problems. In Proceedings of the $22^{\text {ind }}$ Amual Conference off Re* search in Medical Education pp. 41-46. Washington, DC: Association of Arnierican Medical Colleges, $1983:$ p p 41-46.

27 Wainer, H. Esthmationg coefficients in linear modles: It doesn't make no nevermind. Psychological Bulletin, 1976, 83: 213-217.

28 Norman, G.R. Objective Measurement of Clinical Performance. Medical Education, 1985: 19: $43-47$.

29 Norcini J.J., Shea, J.A., Day, S.C. The Use of the Aggregate Scoring for a Recertification Examination. Evaluation and the Health Professions, 1990: 13: 241-251.

30 Bondage, G., Page G. An alternative approach to PMPs: The "key features" concept. In: Hart IR. Harden RM, editors. Funther developments in assessing clinical competence. Montreal: Heal-PubliCations, 1987, 59-75.

31 Feltovich, P.J. Expertise: reorganizing and refining knowledge for use. Professions Education Research Nates, 1983, 4, 5-7.

32 Coles, C.R. Elaborated learning in undergraduate medical education. Medical Education, 1990, 24, $14-22$.

33 Bordage, G. Elaborated Knowledge: A key to Successful Diagnostic Thinking. Academic Medicine. $1994,69,883-885$.

34 Feltovich, P.]. \& Barrows, H.S. Issues of Generality in Medical Problem Solving. In H.G. Schmidt \& M. L. De Volder (Eds.). Tutarials in Problem-Based Learning: A new Direction in Teaching the Health Professions. Assen, Holland: Van Gorcum, 1984.

35 Harden RM, Gleeson FA. Assessment of medical competence using an Dbjective Structured clinical Examination. Med Educ, 1979; 13:39-54.

36 Dauphinee WD. Assessing dinical performance: where do we stand and what might we expect? JANA, 1995;274:741-743 



\section{CHAPTER I}

\section{A theory of clinical knowledge organization}

Published in Academic Medicine 2000, 75: 182-190

Scripts and Medical Diagnostic Knowledge: Theory and Applications for Clinical Reasoning Instruction and Research.

Bernard Charlin, Jacques Tardif, Henny P.A. Boshuizen 


\begin{abstract}
Medical diagnosis is a categorization task that allows physicians to make predictions about features of clinical situations and to determine appropriate course of action. The script concept, which first arose in cognitive psychology, provides a theoretical framework to explain how medical diagnostic knowledge can be structured for diagnostic problem solving. The main characteristics of the script concept are pre-stored knowledge, walues acceptable or not acceptable for each illness attribute, and default values. Scripts are networks of knowledge adapted to goals of clinical tasks. The authors describe how scripts are used in diagnostic tasks, how the script concept fits within the clinical reasoning literature, how it contrasts with competing theories of clinical reasoning, how educators can help students build and refine scripts, and how scripts can be used to assess clinical competence.
\end{abstract}

\title{
Introduction
}

A female patient, hospitalized for severe back pain, is discovered to be hyperglycemic. An endocrinologist, consulting on what he thinks is a glucose adjustment problem, looks carefully at the patient"s face, then at her hands and arms, and says to the resident "this is a case of Cushing's syndrome." The puzzled resident asks the consultant to explain his conclusion. "The patient," the consultant replies, "is 44 years old, female, with a probable pathologic fracture of a vertebral body; this is uncommon for that age. She is obese, but this obesity is central, with sparing of the extremities. She has a moon face with mild facial hirsutism. The skin seems thin and dry, and the arms are covered with bruises. With all these signs, it is improbable that we are facing common obesity or type II diabetes. I am pretty sure that she has Cushing"s. I will order some tests to confirm this hypothesis."

Any clinician can recall similar instances of quick reasoning. In this case, the consultant went into the room with an initial hypothesis; after a quick look at the patient, a new hypothesis popped into his mind. This kind of reasoning implies an amazing sequence of psychological events: perceiving the features of the situation, quickly accessing relevant hypotheses, checking for signs and symptoms that confirm and rule out those competing hypotheses, and using related knowledge to guide appropriate investigations and treatment. These events happen at such a high speed that students have trouble understanding the reasoning process and only perceive the outcome.

This sequence of events raises questions about the structure of clinical knowledge in physicians" memory. The concept of "scripts, "first introduced in medicall literature by Feltovich and Barrows." and evolving ever since, describes the structure of clinical medical knowledge. Our goal in this article is to present to medical educa- 
tors how scripts as a memory structure might be organized for diagnostic tasks. We think that this theoretical framework warrants research to test its plausibility and that it has the potential to assist educators to more efficiently teach and assess clinical reasoning skills.

We will (1) present the psychological context of scripts, (2) illustrate how they apply to diagnostic tasks, (3) explore how this theoretical framework fits within existing clinical reasoning literature and contrasts with competing theories, (4) suggest avenues for future research, and (5) describe implications for clinical education and assessment.

\section{Psychological context}

\section{Diagnosis as Categorization}

Diagnosis is at the core of medical practice. Even in emergency situations, clinicians will not order investigations or begin treatments before they have a rough idea about what is occurring. Cognitive psychologists consider diagnosis as a categorization task ${ }^{2,3}$ that consists of placing patients" illnesses in different classes based on their attributes. ${ }^{4}$ Once clinicians recognize a patient's illness as belonging to a given class of diseases, they can use related knowledge to take actions such as providing a prognosis, planning an investigation, or instituting a treatment.

\section{Hypothetico-deductive Reasoning}

The classic model of clinical diagnosis is the hypothetico-deductive model. ${ }^{2,5-7}$ It is characterized by the generation of multiple competing hypotheses from initial patient cues and collection of data to confirm or refute each hypothesis. If the endeavor is unfruitful, the clinician creates and investigates new hypotheses in an iterative process of hypothesis generation and testing. This model, which represents a description of the mental processes used by clinicians, has been repeatedly validated by empirical studies ${ }^{5-8}$ and underlies most modern clinical instruction. ${ }^{9-11}$ However, the psychological mechanisms responsible for the generation and testing of relevant hypotheses remain largely unknown. According to many researchers and theoreticians, ${ }^{12-17}$ explanations should be found by exploring physicians' knowledge bases, both in content (the specific kmowledge for any topic) and structure (the organization of the knowledge). The script concept offers one model of such a structure.

\section{The Nature of Scripts}

The basic principle underpinning the script concept asserts that, to give meaning to a new situation in our environment, we use prior knowledge that contains in- 
formation about the characteristics and features of the situation and information about the relationships that link those characteristics and features. In other words, incoming information activates a previously acquired network of relevant knowledge and experience - a script-that directs the selection, interpretation, and memorization of that new information. ${ }^{18,19}$ In medicine, when a physician sees a patient, she perceives features-symptoms, signs, and details from the patient's environment-that activate networks of knowledge that contains those features and their relationships to illnesses. Those networks of knowledge then provide context, and thus meaning, to the new situation.

The script concept is a variant of a more general concept, that of schemas. ${ }^{20}$ Schemas are goal-directed knowledge structures adapted to perform tasks efficiently. ${ }^{21}$ Scripts are schemas associated with a sequence of events that occur frequently in a specific order, ${ }^{22}$ and knowledge about illnesses includes information about the spatio-temporal sequence of events in illness development. ${ }^{1}$ Considering that most of the properties of one concept apply to the other, we will use "scripts" to describe properties of both schemas and scripts. Schmidt, Normam. and Boshuizen ${ }^{23}$ have described a theory of development of clinical competence that hinges on the concept of illness scripts. In the next part of this article we will focus on one clinical task-diagnosis-and explain how scripts may be organized to do this task efficiently. The portion of an illness script that is adapted to diagnostic tasks could be called a "diagnostic script."

\section{Scripts and Diagnosis}

$\mathrm{Smith}^{24}$ has provided insights into how scripts can be adapted to a diagnostic (categorization) goal. A script can be described as a set of attributes, each of which can be instantiated by values that have more or less probability of occurring. For each attribute, the value that has the greatest probability of occurrence is the default value. Table 1 contains an example of a script that a physician might have about maxillary sinusitis. The script contains attributes (for example, pain location) for which different values are possible (no pain, dull sensation, infra-orbital pain). In any given instance, only one of the values can fill the slot. Until the physician determines otherwise, the default value (in this case, infra-orbital pain) is assumed to be present.

Two other characteristics of scripts are important. First, the information belonging to a script is not exclusive. Symptoms and signs (unless pathognomonic) can belong to several scripts. The particular script for an illness is characterized by the set of signs and symptoms it contains and by the relationships that link them. It consists of information related to this illness. Second, scripts are generic structures that can represent any instance of an illness. Each medical encounter implies an instantiation process; that is, the finding of the actual values of the attributes observed in the patient. 
Table 1. An Example of a Dagnosis Script Related to Acute Maxilary Sirtusitis*

\begin{tabular}{|c|c|}
\hline Attributes,,- & Values \\
\hline Enabing conditions & $\begin{array}{l}\text { None } \\
\text { Wiral UR: } \\
\text { Allergic thintis } \\
\text { Nasal polyposis... }\end{array}$ \\
\hline Pain location & $\begin{array}{l}\text { No pain } \\
\text { Dull sensation of pressure over the maxilla } \\
\text { Infra-orbital pain }\end{array}$ \\
\hline Duration of pain & $\begin{array}{l}\text { Acute } \\
\text { Subacute }\end{array}$ \\
\hline Nasal obstruction & $\begin{array}{l}\text { Yes* } \\
\text { No } \\
\text { Exacerbated when head is tilted forwand }\end{array}$ \\
\hline Surulent rhinomhed & $\begin{array}{l}\text { Yes" } \\
\text { No }\end{array}$ \\
\hline Pus emanating from the middle meatus & $\begin{array}{l}\text { Yes } \\
\text { No }\end{array}$ \\
\hline Fewer & $\begin{array}{l}\text { None } \\
\text { Subfever } \\
\text { Mild fever }\end{array}$ \\
\hline Malaise & $\begin{array}{l}\text { Yes } \\
\text { No }\end{array}$ \\
\hline Infra-orbital palpation and percussion & $\begin{array}{l}\text { Tenderness } \\
\text { None }\end{array}$ \\
\hline Waters $X$ rays & $\begin{array}{l}\text { Air-fluid level } \\
\text { Opacification } \\
\text { Thickened lining* }\end{array}$ \\
\hline
\end{tabular}

* Adapted from Smith. ${ }^{3}$ Asterisks represent defaut walues.

In 1980, Barrows and Tamblyn ${ }^{25}$ described a model of clinical reasoning that represented a synthesis of works of several researchers. ${ }^{2-5-26}$ From the main characteristics of that model, which is a classic in the clinical reasoning literature, we will describe how the script concept provides an explanation for this reasoning process.

\section{Hypotheses Generation - Activation of Relevant Scripts}

At the beginning of an encounter, the physician perceives instantly and almost unconsciously verbal and nonverbal cues from the patient; within moments hypotheses pop into the physician's mind as possible explamations for the patient's problem. The hypotheses, which are usually a product of the clinician"s past experiences and knowledge, appear quickly, and their activation is an "unconscious. act of memary association." 25 This description fits well with script theory, which 
postulates that script activation is an automatic process, called "script triggering. "27.28 Grant and Marsden ${ }^{29}$ have shown that clinical memory structures are triggered by the clinician's recognizing relevant items of information.

\section{Scripts as Meaning Providers}

Very quickly the clinician builds a representation of the situation that initiates the direction and scope of the reasoning process. ${ }^{25}$ The main function of scripts ${ }^{30}$ is to construct an interpretation of situations. A set of relevant scripts is actiwated from the cues perceived, and the activity is then to find if one of the activated scripts adequately fits the clinical findings. This verification requires that walues be assigned to the different attributes. If the physician cannot adequately fit an activated script to the findings, he rejects it and begins to verify another one. Hence, according to the script concept, the fundamental aspect of understanding a situation is a hypothesis-testing activity.

The activation of a script provides access to a set of attributes and allows an active search to find appropriate values. This process is called "script processing." 28 There appears to be no fixed order for checking a script's attributes; individual clinicians proceed in different orders. This accounts for the variability in data colLection observed among clinicians. Different people rarely use the same set of questions to solve any one clinical problem. ${ }^{2,31}$ Experienced physicians asik questions and do physical exams that are most efficient according to their own activated scripts.

Reasoning with an illness script is hence hypothetico-deductive, but not in a very conscious way. The activation phase is usually automatic, while the processing phase - the search for evidence to rule hypotheses in or out-is controlled and deliberate.

\section{Scripts as Organizers of the Flow of Clinical Information}

The set of hypotheses considered by a physician in a given clinical situation guides the physician's interview and examination of the patient. It represents the initial possibilities that he feels need to be pursued. Many physicians are unaware of the existence of these processes, but observation of their reasoning shows that the questions they ask and the items of physical examination they perform are, for the most part, specifically chosen to rule in or rule out, or at least strengthen or weaken, the likelihood of the hypotheses they have considered. ${ }^{25}$

An important characteristic of the script concept is default values. ${ }^{24}$ Among the acceptable values for each attribute, one is assumed to be present until a value has been specifically verified. This explains why clinicians do not always look for all signs and symptoms. When they have enough evidence to establish their diagnosis, they often assume that other values are present and do not specifically 
check them (in the example in Table 1 , if a patient has an acute nasal obstruction and pus emanating from middle meatus, the physician may not do percussion over the infra-orbital area). Default values are also important for communication between clinicians. When a physician discusses the diagnosis of a patient with colleagues, he need not explicitly specify all attributes of the illness; his colleagues will build a picture of the patient using their own scripts, filling in gaps with the default values. For instance, if a clinician speaks of a patient with maxillary sinusitis, he will mention only the signs and symptoms that differ from a typical presentation.

In addition to knowledge about clinical features of illnesses, scripts contain knowledge about appropriate actions to take. For example, if a child presents in acute and rapidly progressing respiratory distress with a high fever and an odynophagia, many clinicians will act as if the child has an epiglotitis until contradictory information appears. This leads them to make inferences, some of them related to diagnosis (for example, detection of a large epiglottis on a lateral $x$-rays), others related to management of the condition (for example, to bring the child to the operating room for naso-tracheal intubation).

As the encounter with the patient progresses, a large amount of information accumulates. The major difference between students and experienced clinicians is that, when asked for a summary of the patient's problem, students tend to recite endless amounts of data about clinical findings, while experienced clinicians are able to summarize the patient's problem in a way that captures the significant information obtained. ${ }^{25}$ Scripts also provide an explanation for this process, because their structures, each with its set of attributes, serve as organizers. Coughlin and Patel ${ }^{32}$ have provided evidence for the existence of illness scripts as organizers in memory. They presented medical students and physicians with both organized and disorganized (random) texts describing disease histories. In recalling both the organized and the disorganized versions of the same cases, the physicians reported the information in the same script-like order, while students showed much less organization.

\section{Assessment of the Fit between a Script and a Given Clinical Situation}

According to the script concept, during the data collection process, physicians systematically fit incoming information to the script's attribute slots. ${ }^{24}$ For each slot, there are acceptable and unacceptable values. If unacceptable values are found, the script is rejected (for example, the maxillary sinusitis script would be rejected if a history of bloody rhinorrhea were discovered), and other scripts that accept that value are activated or reinforced (for example, maxillary sinus cancer). Among acceptable values for an attribute, some bring more weight to a hypothesis than others. The default value brings the most weight for the hypothesis; unusual values bear less weight. 
The assessment of each value in the activated scripts explains the moving status of the set of hypotheses in an encounter. Hypotheses can be reinforced, or be attenuated, or disappear, while others are activated..$^{25}$ The accumulation of acceptable values within a script raises the level of activation of that script, and at a particular moment, the clinician decides that there is enough evidence to bring clasure to the diagnostic process. He then settles on a definitive or working diagnosis, depending on the situation.

\section{Scripts and clinical reasoning literature}

The clinical reasoning literature contains several competing theories. We will now describe how the script concept stands among them. Patel and Groen ${ }^{40}$ asked both expert and novice clinicians to describe aloud their process of reasoning. They argue that experts reason forward, from data to diagnosis, while novices reason backward, from hypotheses to data. Their view, though often cited in the medical reasoning literature, has several arguments against it. First, even in their own research, the authors did not always find this effect and in cases where information is only sequentially available (e.g., interactive tasks), working forward may be impeded. Second, Eva, Brooks, and Norman ${ }^{41}$ showed that differences in the talk-aloud protocols of experts and novices may reflect differences not in reasoning strategies but in explanatory ability or confidence. Using a within-subject design, they found that responses appeared to vary between forward and backward reasoning strategies depending on both the amount of information available before the responses were requested and the degree of confidence the participants had as a result of previous feedback. Last, in a script concept perspective, script activation is hypothesis generation, while the verification is the deduction. The more easily the script can be activated, the more automatically information can be taken in, the more it looks like forward reasoning. Then, when activation stops, some verification has to take place, and the process looks like deduction and backward reasoning. Sometimes the verification part can be very much effortless like the physician in the introduction shows.

Elstein and colleagues ${ }^{2}$ have pointed out that representing a problem through hypotheses generation is a psychological necessity due to the complexity of clinical situations, the enormous amount of data that is potentially available, and the limited capacity of working memory. In unfamiliar, complex situations, experts constrain the problem by generating manageable sets of clinical interpretations and then use them in an active and conscious way to do an oriented data collection aimed at confirming or refuting the corresponding hypotheses.

Grant and Marsden ${ }^{29-31}$ have confirmed that clinicians actively process dinical information, recognizing items of information that act as keys to particular memory structures. These structures, in turn, dictate particular interpretations. Those in- 
terpretations then begin a search for confirming or excluding features, a search governed by the precise contents and organization of knowledge in memory.

In Bordage's studies of diagnostic thinking, ${ }^{33,34}$ the more astute diagnosticians are those who build a global representation of the case based on the relational structure of their medical knowledge in long-term memory. Their knowledge is organized not only as simple lists of signs, symptoms, and rules, but as a rich network of knowledge held together by abstract relationships. These relationships are used to interpret similar and opposing bits of information in memory. In contrast, weaker students operate from disjointed lists of signs and symptoms, where the basic diagnostic strategy is to include or exclude disorders as signs and symptoms come and go. Hence the major determinant of diagnostic competence is the capacity to compare and contrast the signs and symptoms presented, transferring the patient's findings into abstract qualities that relate to stored memory structures.

The script concept implies that as individuals repeatedly perform tasks, they rearganize their knowledge to do the tasks as efficiently as possible and with the most economic cognitive processing. For Feltovich, ${ }^{35}$ the development of expertise is largely a matter of reorganizing knowledge and cognitive processes to perform tasks. "Experts restructure their inner working-knowledge and procedures for efficient application in their work-a-day environment. "In a categorization task, individuals use perceived features of objects or situations to place them in categories. Such a task requires knowledge about the perceptible features of objects or situations and on their relationship within categories.

Authors differ in their conceptions of script structure. According to Feltovich and Barrows, ${ }^{1}$ a new script is constructed during each clinical encounter. Scripts, then, are temporary mental representations consisting of existing knowledge and new information. They contain three parts: enabling conditions (features associated with the acquisition of illness, e.g., fatigue or hereditary factors); fault (malfunctions in illness, e.g. invasion of tissue by pathogenic organisms or metabolic disorders); and consequences of faults (signs and symptoms). This conception of scripts implies that clinical reasoning is a mix of causal and associative reasoning and script is a mental model of the situation, which allows the clinician to efficientiy generate hypotheses and strategically gather data. In script processing for assessment of a fit, according to this conception, patient clinical features never perfectly match the attributes of an illness scripts. Scripts work in such a way that a physician makes a "reasomed decision" about why some expectations are violated. Our concept of scripts differs from that of Feltovitch and Barrows in at least four major respects. (1) Scripts are pre-stored knowledge structures. (2) They are activated almost unconsciously from initial clinical clues. (3) They are made of known links among clinical features including enabling factors, fault, and consequence. (4) They function by memory assaciation, not by causal reasoning. 
Patel et al. ${ }^{36}$ and Schmidt et al. "ave shown that, when medical students solve clinical problems, they reason causally based on their biomedical knowledge. During their preclinical studies, they progressively build rich and elaborated networks explaining the causes and consequences of disease in terms of general underlying pathophysiological processes. These studies have also shown that the explicit use of biomedical knowledge in clinical problem solving decreases with expertise. Boshuizen and Schmidt ${ }^{13}$ explain this phenomenon as experts encapsulating biomedical knowledge by subsuming low-level, detailled biomedical knowledge into high-level, simplified causal models.

Thinking causally to carry out a categorization task is cognitively demanding. ${ }^{43}$ It is more efficient to use known associations between clinical features and illnesses. Hence, when students begin to see patients and are confronted with constraints of time and efficiency, they progressively acquire illness scripts. According to Schmidt, Normam, and Boshuizen, ${ }^{23}$ these structures encode the signs and symptoms of illnesses, with their relationships, their range of variation, and the enabling conditions. The use of these structures is very efficient because (1) their activation is automatic and almost unconscious (triggering of scripts). (2) the activated scripts are then used in a conscious and strategic way to confirm or refute the corresponding hypotheses (script processing), and (3) in 50 doing, activated scripts serve to guide information selection, memorization, and interpretation. Biomedical knowledge remains, mevertheless, present and accessible. It places constraints on the acceptable values for the different attributes of scripts and on their relationships."

It also alerts clinicians when they find abnormal findings or events that violate normal physiologic expectations, serving as a coherence criterion for hypotheses about the patient. ${ }^{38}$ Biomedical knowledge is also used in situations where scripts are not found. In such cases, clinicians use their biomedical knowledge to understand the situation and to find pertinent hypotheses through a chain of causal reasoning. According to these theories, knowledge used in clinical tasks can be conceived as a structure with two "layer"s" that are strongly interrelated. One is a layer of biomedical knowledge that is used in unfamiliar or atypical cases; the other a layer of specialized knowledge (the diagnostic scripts) that is used in familiar or typical cases that do not require causal reasaning. allowing quick and efficient performance. ${ }^{23}$

According to Schmidt, Norman, and Boshuizen, physicians store memories of previous patients and, to a large extent, expert clinical reasoning is the comparison of the current patient to a previous patient-and the recognition of similarities. Brooks, Norman, and Allen ${ }^{39}$ have provided empirical evidence on the importance of similarity in clinical reasoning, but the place of similarity can be discussed in the script perspective. Similarity, instead of being the whole mechanism of diagnostic reasoning, may also be a way of script activation, which might be followed by script processing to check for the presence or absence of features that will al- 
Low the clinician to confirm or reject the diagnosis. This alternative explanation illustrates that the script theory has the potential to explain empirical evidence from other conceptual frameworks, but illustrates also the need for research to explore it.

\section{Avenues for future research}

Bordage and Williams ${ }^{42}$ have recommended a practice-theory-practice approach for research in medical education, in which questions pertinent to educational practice are built in the context of existing theory, and results are interpreted to confirm or refute these theories. This in an iterative conception of research where practice is used to formulate and refine theory, which in turn guides practice. Finding ways to help students to become efficient in solving patients' problems is a central issue for medical educators. Research has shown that organization of knowledge is the key in the construction of clinical expertise. The script concept explains many features of medical diagnosis and provides a theoretical foundation on which clinical education can be based. Therefore, there is a need for more research to validate this theoretical construct and to determine its effective contribution in the diagnostic process. To illustrate how this endeavor can be pursued, we will describe here three research issues that are central in the script concept and how they can be addressed.

The first issue concerns the nature of the links within clinical knowledge networks. Do clinicians use associative links within pre-stored knowledge structures in familiar diagnostic tasks in contrast to causal reasoning in less familiar situations? A method of addressing this question might be to recruit expert physicians to treat simulated patients in contexts as authentic as possible. These experts would have to solve problems from their domain of expertise, some being typical and familiar, others being atypical and unfamiliar. In both situations, they would be asked to make their diagnostic processes explicit, by thinking aloud, and would be asked to describe the rationales that justify their clinical decisions. Content analysis of protocols would allow examination and contrast of the organization of knowledge they use in both situations.

A second issue concerns the concept of default values, which is crucial within the conceptual framework of scripts. If, among the acceptable values for each clinical attribute, one is assumed to be present up to the moment when values of the attribute are specifically verified, and if clinicians close their diagnostic inquiry when they have enough evidence to make a diagnosis, then they should make inferences concerning the values of the attributes they have not specifically checked. Research in this area has provided evidence to sustain this concept. ${ }^{43}$ After having read paper-based cases, physicians were asked to remember or recognize clinical features, some that were present in the text, others that would result from inferences (false recognition). The authors, found only a few instances of 
false recognition. An explanation to this finding could be that the process of getting elinical information is very different in an authentic clinical encounter than in a paper-based case. In the latter situation all information is present, in a written form, while in the former information has to be specifically sought and can be neglected if the clinician finds that she has enough information to reach a diagnosis. Therefore, research protocols using real or simulated patients might reveal a phenomenon that was not evident on paper-based cases.

A third issue concerns the dynamic or stable nature of scripts. According to theory, ${ }^{30}$ scripts are dynamic structures, modified by each new encounter. The memory of an encounter consists of some combination of specific information stored about that experience and of general information about the illness contained in the relevant script. Obviously the $n^{\text {th }}$ encounter with a similar illness will not modify the relevant script significantly, but the encounter of a rare illness or of an atypical presentation of a common illmess will have more effect on memory. Experimental studies on the issue of different effects of encounters on memory structures, depending on the rare or familiar nature of illnesses, require manipulation of previous experience in a domain. However to compare experts' and non-experts' performances in diagnostic tasks while controlling experience as an independent variable is difficult to achieve, because if experts do not have experience for a specific task, they can no longer be qualified as experts. This implies the development of new scripts about illnesses that are authentic, that are related to the previous knowledge of the expert, but with which they have no previous experience. Research exploring scripts of illnesses that are rarely seen in a particular geographic area, such as malaria in Holland, could overcome these difficulties.

\section{Scripts and clinical reasoning instruction and assessment}

The conceptual framework of scripts raises a series of educational issues concerning (1) the period of script construction that is optimal within curricula, (2) the instructional methods that foster their construction and refinement and, (3) their implications for the assessment of clinical competence.

According to Schmidt, Norman, and Boshuizen, ${ }^{23}$ illness scripts emerge when students are exposed to real patients. In their first encounters, they apply their biamedical knowledge. They consciously relate symptoms to concepts in the relevant pathophysiological networks they possess. Diagnosing their first clinical cases requires a lot of mental effort. While they begin to assume the full pressure of patient responsibility, ${ }^{25}$ a transition takes place from a kind of knowledge fitted to description and explanation tasks to knowledge structures adapted to clinical tasks, i.e., that is diagnostics, management, treatment, and prognosis. 
Such a developmental sequence is not inescapable and may reflect a conception of medical training where biomedical knowledge is built first, and then clinical knowledge, as has traditionally been the case in medical education. ${ }^{44}$ In fact the acquisition of diagnosis scripts could be undertaken at the wery beginning of medical curricula, and there is a trend in contemporary method of instruction to early exposure to authentic professional tasks; therefore the desirability of waiting until clerkship to begin the development of scripts adapted to diagnosis tasks is questionable. Early exposure can help students to develop scripts very early and help them to incorporate biomedical and clinical knowledge that they would acquire subsequently within their scripts, if appropriate care is taken about integration of this knowledge. This is in accordance with principles of situated learning. In contrast to such a strategy is the more traditional conception that the construction of biomedical knowledge is a critical foundation phase of medical training and that an early construction of diagnosis scripts would threaten the construction of a strong base of biomedical knowledge.

Whether scripts are built early or later in curricula, their acquisition and refinement cannot be left entirely to the variability of clinical exposure. Knowing that elaborated and organized knowledge is the key to clinical expertise, clinical teachers should explicitly assist students in the construction of efficient and well-structured knowledge bases. Such a knowledge base allows students to give meaning to clinical situations, to guide their clinical inquiry, to interpret clinical information in order to reinforce their hypotheses or weaken them, to activate new ones because entertained ones are not fitted to the situation, and to decide when they have enough data to close the diagnostic process. Educational methods adapted to the requirements of clinical settings have been described. ${ }^{45,46}$ They follow a series of principles established from cognitive psychology ${ }^{47}$ (1) learners actively engage in the educational activity (scripts cannot be transmitted directly from teachers" mind to students" minds; they have to be constructed by each learner); (2) new information is articulated on students." prior knowledge (this implies the activation of prior knowledge): (3) intermediate stages of clinical reasoning are made explicit; (4) students are asked to use their clinical knowledge to assess incoming clinical information and, in 50 doing, to reinforce or reject entertained hypotheses; and (5) acquired knowledge is validated through its use with peers and teachers.

Another educational cansequence of the script concept is its potential usefulness in assessing clinical competence. Contemporary methods of clinical assessment have repeatedly shown the puzzling fact that experienced clinicians score little better and sometimes worse than less experienced clinicians or students. ${ }^{48}$ A possible reason for this is that most methods measure clinical factual knowledge rather tham the organization of knowledge that allows clinicians to recognize and handle situations effectively. In so doing, they place experts, whose strength is organization of knowledge rather that linear accumulation of knowledge, at a disadvantage. 
In Bordage"s studies of diagnostic thinking, ${ }^{33,34}$ the efficient diagnosticians are those who build a global representation of the case based on the relational structure of their medical knowledge in long-term memory. Their knowledge is organized not only as simple lists of signs, symptoms, and rules, but as a rich network of knowledge held together by abstract relationships. Assessment tools have been tested that place clinicians in specific contexts and probe their capacity to interpret data in the perspective of activated hypotheses. These "script assessments $^{.49,50}$ appear as reliable tools that allow discrimination among individuals on the basis of their climical competence. Scores obtained from these questionnaires are higher for the clinicians that have more experience in the field, which is one would expect from a valid assessment tool of clinical competence.

\section{Conclusion}

Script conceptual framework implies that when clinicians see a patient, they search their memory for an appropriate script, and instantiate it with the specific information provided by the case. So problem solving, at least in routine cases, is a process of script search, script selection, and script verification. ${ }^{23}$ Scripts are pre-stored knowledge structures that are used to actively process clinical information to confirm or eliminate the diagnostic hypotheses the clinician has in mind at a given moment, and collected information is constantly checked with predetermined values to assess for a fit. Scripts are organized for specific tasks. Diagnosis being at the core of medical practice, an important part of the acquisition of expertise is related to script construction. In this perspective the acquisition of medical expertise consists in building, refining, and linking scripts that alLows students to become active processors of clinical information instead of simple collectors of as much information they can get "without giving meaning to it.

Much evidence already favors the script conceptual framework's ability to explain and predict medical performance; still, there is a strong need to enrich that body of evidence. The framework helps medical educators because it focuses on the progressive construction of elaborated knowledge, ${ }^{51-52}$ knowledge that is refined throughout a clinician's professional life. For the development of clinical competence, organization of knowledge is as important as its acquisition. The framework offers a model of what kind of knowledge organization sustains clinical competence. It may therefore guide clinical instruction. It is also a concept that opens a field of assessment of clinical competence that is practice-based and overcomes some limitations of existing methods of assessment of clinical competence.

Acknowledgement: The authors thank Georges Bordage, Martine Chamberland, and Karen Mann who have provided precious comments and insights for this work. 


\section{References}

1. Feltovich PJ, Barrows HS. Issues of generality in medical problem solwing. In Schmidt HG, De Volder ML (eds). Tutorials in Problem-based leaming; A New Diredion in Teaching the thealth Professions. Assen, The Netherlands: Van Gorcum, 1984.

2 Elstein AS, Shulman LS, Sprafka SA. Wedical Problem Solwing: An Analysis of Clinical Reasoning. Cantbridge, MA: Harvard Uniwersity Pres5, 1978.

3 Glhooly ks. Cognitive psychology and medical diagnosis. Applied cognitive psychology: $1990 ; 4$. $261-72$.

4. Marzano RJ , Brandt RS, Hughes CS, et al. Dinensions of Thinking: A Framework for Curnculum and Inm struction. Alexandria, WA: Association for Supervision and Cumculum Development, 1988.

5 Barrows $H_{4}$, Feightmer JW, Neufeld VR, Noman GR. Analysis of the Clinical Methods of Medical Students and Physicians. Final Report, Ontario Department of Health, Grants (ODH-PR-273 and ODH-0M-225). Hamilton, Ontario, Canada: McMaster Unikersity, 1978.

6 Barrows, H.S. Noman, G.R., Neufeld, W.R., Feightner, J.W. The Clinical Reasoning of Randonnly Selected Physicians in General Medical Practice. Clinical and Investigative Medicine, 1982,5:49-55.

7 Feltovich PJ, Johnson PE, Molier JH, Swanson DB. LCS: the role and development of medical knowledge in diagnosis expertise. In: Clancey WJ, Shortlife EH (eds). Readings in Medical Artificial Intelligence: The Wirst Decade. Reading. MA: Addison-Wesley, 1984: 275-319.

8 Kassürer IP. Gorny GA. Clinical problem solwing; a behavioral analysis. Ann Intem Med. 1978; 89. 245-55.

9 Balla JI. The Diagnostic Process: A Model for Clinical Teachers. Cambridge: Cambridge University Press, 1985.

10 Barrows HS. Practice-based Learning: Problem-based Learning Applied to Medical Educationi. 5pringfield, IL: Southem Illinois University School of Medicine, 1994.

11 Kassirer JP, Kopelman RI. Learning Clinical Reasoning. Baltimore, MD: Williams \& Wilkins, Co. 1991"

12 Bordage G. Lemieux M. Semantic structures and diagnostic thinking of experts and novices. Acad Med. $1991 ; 66,570 \mathrm{~m} 572$.

13 Boshuizen HPA, Schmidt HG. On the role of biomiedical knowledge in clinical reasoning by experts, intermediates and novices. Cogn 5ci, 1992;16, 153-84.

14 Gale J, Marsdien P. Medical Diagnosis: From Sturtent to Clinician. Oxford. Oxford University Press, 1983.

15 Groen 6J, Patel VL. Medical problem solving: some questionable assumptions. Med Eviluc. 1985, 19. $95-100$.

16 Noman GR, Tugwell P, Feightner JW, Muzzin LJ, Jacoby LL. Knowledge and clinical problem solving. Med Educ. $1985 ; 19: 344,-536$.

17 Custers $E_{*}$ Regehr $G$. Norman GR Mental representations of medical diagnostic knowledge: a review. Acad Med. 1996,71 (0ct Suppl): \$55-561.

18 Schacter DL. Memony. In Posmer MI (ed). Foundations of Cognitive Science. Cambridge, MA: A Bradford Book, MitT Press, 1989.

19 Schallert DL. The significance of knowledge: a 5 ynthesis of research related to scherma theony. In Otto W. White 5 (eds). Reading Expositony Prose. New York: Academic; 1982: 13 48.

20 Johnson Mk, Hasher L. Human learning and memory. Mnn Rev Psychot, 1987,38, 631-68

21 Nelson K Event knowledge and cognitive development. In Nelson K (ed). Event Knowledge Structure and Function in Development. Hillsdale, NJ: Lawrence Erlbaum Associates, 1986.

22 Fayol M, Monteil J-M. The notion of script: from general to developmental and social psychology. Eur Bull Cogn Psychol. 1988;8, 335-61.

23 Schmidt HG, Norman GR, Boshuizen HPA. A cognitive perspective on med ical expertise: theory and inplications. Acad Med. 1990;65, 611-21.

24 Smith EE. Concepts and induction. In: Posner ML(ed). Foundations of Cognitive Science. Cambridge, MA: MiT Press, 1989.

25 Barrows HS, Tamblyn RM. Problem-based Learming: An Approach ta Medical Education, Series on Meditcal Education. New York, NY: Springer Publishing $\mathrm{Co}_{*} 1980$.

26 Barrows H5, Bennett. K. The diagnostic (problem solving) skill of the neurologist: experimental studies and their implications for neurological training. Arch Neurol, 1972,26, 273-7. 
27 Lesgold A, Rubinson H, Fetowich $P$, et al. Expertise in a complex skill: diagnosing x-ray pirtures. In Chi MTH, Gaser R, Far Wa (eds). The Nature of Expertise. Hilsdale, Ni: Lawence Erbaum Associates. 1988.

28. Lesgold A. Context-specific requirements for models of expertise. In Evans DA. Patel VL (eds). Cogmitive Science in Medicine. Cambridge, MA: Aradford Book, MII Press, 1989.

29 Grant J. Marsder P. The structure of memorized knowledge in studerts and dinicians: an explanation for diagnostic expertise. Med Educ. 1987:21, $92-8$.

30 Rumethart DE. Schendat the building blocs of cogrition. In: Spiro RA, Bruce BC, Brewer WF (eds). Theoretical Issues in Reading Comprehension. Huledale, N: Lawrence Erlbaum Associates, 1980.

31 Grant 3. Marsden P. Primary knowledge, medical education and consultant expertise. Med Educ. $1988: 22,173-9$.

32 Coughthlin L. Patel VL. Text comprehension and expentise in the domain of medicine. Paper presented at the Annual Meeting of the Antarican Educational Research Association, San Francisco, California, 1986.

33 Bordage 6 , Lemieux . Some cognithe characteristics of students with and without diagnostic reasoming difficulties. Proceedings of the 21 trt Annual Conference on Research in Medical Education of the Amencan Association of Wedical Colleges, Washington, DC., 1986: 171-6.

34. Bordage 6 , Lemeux M. Structuralism and medical problem solving. Int Semiotic Spectrum. $1987,7: 3-4$.

35. Feltovich PJ. Experise: reorganizing and refining knowledge for use. Professions Educ Res Notes. $1983: 4: 5-9$.

35 Patel WL, Evans DA, Groen GJ. Biomedical knowledge and clinical reasoming. In: Evans DA, Patel VL (eds). Cognitive Science in Medicine: Biomedical Modeling. Cambridge, MA: MIT Press, 1989.

37 Schmidt $H G_{n}$ Boshuizen HPA, Hobus PP. Transitory stages in the development of medical expertise: the "intermediate effect" in clinical case representation studies. In: Proceedings of the 10th Annual Conference of the Cognitive Science Society. Hillsdale, Nu: Erlbaum, 1988.

38 Kassirer JP. Diagnostic reasoning. Ann Intern Med. 1989;110:893-900.

39 Brooks LR, Noman GR, Allen SW. Ro of specific sirilarity in a medical diagnostic task. J Exp Psychol: General. 1991:120:278-87.

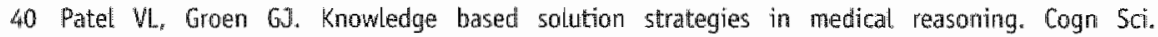
$1986 ; 10: 91-116$.

41 Eva KW, Brooks $L R$, Norman GR. Is on-line reasoning equivalent to post-hoc explaining? Presentation at the $109^{\text {th }}$ Annual Meeting of the Association of American Medical Colleges, New Orleans, 1998.

42 Bordage $G$, Williams. RG. Theory and practice in medical education. Professions Educ Res Q. 1992;14 (2): $: 1-5$,

43 Custers E The Development and Function of Illness Scripts: Studies on the Structure of Medical Diagnostic Knowledge. University of Mastricht: PhD Thesis, 1995.

44 Bashuizen H, Schmidt HG. The development of climical reasoning expertise. In: Higgs J, Jones M (eds). Clinical Reasoning in the Health Profession. Oxford, Buttenworth Heinemarn, $1995: 24-32$.

45 Kassirer JP. Teaching clinical medicine by iterative laypothesis testing: let's preach what we practice. New England J Med. 1983:309:921-3.

46 Chamber and M, Des Marchais JE, Charlin B. Carnying PBL into the clerkship: a second reform in the Sherbrooke curriculum. Ann Communty Oriented Educ. 1992:5:235-47.

47 Tardif $\mathrm{y}$. Pour un enseignement strakegique. L"apport de la psychologie cognitive. Montreal: Les Editions Logiques, 1992.

48 Van der Whet ten CPM. The assessment of professional competence: development, research and practical implications. Adr Heath Sci Educ, 1996;1:41 -67.

49 Charlin B, Brailowsky CA, Brazeau-Lamontagne L, Samson L, Leduc C. Script questionnaires: their use for assessment of diagnostic knowledge in radiology. Med Teacher. 1998;20:567-71.

50 Charlin B, Ray L, Bralowsky C, Van der Wleuten C. How to build a script concondance test to assess the reflective clinician. Submitted to Teach Leam Med, 1999.

51 Coles CR. Elaborated learning in undergraduate medical education. Med Educ. 1990;24:14-22.

52 Bordage 6. Elaborated knowledge: a key to successful diagnostic thinking. Acad Med. 1994;69:883-5. 


\section{CHAPTER 2}

\section{From theory to clinical reasoning assessment \\ The Script Concordance Test}

Published in Teaching and Learning in Medicine 2000, 12: 189-195

The Script Concordance Test, a Toal to Assess the Reflective Clinician

Bernard Charlin, Louise Roy, Carlos Brailovsky, Cees van der Vleuten

This study received funding from the Association of Canadian Medical Colleges and the Medical Research Council of Canada. 


\begin{abstract}
Background: The Script Concordance test (SC test) is a new assessment tool. It is designed to probe if knowledge of examinees is efficiently organized for clinical actions. That kind of organization of knowledge is named a script. SC test places examinees in written, but authentic clinical situations in which they must interpret data to make decisions.
\end{abstract}

Purpose: The test is designed to measure the degree of concordance that exists between examinees" scripts and scripts of a panel of experts. The objective of the paper is to provide interested educators with the practical "how to do" information needed to build and use a SC Test.

Methods: The theoretical background of the test is described. The principles of construction of a SC test are presented, with the writing of clinical cases, the choice of item format, the validation of the test and the elaboration of the scoring system.

Results: A series of studies have show that the SCT has interesting psychometric properties, in terms of reliability, face validity, and construct validity. Results from these studies are succinctly presented and commented.

Conclusion: The SC test is a simple and direct approach to testing organization and use of knowledge. it has the strong adwantage for a testing method of being relatively easy to construct and use and to be machine-scorable. it can be either paper or computer-based and can be used in under-graduate, post-graduate, or continuing medical education.

\title{
Introduction
}

Professional practice addresses problems that do not always have straightforward, algorithmic solutions. At the core of professiomal competence are judgment and insight, which rest on tacit knowledge. That kind of knowledge is neither visible nor tangible, and it cannot easily be evaluated using multiple-choice questions; yet it is the touchstone of competent professional practice. ${ }^{1}$ It is revealed only in action, in authentic situations when practitioners have to reflect on real concerns. $2,3,4$

Several authors hypothesize that, in clinical medicine, skilled and experienced practitioners differ from those less experienced and skilled because they possess elaborated networks of knowledge fitted to the tasks they regularly do. $5,6,7,8$ These networks, named scripts, $9,10,11$ are organized to fulfill goals within tasks concerning diagnosis, strategies of investigation, or treatment options. They be- 
gin to appear when students are faced with their first clinical cases and are then developed and refined during the whole clinical life. ${ }^{10,11}$

In this paper we describe a new assessment tool, the script concordance test (SC test), that stems from this cognitive theory of clinical expertise development. It places examinees in written, but authentic, clinical situations in which they have to interpret data to make decisions. The test belongs to the class of written simulations, ${ }^{12}$ which could be either paper or computer-based. It can be used in under-graduate, post-graduate, or continuing medical education. Our goal is to provide interested educators with all the information needed to construct and use SC test adapted to their needs.

\section{Theoretical background}

In cognitive research on medical expertise, there has been a shift from the search for a generic problem-solving skill toward a focus on memory organization, knowledge use, problem representation, and how they change with experience. In the testing and evaluation domain, this change of focus has not had many applications. In this perspective, Elstein, Shulman and Sprafka ${ }^{13}$ suggest that evaluation should concentrate on judging the quality of a set of cognitive operations or knowledge structures by comparing a student's problem representation, judgments, and choices to those of the experienced group.

The SC test follows this approach. It is based on the script theory, 70,11 which postulates that in specific situations clinicians mobilize pre-stored sets of knowledge, their scripts, that are used to understand the situation and act according to specific goats (e.g., diagnosis, investigation or treatment). Scripts of experienced clinicians vary on details, because each clinician has his/her own clinical experience, but they are similar for the essential elements. If it were not the case, clinicians would be unable to communicate efficiently about diseases or patients and they would not reach the same diagnosis in similar situations. Scripts contain information about the links that unit the items of knowledge (clinical features) related with an illness. It is these links, in diagnosis situations, that allow making decisions concerning the strength or the weakness of a hypothesis or to decide if a clinical feature is never associated with such hypothesis, in which case the hypothesis has to be rejected. Similar links are used to manage investigation or treatment decisions. ${ }^{11}$

The test approach consists of presenting examinees with a series of patient problems and then asking examinees to make diagnostic, investigative or therapeutic decisions, when specific elements of information are provided. Examples of test items are given in Figure 1. The test is designed to probe if the organization of clinical knowledge i.e., if the nature of the links between items of knowledge allow adequate clinical decisions. The test intends to assess the meaningfulness of 


\begin{tabular}{|c|c|c|c|c|c|c|}
\hline U you were thinking of & And then the patient reports & \multicolumn{5}{|c|}{ This hypothesis becomes } \\
\hline 1. Yeast infection & She had an STl a few years ago & -2 & -1 & 0 & +1 & +2 \\
\hline 2. Chlamydial infection & She is taking a contraceptive pill & -2 & -1 & 0 & +1 & +2 \\
\hline 3. Herpes infection & She hats an itchy vulwate & -2 & -1 & 0 & +1 & +2 \\
\hline 4. Herpes infection & She thas dysuria & $\cdot 2$ & -1 & 0 & +1 & +2 \\
\hline 5. Yeast infection & Her discharge is greenish and itchy & -2 & -1 & 0 & +1 & +2 \\
\hline
\end{tabular}

Figure 1: Example of items from the diagnostic section of a test.

the links among items, rather than assessing items in isolation. The scoring system of the test is designed to measures the distance, the gap. which exists between examinees" scripts and scripts of a panel of experts.

\section{Principles of construction of the SC test}

Construction requires the collaboration of a small number of experts (two is usually sufficient at the stage of test item production). They are asked in an informal interview to describe some clinical situations that are representative of the field. They then must specify for each situation (1) the relevant hypotheses, investigation strategies, or treatment options, (2) the questions they ask, the physical examinations they do, and the tests they order to solve the problem, and (3) what clinical information, positive or negative, they would look for in these inquiries. In a SC test there is no need to look for unusual clinical data. It is possible to discriminate among examinees with common data that require interpretation. Test items are built using the material obtained at this stage. The test consists of several patient problems, presented in short vignettes, each of them followed by a series of related test items.

Clinical vignette: Joyce, 20 years old, is consulting at your office for a "vaginal discharge" she has been experiencing for the past week. She has had a new sexual partner for the past three months and she is worried about getting an sexually transmitted disease.

\section{Clinical vignettes}

Each part of the test is based on a clinical case described in a few sentences. The description could be simple, as in "the patient is in her third semester of pregnancy and she is bleeding"for a diagnostic knowledge assessment; or it could be more 
detailed, such as "a 50 year old woman presents an history of documented angina pectoris. She is sedentary but has no other risk factors. She has had hysterectomy with bilateral ovariectomy at the age of 39 and has never had replacement hormonotherapy, although there were no contra-indication for its use." for an assessment of treatment knowledge in coronary wascular disease. The description must systematically contain all the necessary information for an expert to make an informed choice in the situation. For instance, in a situation of therapeutic choice in cardiac failure, the expert must know if the patient is short of breath and has pulmonary ronchus before deciding if a diuretic will be prescribed.

In some assessment situations there is a need to describe an evolution of the situation. For instance, in a geriatric assessment tool, the first set of information could be such as: "An 82 year old lady is howling in the emergency room and pulls out the solution which contains the antibiotics required by her pneumonia. The attending staff has given a diagnosis of delirium whose ongin has to be found. After the presentation of a series of diagnosis questions, a text describes the new requirement of the situation: "the nurse now asks for an efficient treatment for the delirium while waiting for the results of the investigation." This information is followed by a new series of treatment related questions.

\section{Choice of test item format}

The item format differs with the objective of assessment (diagnosis, investigation, or treatment), and for a given vignette, items are regrouped by format (e.g.. some items on diagnosis, followed by some items on investigation). Each test item consists of three parts. The first part includes a diagnostic hypothesis, an inwestigative action or a treatment option that is relevant to the situation. The second presents new information e.g., a sign, a condition, an imaging study or a laboratory test result that may have an effect on the diagnostic hypothesis, the investigative action or the treatment option. The third part is a 5-point Likert scale. An illustration of the three formats is given in Figure 2. Other formats may be established to assess other situations, such as giving prognosis or providing coumseling.

\section{Construction of test items}

The construction of items follows the key features appraach ${ }^{14}$ i.e., the choice of question is focused on the elements that are the most useful to solve a clinical problem. Each item is build so that a reflection is necessary to answer it, and each is independent of the others. To prevent examinees from considering data on several following questions as cumulative information about the patient, hypotheses or options change for each question. It is also clearly specified in instructions for participants that within vigmettes, each item is independent of the others. The goal of each item is mot to determine the additive effect of a series of clinical information elements but to determine the effect of isolated clinical information on 
1- For diagnostic knowledge assessment

\begin{tabular}{|c|c|c|c|c|c|c|}
\hline If you were thinking of & And them you find: & \multicolumn{5}{|c|}{ This hypothesis become } \\
\hline (a diagnostic hypothesis) & $\begin{array}{l}\text { (a new clinical information, an imaging } \\
\text { study or a laboratory test result) }\end{array}$ & -2 & -1 & 0 & $\$ 1$ & +2 \\
\hline
\end{tabular}

-2 Ruled out or atmost ruled out

- 1 Less probable

- Neither less or more probable

-1 More probable

+2 Centain or alumost certain

2- For investigation knowledge assessment

\begin{tabular}{|c|c|c|}
\hline $\begin{array}{l}\text { If you were considering } \\
\text { to ask }\end{array}$ & And them you find & $\begin{array}{l}\text { This Investigation } \\
\text { becomes }\end{array}$ \\
\hline (a diagnostic test) & $\begin{array}{l}\text { (a new clinical information an imaging } \\
\text { study or a laboratory test restlts) }\end{array}$ & $\begin{array}{llll}-2 & -1 & 0 & +1\end{array}$ \\
\hline
\end{tabular}

-2 Contra-indicated totally or almost totally

- 1 Mot useful or even detrimental

0 Mor less nor more usieful

+1 Useful

+2 Absolutely necessary

3- For treatment knowhedge assessment

\begin{tabular}{|c|c|c|c|c|c|c|}
\hline $\begin{array}{l}\text { If you were considering } \\
\text { to prescribe }\end{array}$ & And then you find & \multicolumn{4}{|c|}{$\begin{array}{l}\text { That prescription } \\
\text { becomes }\end{array}$} & \\
\hline (a treatment optian) & $\begin{array}{l}\text { (a new clinical information, an imaging } \\
\text { study or a laboratory test result) }\end{array}$ & -2 & -1 & 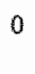 & +1 & +2 \\
\hline
\end{tabular}

-2 Contra-indicated totally or almost totally

-1 Not useful or ewen dewimental

0 Nor less nor more useful.

+1 Useful

+2 Necessary or absolutely necessary

Figure 2: The item format waries with the object of assessment (diagnosis, investigation, treatment).

a hypothesis, action or treatment option. An example of a diagnostic section of a test is provided in Figure 1.

Elstein, Shulman and Sprafka ${ }^{95}$ have shown that clinicians do not entertain Large numbers of hypotheses at the same time. They found that when this number exceeds five, clinicians feel a cognitive need to reformulate their hypotheses in more inclusive and less numerous diagnoses. For this reason, we think that the number of tested hypotheses should not exceed five, while there should be at least two (if there is only one, this is not a diagnostic problem). The exact number depends on the relevance of the hypotheses to the situation. 
To prevent cueing effect on examinees, iterns are constructed to disperse answers among all values of the Likert scale. The number of items necessary for a test depends on its goal. For a CME pretest, where the goal is to activate participants' prior knowledge and induce reflection on the appropriateness of that knowledge, the number of necessary items will be minimal (usually around 20 to 30). For a test that will have certification or promotion consequences, where reliability is a major issue, the number of necessary items will be higher, and will depend on the size of the probed domain.

\section{Validation of the test}

The test is then submitted to a group of experts. The same group will serve for the elaboration of the scoring system. The definition of experts depends on the assessment situation. For example, to build a test that will serve to assess the knowledge of residents in cardiology, experts will often be chosen among certified cardiology specialists. Alternatively, if the test is built to assess knowledge for a CME activity aimed at family physicians, experts might be family physicians who have an important part of their clinical activities within that domain, along with some cardiology specialists. During their completion of the test, experts are asked to identify the items they find confusing or not relevant. These items are then either discarded or rewritten.

\section{Elaboration of the scoring system}

The number of experts used to develop the scoring system must be sufficient (five to ten) to express the variability in answers that experts may show for each item. Our first studies ${ }^{16,17,18}$ have shown that experts provide the same answer on some items, but also provide different answers for others. This is in accordance with other studies that have shown that experts answers vary when they have to solve problems, even in their own field of expertise. ${ }^{19,20}$ The scoring process of the test is based on the principle that any expert answer reflects the opinion of an expert. and that answers for which there is no agreement among all the experts should not be discarded. In other words, any answer given by an expert has an intrinsic value, even if other experts do not agree with it. Hence, scores for each item are computed from the frequencies given to each point of the Likert scale by the experts. Figure 3 gives an example of the scoring grid obtained for the items of Figure 1 by a set of 10 experts.

Clinical vignette: Joyce, 20 years old, is consulting at your office for a "vaginal discharge" she has been experiencing for the past week. She has had a new sexual partner for the past three months and she is worried about getting an sexually transmitted disease.

For the first item, 8 experts have answered (0), one expert has answered ( -1$)$, and one expert has answered $(+1)$. Hence scores for a student who answers $(-1)$ is 0.1 , 


\begin{tabular}{|c|c|c|c|c|c|c|}
\hline It youl wera nolnking of & $\begin{array}{l}\text { And then the patlent reponts } \\
\text { or you find ypon dinical examination }\end{array}$ & This & hypo & thes? & $\begin{array}{l}\text { bers } \\
+1\end{array}$ & $\begin{array}{l}\text { nes } \\
+2\end{array}$ \\
\hline 1. Yeast infection & She had an STD a few years ago & 0 & 0.1 & 0.8 & 0.1 & 0 \\
\hline 2. Chlamydial indrection & She is taking a contraceptive pill & 0 & 0.1 & 0.8 & 0 & 0.1 \\
\hline 3. Herpes infection & She has an itchy vuluae & 0 & 0.5 & 0.1 & 0.4 & 0 \\
\hline 4. Herpes infection & She has dysuria & 0.1 & 0.1 & 0.2 & 0.5 & 0.1 \\
\hline 5. Yeastinfection & Her discharge is greenish and itchy & 0.1 & 0.5 & 0.1 & 0.3 & 0 \\
\hline
\end{tabular}

Figure 3: Example of the scoring grid obtained for the items of Figure 1 with a set of 10 experts. The group was composed of general practitioners.

(0) is 0.8 and $(+1)$ is 0.1 . Other answers are scored 0 . Items in a SCT do not have the same maximum walue: for the first item the maximum score is 0.8 and for the third it is 0.5 . That walue depends on the agreement between experts. Scoring is weighted by the degree of agreement between experts. This weighting is in no way artificial or arbitrary. It reflects the way experts answer the question.

The results of the test are represented by the sum of the scores obtained at each item. The maximum score for a test is the sum of the higher score obtainable on each item. The total score for the set of 20 items from which Figure 1 and 3 are taken is 11.4. For the convenience of interpretation it is suggested to transform all scores to get a maximum score of 100 . A score of 100 signifies that the examinee gives on each item the answer that most experts provide, and the lower the score the farther examinees are from the experts prototypic script for the situation.

\section{Results from previous studies}

In previous studies, three SC Tests with different contents (gynecology, radiology \& surgery) were administered at different groups of participants. ${ }^{16,17.18}$ Results from these studies are succinctly presented in Table I with mean scores, standard deviations and size of groups of participants. The students have shown the widest variability in their scores, followed by the residents in the studies in which they took part (they were not part of the study done in surgery). Levene's test of homogeneity of variance was used to verify whether the variances were equal in each study. The results indicated that the variances could be considered equal. The factorial ANOVA used to test the mean group differences have shown significant differences between students, residents and faculty groups, as indicated in Table $I$.

The scores increased with the clinical expertise of group participants, the students getting lower scores than the residents and the residents lower scores than 
Table I. Comparison of man scores by groups in thee different studies

\begin{tabular}{|l|l|l|l|l|}
\hline \multirow{2}{*}{} & & Mear & S.0. & Size \\
\hline \multirow{3}{*}{ Gynaecology* } & faculty & 78.1 & 7.2 & 15 \\
\cline { 2 - 6 } & residents & 75.9 & 12.8 & 12 \\
\cline { 2 - 6 } & clerks & 67.1 & 14.0 & 76 \\
\hline \multirow{3}{*}{ Radiology* ** } & faculty & 86.7 & 7.0 & 6 \\
\cline { 2 - 6 } & residents & 69.3 & 7.6 & 10 \\
\cline { 2 - 6 } & clerks & 62.6 & 14.0 & 14 \\
\hline \multirow{3}{*}{ Surgery*** } & faculty & 80.5 & 8.8 & 96 \\
\cline { 2 - 6 } & clerks & 62.1 & 9.5 & 9 \\
\hline
\end{tabular}

* Clerks vs faculty $<0.001$, ather comparisons between groups were not significant

the faculty participants. These observations were similar in the three studies already performed.

We used generalizability studies to evaluate the internal consistency of each test administration. It was dome with Etudgen for Macintosh. ${ }^{21}$ Coefficients were calculated with the results of the group of students that participated in each study. The observed generalizability coefficients (identical to the coefficient alpha) for each test are presented in Table II. D-studies showed the number of items than are necessary in each test administration to achieve an alpha of 0.8 .

Table II. Mumber of items in three different studies

\begin{tabular}{|c|c|c|c|}
\hline & No thems & A obsenved & No items for alpha $\geq 0.8^{*}$ \\
\hline Gynaecology & 50 & 0.794 & 51 \\
\hline Radiology & 48 & 0.804 & 46 \\
\hline Surgery & 26 & 0.54 .4 & 59 \\
\hline
\end{tabular}

\section{Discussion}

The principle of the Script Concordance Test is to compare the script of examinees to those of experienced clinicians using a series of clinical tasks, in specific contexts. The test possesses several advantages related to reliability and validity issues, to the scoring process, and to its educational effects.

The reliability studies have shown good alpha coefficients around 0.8 in two $5 C$ Test administrations, thus indicating homogeneity of items. In the case of the surgery study, were the number of items was low, D-studies indicate that 50 to 60 
items are sufficient to achieve alphas of 0.8 . The discrimination power of individual items was good.

In most research concerning assessment of campetence, experienced clinicians score little better or even worse than end of training residents, while one would expect that greater experience would be reflected in scores. ${ }^{12}$ This counterintuitive finding, called "the intermediate effect," indicates that the proxy measures used in many studies, especially multiple-choice tests, are probably measuring competence poorly, and are invalid indicators of the work clinicians actually do in the practice setting. ${ }^{1}$ In contrast to these findings, in our first studies ${ }^{16,17,18}$ we found that with SC tests, scores increase with clinical experience (see Table I). This lends support to the construct validity of the tool. An explanation may be that most assessment tools, especially written ones, probe factual knowledge and interpretation of data using factual knowledge. Script Concordance Tests go further. They explore the capacity of data interpretation in the making of clinical decision i.e., clearly a skill that belongs more to clinical competence than the simple recall of factual data.

Another measure of test validity is the face validity and the relevance of the tasks posed to examinees. In SC tests, examinees must solve problems belonging to the real world of the profession and must answer questions that experts consider of crucial importance in the process of solving that problem. Advantages of bringing these relevant contexts into test items are two folds. First, examinees, either students, residents or practicing physicians find the test relevant and interesting to complete. Second, placing examinees in real world situation allows expertise to emerge as the disappearance of the "intermediate effect" suggests.

The scoring system has several advantages. First, ance the response grid is built, there is no answer interpretation, the test is standardized, scoring is straightforward, and the test is machine-scorable. Second, knowing that there is no single "best answer" the test can be used in test-retest situations. Finally, the test can also be used in situations where there is no consensus among experts, in the literature or in practice. Among advantages of the test, it is also important to mention that relatively modest resources are required to develop it.

It is well known that assessment has a strong impact on learning. Students adapt what they learn to what they believe will be tested. $S C$ tests reflect professional reality and are problems solving oriented; hence they should influence the adaptation of students' learning activities in that direction. Furthermore, in CME activities, a SC test used at the beginning of activities to assess prior knowledge, produced better retention of knowledge both at the end of the process, and three months after the activity. ${ }^{22}$ We interpret that positive effect as an activation of the knowledge that is relevant for the educational activity, which allows participants to detect where their prior knowledge might be insufficientt or inaccurate. 


\section{Conclusion}

The SC test is a simple and direct approach to testing organization and use of knowledge. It has the strong advantage for a testing method of being relatively easy to construct and use and to be machine-scorable. It can be either paper or computer-based and can be used in under-graduate, post-graduate, or continuing medical education. It has also several psychometric advantages and good face validity for assessment of clinical competence. It is well accepted by students, residents and physicians ${ }^{16,17,18,22}$ because examinees find that the tasks they have to fulfill are closely linked to professional reality, and because it does not assess. trivial knowledge, but rather probes real world clinical knowledge. More research to support these claims is warranted and will be conducted.

\section{References}

1 McGaghie, W.C. Evaluating Competence for Professional Practice. In L. Curry B. J.F. Wegin (Eds), Educating Professionals. Responding to new expectations for competence and accountability. San Francisco: Jossey-Bath Publishers, 1993, pp. 229-261.

2 Harrs, I. New Expectations for Professional Competence. In L. Curry \& J. F. Wegin (Eds), Educating Professionals "Responding to new expectations for competence and accountability. San Francisco: Jossey-Bath Publishers, 1993, pp. 17-52.

3 Schön, D.A. Educating the Reflectiwe Practitioner: Toward a New design for teaching and Learning in the Professions. Sari Francisco: Jossey-Bass, 1987.

4 Epstein, R.M. Mindful Practice. JAMA, 1999, 282: 833-839.

5 Custers, E., Regehr, G. Norman, G.R. Mental Representations of Medical Diagnostic Krowledge: A Rewiew. Academic Medicine, 1996, 71, Oct. Suppiement: \$55-561.

6 Bordage, G. Elaborated knowledge: A key to Successful Diagnostic Thinking. Academic Medicine, $1994,69,883-885$.

7 Feltowich, P.J. Expertise: reorganizing and refining knowledge for use. Professions Education Research Notes, $1983,4,5,-7$.

8. Zeitz, C.M. Some Concrete Adwantages of Abstraction: How Experts' Representations Facilitate Reasoning. In P.J Feltovich. K.M. Ford, R.R. Hoffman (Eds.), Expertise in Context" Human and Ma" chine. Hemlo Park, CA: AAAI/MIT press, 1997.

9. Feltovich, P.J. \& Barrows, H.S. Issues of Generality in Medical Problen Solwing. In H.G. Schmidt \& M. L. De Volder (Eds.). Tutorials in Problem-Based Learning: A mew Drecton in Teaching the Health Professions. Assen, Holland: Van Gorcum, 1984.

10 Schmidt, H.G. Norman, G.R. and Boshuizen, H.P.A. A Cognitive Perspective on Medical Expertise: Theory and Implications. Academic Medicine, 1990, 65, 611-621.

11 Charlin, B., Tardif, J., Boshunzen, H.P.A. Scripts And Medical Diagnostíc Knowledge: Theory and Applications for Clinical Reasoning Instruction and Research. Academic Medicine, 1999, 75 : $182-190$.

12. Van der Vleuten, C.P.W. The Assessment of Professional Competence: Davelopment, Research and Practical Inplications. Advances in Heath Sciences Education, 1996, 1:41-67.

13 Elstein, A.S. Shuman, L.S. and Sprafka, S.A. Medical Problen Solving, a Ten-Year Retrospective. Evaluation and the Health Profession, 1990, 13: 5-36.

14 Bordage, G., Page G. An alternative approach to PMPs: The "key features" concept. In: Hart IR, Harden RM, editors. Further developments in assessing clinical competence. Montreal: Heal Publi $_{\text {- }}$ cations, $1987,59-75$.

15 Elstein, A.S., Shulman, L.S., Spratka, S.A. Medical Problemi Solving: Arr Analysis of Clinical Reasoning. Canbridge, MA: Harvard Unjersity Press, 1978. 
16 Charlin, B., Bralloysky, C. Leduc, C., Bloun, D. The Diagnostic Seript Questionaire: A New Tool to Assess a Specific Dimension of Clinical Competence. Advances in Heath Sciences Education, 1998 . $3: 51-58$.

17 Charlin, B., Bratowsky, C. A., Brazeau-Lamontagne, L., Samson, L., Leduc C. Script Questionnaires: Their Use for Assessment of Diagnostic Knowledge in Radiology. Medical Teacher, 1998, 20: $567-571$.

18 Brailowsky, C., Charlin, B., Beausolelt, S, Coté, S., van der Vleuten, C. Measurement of Clinical Reflective Capacity Early in Training as a Predictor of Clinical Reasoning Performance at the End of Residency: An Exploratory Study on the Script Concordance Test. Medical Education, 2001, 35: $430-436$.

19 Elstein, A.S., Holzman, G.B., Ravitch, M.M., et al Comparison of physicians ${ }^{r}$ decision regarding estrogen replacement therapy for menopausal women and decisions derived from a decision analytic model. American Journail of Medicine, 1986, 80:246-258.

20 Norman, G.R., Tugwell, P., Feightner, J.W., Muzzin, L.J. \& Jacoby, L.L. Knowledge and Clinical Problem Solving. Medical Education, 1985, 19: 344-356.

21 McNicoll A., Brailovsky $C A$, Bertrand $R$, Cardinet J. EtudGen, programme pour l"analyse de la gênéralisabilité pour Macintosh. CESSUL 1992, 1996, 1999. in D. Bain et G. Pini Pour évaluer wos êvaluations: la généralisabitité, mode d'emploi. Centre de recherches psychopédagogiques, Genève, 1996.

22 Brailowsky C. Charlin B. Emond C, Maltais P. Script Questionnaire as a Method of Assessing Clinical Reasoning after Educational Programs. Workshop at the Alliance for Continuing Medical education Education's 24th Annual Conference. Atlanta, Hilton \& Towers, Georgia, Jantuary 29, 1999. 


\section{CHAPTER 3}

\section{Overcoming the intermediate effect A study in gynecology}

Published in Advances in Health Sciences Education, 1998, 3: 51-58

The Diagnostic Script Questionnaire: A New Tool to Assess a Specific Dimension of Clinical Competence

Bernard Charlin, Carlos Brailovsky, Charles Leduc, Daniel Blouin

This study has benefited of a grant from the Association of Camadian Medical Schools and the Medical Research Council of Carada. 


\begin{abstract}
The Diagnosis Script Questionnaire (DSQ) assesses a specific skill of clinical competence: the ability to weigh collected information in light of entertained hypotheses. The questionnaire presents a clinical vignette for which several hypotheses are relevant. The model of the questions is: if you are thinking of hypothesis $A$ and you find $\operatorname{sign} Z$, what is the effect on your hypothesis? Answers are placed on a 7-point Likert scale, with values ranging from "it can only be this hypothesis" to "this hypothesis is definitely rejected." The scoring process is innovative and reflects the variability of answers among experts.
\end{abstract}

The questionnaire was administered in gynecology-obstetrics: 103 respondents, divided into three groups, 15 faculty, 12 residents, and 76 clerkship students volunteered. The Chi Square statistic $(58.12 ; p<0.001)$ indicates that the three groups behave as being three different populations. Mean glabal scores were 45.3 for faculty, 40.5 for residents, and 35.8 for students. The differences between the three groups were statistically significant with Welch ANOVA $(p<0.001)$. The Bonferroni post-hoc correction however indicated that the only significant difference was between student and faculty groups $(p<0.001)$. Cronbach"s alpha was 0.822 for the total group; for the student and resident groups, 0.794 and 0.812 respectively. The proportion of the total variance explained by the interaction items/participants as estimated by generalizability was $42.1 \%, 65.4 \%$ and $73.4 \%$ for the faculty, resident and student groups respectively.

Results agree with the theories of development of clinical competence, which states that knowledge structures specifically adapted to diagnostic tasks appear with clinical experience. This new assessment tool appears promising and warrants future development.

\title{
Introduction
}

A new assessment tool, the Diagnosis Script Questionnaire, (DSQ) has been designed to assers a specific skill of clinical competence: the ability to weigh clinical information in light of entertained hypotheses in diagnostic situations. The DSO is grounded in two theories of clinical reasoning: the hypothetica-deductive theory and the illness script theory.

Since the work by Elstein, ${ }^{1}$ we know that clinical reasoning is a hypothetico-deductive process characterized by the early generation of hypotheses, oriented data collection and decision making judgment, and the use of data to confirm or reject hypotheses. According to Schmidt, Norman and Boshuizen, ${ }^{2}$ the acquisition of clinical expertise is related to the development of specialized knowledge structures, referred to as illness scripts, that contain the clinically relevant information that clinicians will use in their clinical activities. The theory considers that in 
diagnostic situations clinicians bring in their working memory knowledge related to each relevant hypotheses. Such knowledge encompasses all clinical features (that is symptoms, signs, laboratory or radiology data and/or previous experiences) that clinicians know to be useful for diagnosis. Knowledge activated from memory is then used in a deductive process to actively seek information that will allow confirmation or rejection of entertained hypotheses. ${ }^{3}$

This theory rests on the assumption that clinicians have idiosyncratic memory structures which are meaningful sets of connections among clinical features ${ }^{4}$ and that these connections reflect the organization of knowledge that takes place when students begin to be exposed to real clinical tasks. ${ }^{2}$ The concept of illness script has been extensively tested in a recent series of experiments by Custers. ${ }^{5}$

The DSQ (Figure 1) is built around the information clinicians look for in the hypothetico-deductive processes of clinical reasoning. The questionnaire depicts within a short vignette a clinical situation for which a few hypotheses are relevant, all of them being specified. A series of questions are presented, based on the model: if you are thinking of hypothesis $A$ and you discover a sign $Z$, what is the effect on your hypothesis? Answers are placed on a 7-point Likert scale, with values ranging from "it can only be that hypothesis" to: "it definitely rejects the hypothesis." The midpoint of the scale stands for "there is no effect on the hypothesis."

Research hypotheses were: (1) Since we postulate that specific knowledge structures are built with clinical experience, if the group of higher expertise is considered as a reference group, scores reflecting the ability to weigh clinical information will be lower for the other groups; (2) With this assessment tool it should be possible to discriminate students with different levels of competence; (3) The interaction item/candidates increases with the decrease of expertise while the importance of individual item difficulties in the total score increases with the increase of the clinical expertise.

\section{Material and method}

This new kind of questionnaire was tested in the field of obstetrics. The clinical situation was bleeding in the third trimester of pregnancy. The four more relevant competing hypotheses (placenta previa, abruptio placenta, uterine rupture, and bleeding from cervical os) were explicitly stated. An obstetrician generated the positive and negative signs he would seek in this situation. For each hypothesis there were less than 10 positive signs; negative signs were the positive signs of the other competing hypotheses. A questionnaire of 50 questions was then drawn up. The resulting questionnaire reflects the clinical reasoning of one expert. The questionnaire was then shown to two other experts for validation before use. This validation resulted in only minor wording corrections. 


\begin{tabular}{|c|c|c|c|c|c|c|c|c|}
\hline \multirow{2}{*}{$\begin{array}{l}\text { If you find } \\
\text { 1. Bleeding happening at } 39 \text { weeks } \\
\text { of pregnancy }\end{array}$} & \multirow{2}{*}{$\begin{array}{l}\text { While you twere } \\
\text { thinking of the } \\
\text { following hypothesis } \\
\text { Placenta previa }\end{array}$} & \multicolumn{7}{|c|}{$\begin{array}{l}\text { It has the following effect } \\
\text { (please encircle your } \\
\text { answer) }\end{array}$} \\
\hline & & A & $B$ & $c$ & D & $E$ & $F$ & $\sqrt{3}$ \\
\hline $\begin{array}{l}\text { 2. Candida vaiginitis in warly } \\
\text { pregnancy }\end{array}$ & Abruptia placenta & A & $\mathrm{B}$ & C & D & $\mathrm{E}$ & $F$ & \\
\hline $\begin{array}{l}\text { 3. Placenta normally inserted at } 20 \\
\text { weeks of pregnancy }\end{array}$ & Uterine rupture & A & 8 & C & D & E & $\mathbb{F}$ & 6 \\
\hline $\begin{array}{l}\text { 4. Chromic hypertensian diagnosed } \\
\text { before pregnancy }\end{array}$ & Abruptio placenta & A & $\mathrm{B}$ & C & D & E & 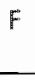 & G \\
\hline $\begin{array}{l}\text { 5. Cervical comization done one } \\
\text { month before pregnancy }\end{array}$ & Uterine rupture & A & $B$ & c & D & E & $F$ & G \\
\hline $\begin{array}{l}\text { 6. Late deceleration of the fetal } \\
\text { heart rate }\end{array}$ & Placenta previa & & $\mathrm{B}$ & C & D & $\mathbb{E}$ & $r$ & G \\
\hline
\end{tabular}

$A=$ It can only be that hypothesis; $D=$ There is no effect on the hypothesis: $G=$ It definitely rejects the hypothesis

Figure 1. Principle of the questionnaire

The study $(n=103)$ compared three groups with different levels of clinical experience: faculty members $(n=15)$, from the gyneco-obstetrics departments of two universities (University of Sherbrooke, and Laval); all the residents from the Gynecology/0bstetrics residency program (from year 1 to year 5) $(n=12)$ that were intraining at Sherbrooke Medical School, and all clerkship students within a class in Sherbrooke just before the end of their MD program $(n=76)$. Students and residents from Sherbrooke do not differ in training from those of the other medical school in Canada, and they perform in a similar way in national examinations. Ten students refused to answer the questionnaire. Due to anonymity of participation, we do not have any data allowing to compare them to those who have accepted.

The scoring process is an original aspect of this questionnaire. We approached it with the idea that any faculty member's answer reflects the opinion of an expert, and that we should not discard answers for which there is no agreement among all the experts. In other words, we thought that any answer given by an expert has an intrinsic value even if other experts do not agree with it. Hence, scores for each item were computed from the frequencies given to each point of the Likert scale by faculty members. If for instance, for a given question, the distribution of faculty members answers is 11 for one point of the scale and 4 for another one, scores for the participants who answer that item in the same manner would be $0.73(11 / 15), 0.27(4 / 15)$ and 0 for all others. The results of the test are represented by the sum of the scores obtained at each question. 
Three different types of statistical analyses were performed: (1.) Descriptive statistics of the participants' scores on the DSQ, followed by a factorial analysis of variance (ANOVA) to study differences between groups" means. For all the studies, the homogeneity of group variances was estimated using the Levenes' test. Pair wise comparisons were then used to determine precisely which differences of scores between groups of participants were significant. Since the study required multiple contrast analyses, the Bonferroni correction was utilized to decrease the probability of finding significant results due to chance. (2) Item analysis (i.e., the study of reliability coefficients of the test for each group, item/total correlations, and alpha values if the item is excluded from the total) were performed using the SPSS system for Macintash. (3) Generalizability studies were performed using the Etudgen program developed by McNicoll et al. ${ }^{6}$ The facets for the analysis were participants and items. The generalizability coefficients were calculated using the persons $X$ items design $(P \times I)$. For the analysis of the interactions between persons and items, facet analyses, were performed using the items as differentiation facet and the participants as instrumentation facet (I/P).

Statistics were computed with the global scores obtained by adding for each participant the score obtained on each item. In this exploratory research, faculty members are considered as a reference group (but not as a gold standard).

\section{Results}

The mean scores of the three groups of participants are shown in table I

The students show the widest range of scores, ranging from 13.3 to 48.7 (36), followed by residents (21) and faculty participants (16). One faculty participant behaved in a different manner than his colleagues, his score being below the 10th percentile of his group. From these observations and the scores' standard deviations, it appeared that the groups were not homogeneous. To test this hypothesis the Levene's test of homogeneity of variance was used to verify whether the three group variances were equal. The results were significant $(F=4.2101, p<0.018)$, thus indicating that the three variances were in fact not equal. The Welch ANOVA test for unequal variances was then used to compare groups ${ }^{*}$ means. The results were significant for the three groups $(p<0.001)$. The Bonferroni post hoc correction however, indicated that the only significant difference was present between the scores of student and faculty groups $(p<0.001)$. Furthermore, even if the mean score of residents appears to be different from these of the faculty participants, the lack of significance in the difference of the scores between residents and faculty can be explained by the higher variability of resident scores.

The distributions of scores for individual items for the three groups of participants varied from item to item. This was due to the relative difficulty of the individual items for the different subjects. Furthermore, individuals who had the 
Table 1.: Comparison of mean scores by groups.

\begin{tabular}{|l|c|c|c|c|c|}
\hline Groups & N & Meam & St.dev. & Mn. & Max. \\
\hline Faculty & 15 & 45.3 & 3.7 & 36.3 & 52.4 \\
\hline Residents & 12 & 40.5 & 7.1 & 28.5 & 49.5 \\
\hline Students & 76 & 35.8 & 7.4 & 13.3 & 48.7 \\
\hline
\end{tabular}

Students ws. faculty: $p<0.001$ (Welch Anowa and Bonferroni posthoc correction); other comparisons between groups were not significant.

same total score showed high variations in their scores for individual items, a phenomenon called case specificity, that is, the low predictability of the performance of one item from the performance on another item.

The alpha coefficient for the entire group was 0.822 . The alpha coefficient for the residents. group was 0.812 and for the students group 0.794 . The elimination of the "low score" participant in the fiaculty group increased the mean and decreased the standard deviation of the group but had no influence on group test reliability and it was decided to include the scores of this participant in the subsequent analyses. The item/total correlations showed in the majority of cases a strong and significant correlation between all items and the results of the test for the resident and student groups. The alpha values obtaimed when each item was excluded from the test indicated that almost all the items contributed positively to tatal reliability.

The generalizability studies have shown that the true variances increased from the faculty group to the student group, the resident group being intermediate (Figure 2). The variance component for the interaction between participants and tems accounted for $71.6 \%, 65.4 \%$ and $46.3 \%$ of the variance in the case of students, residents and faculty respectively. This variance component seems to be related to the structure of the participants' knowledge. The less experienced ones perceive each item as a unique task whereas the experts hawe global perception across items, the residents being in between. The variance component for items was $53.7 \%$ for faculty participants, $34.6 \%$ for residents and $28.4 \%$ for students. These values indicate that item difficulties and item specificity were different for each group of participants depending on their respective expertise.

\section{Discussion}

Contemporary methods of assessment of clinical competence have repeatedly shown the puzzling fact that experienced clinicians score little better and sometimes worse than less experienced clinicians or students. ${ }^{78.9}$ Most of these methods of assessment measure climical factual knowledge rather than the organiza- 


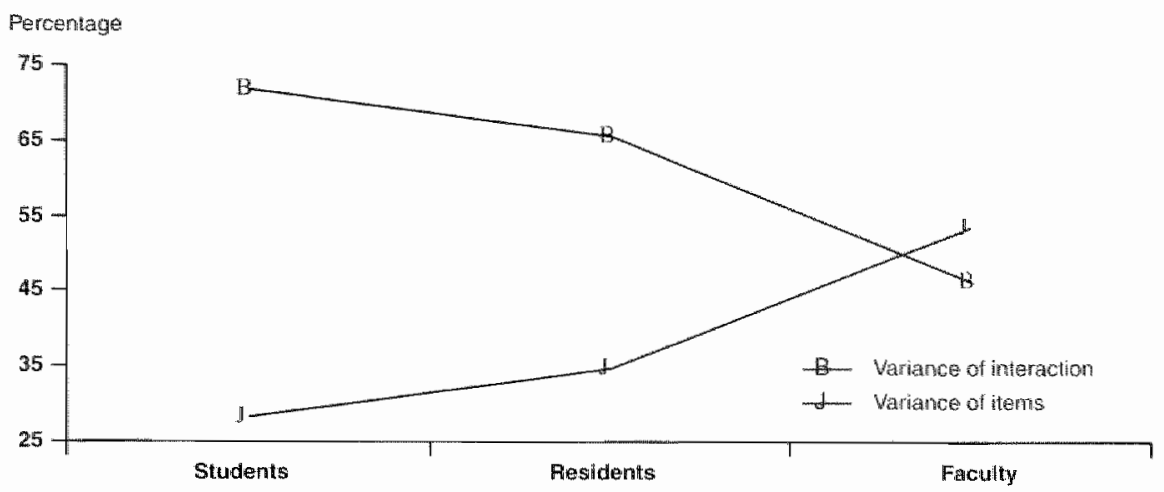

Figure 2. Percentage of wariance for item/candidates interaction and for item difficulty for each group.

tion of knowledge that allows clinicians to recognize and handle situations effectively. According to Feltovich, ${ }^{10}$ the development of expertise is largely a matter of reorganizing knowledge and cognitive processes to fit the demand of tasks within the domain of expertise. An assessment tool that would explore the ability among clinicians to weigh incoming clinical information to make judgments about entertained hypotheses may support what Bordage ${ }^{11}$ and Coles $^{12}$ call elaborated knowledge which is supposed to be a key component of clinical competence. It is in this perspective that we developed the DSQ.

In a usual clinical situation, a skilled clinician activates relevant diagnostic hypothesis by pattern recognition. He then uses illness scripts to ask questions and perform physical examinations in order to make decisions about the right diagnostic. In the DSQ the pattern recognition stage is skipped because the relevant hypotheses are given. The goal of the questionnaire is to assess if the richness of existing illness scripts allows adequate interpretation of provided clinical data.

The content validity of the DSQ and the relevance of competing hypotheses were assessed by two gynecology-obstetric experts. The reliability (homogeneity) of the test was calculated and shows acceptable coefficients. The test-retest reliability was not yet assessed because the OSD was utilized only once with each group. However, the instrument is being tested in other settings in various medical specialties and test-retest is in the way.

Our results show an increase in the mean scores on the DSQ of groups with different clinical expertise, the less experienced getting the lower results. This may mean that the DSO measures a dimension for which, as one should expect, experts get better scores than less experienced subjects, thus supporting the construct validity of the instrument. Furthermore, the observation that the interaction 
item/candidates increases inversely to the expertise of the group under study, whereas the importance of the item difficulty decreases, suggests that the expertise of the individuals plays a role in overcoming the problems raised by the content of the items.

Clinical competence is a multidimensional entity. No single assessment method can adequately measure it. The DSQ measures a specific dimension of clinical competence. It is built by interviewing clinicians about the information they look for in given clinical situation and is relatively easy to build and administer. The large variability found among students suggests that it may be possible to discriminate among students with the use of the DSQ as an assessment tool. To validate this passibility, we are now analyzing and comparing the results of strong and weak students' scores on the DSQ to their performances on other already validated tests. The results obtained with participants in obstetrics have to be confirmed with other studies that will allow the verification of the validity of this model of evaluation. In our experimental design we used only one clinical situation within one medical discipline. We are already doing similar research in other disciplines, with more clinical situations.

In medical education few assessment tools are available that allow the comparison of clinical knowledge among subjects as different as students, residents and faculty. Depending on the goal, in DSQ construction it is possible to introduce items that could differentiate between the groups of candidates in relation to their level of clinical competence. If one wants to build a questionnaire that assesses clinical competence related to the more frequent clinical situations of a domain, a ceiling effect will be reached between senior residents and faculty. On the contrary, it is possible to build a questionnaire that would allow a good dispersion of candidates' results but this will need the introduction of items that reflect competence in a rather rare clinical situation and hence this will pose a problem of content validity of the instrument.

Results agree with theories that relate the development of clinical competence with the acquisition of specific knowledge structures adapted to clinical tasks. ${ }^{2,10,11}$ However, the fact that one expert gave very different answers from other experts may indicate that a few individuals have a different way of reasoning in diagnosis situations and open further research in the definition of "expert competence" for this kind of research. Finally, our results showed that experts provide different answers for questions that do not appear ambiguous. This raised questions about the usual practice of seeking consensus among experts in the scoring process of examinations. Consensus decisions (i.e. to decide in an examination which are the accepted answers) are classically obtained among experts ${ }^{r}$ in-group discussions. From the results presented, when they make individual choices, the variability of decisions is quite high. It may be more valid to permit students the same differences among answers that experts themselves provide for the very same questions. 


\section{References}

1. Estein, A.S., Shutman, L.S., Sprafka, S.A. Medical Problem Solwing: An Analysis of dinical Reasoning. Harward Unversity Press: Cambridge, MA, 1978.

2 Schmidt, H.G., Norman, G.R. and Boshumen, H.P.A. A Cognitive Perspective on Medical Expertise: Theory and Implications. Academic Medicine, 1990, 65: 611-21.

3 Charlin, B. Le schema conme structure de connaissances sousuacente aux hypotheses dans 1"investigation chinique médicale. Menoire pour lobtention du diplome de maitrise es ats en 5 ciences de 1'éducation. Université de Sherbrooke. 1994.

4 Regehr, D. \& Norman, G.R. Issues in Cognitive psychology: Implications for Professional Education. Academic Medicine, 1996, 71: 988-1001.

5 Custers, J.F.M. The development and function of illness scripts. Studies on the sturucture of medical diagnostic knowledge; PhD thesis. Mastricht, Netherlands: Unversitaine Pers Mastricht. 1995.

6 McMicoll, A. Brailovsky, C.A. Bertrand, R. et Cardinet, J. EtudGen, programme pour 1"analyse de la généralisabilité pour Macintosh. CESSUL 1992, 1996. in D. Bain et G. Pin "Pour evaluer vos évaluations: La génêralisabilité, mode d'emploi." Centre de recherches psychopédagogiques, Genève, 1996, p. 51.

7 Van Der Wteuten. C.P.M. The Assessment of Professional Competence: Developrant, Reseanch and Practical Inplications. Advances un Healh Sciences Education, 1996, 1:41-67.

8 Newble, D.I. Hoare, J. \& Baxter, A. Patient Management Problems: Issues of Validity, Medicall Education, 1982, 16: 137-142.

9 Marshall, J. Assessment of Problem-Solving Ability. Medical Education, 1977, 11: 329-334.

10 Feltovich, P.J. Expertise: reorganizing and refining knowledge for wse. Professions Education Research Notes, $1983,4: 5-7$.

11 Bordage, G. Elaborated Knowledge: A key to Successful Diagnostic Thunking. Academic Medicine, $1994,69: 883-85$.

12 Coles, C.R. Elaborated learning in undergraduate medical education. Medical Ed lication, 1990. 24: $14-22$. 


\section{A comparison between the aggregate and the consensus scoring method}

Published in Teaching and Learning in Medicine, 2002, 14: 148-154

Comparison of an aggregate scoring method with a consensus scoring method in a measure of clinical reasoning capacity

Bernard Charlin, Martin Desaulniers, Robert Gagnon. Daniel Blouin, Cees van der Vleuten

This research project has been funded by a grant from the Medical Council of Canada. 


\section{Abstract}

Background: Diversity of clinical reasoning paths of thought among experts is well knowh. Nevertheless, in writen clinical reasoning assessment the common practice is to ask experts to reach a consensus om each item and to assess students on a unique "good answer."

Purposes: To explore the effects of taking the variability of experts answers into account in a method of clinical reasoning assessment based on authentic tasks: the Script Concordance Test (SC Test).

Methods: Two different methods are used to build answer keys. The first incorporates variability among a group of experts (criterion experts) through an aggregate scoring method. The second is made with the consensus obtained from the group of criterion experts for each answer. Scores obtained with the two methods by students and another group of experts (tested experts) are compared. The domain of assessment is gynecology-obstetric clinical knowledge. The sample consists of 150 clerkship students, and 7 other experts (tested experts).

Results: (1) In a context of authentic tasks, experts' answers on items vary substantially. (2) Amazingly, 59\% of answers given individually by criterion group experts differ from the answer they provide when they are asked in a group to provide the agood answers required from students. (3) The aggregate scoring method shows several advantages and is more sensible to detect expertise.

Conclusions: The findings suggest that, in assessment of complex performance in ill-defined situations, the usual practice of asking experts to reach a consensus on each item reduces and hinders the detection of expentise. If these results are confirmed by other researches, this practice should be reconsidered.

\section{Introduction}

In similar clinical situations, physicians do not collect exactly the same data and do not follow the same paths of thought, even if they obtain the same diagnostic outcome. ${ }^{1}$ Furthermore, physicians show substantial variation in performance on any particular real or simulated case. ${ }^{2,3}$ These research findings have brought educators to abandon the traditional approach of clinical reasoning teaching and use methods that foster the acquisition of the reasoning processes physicians really use in practice. $4,5,6$

Unfortunately, assessment practice has not yet incorporated these findings. We often continue to require a group of experts to provide a common answer for each item in the examination when constructing an answer key for a clinical simulation examination. Items are then removed from tests when consensus is not reached. 
This may prevent the assessment of situations that belong to authentic clinical life. We also continue to demand that students provide "the good answers" while we know that in practice there is rarely such thing as an absolute good answer.

In clinical simulations used for testing purposes, it is agreed that the diversity of opinion among experts precludes key development by a single individual and that the judgments of several experts are required to develop the answer key. Variations among experts about what constitutes optimal patient management are well-documented. ${ }^{8.9}$ Until now, while there have been some proposals to account for these variations with an aggregate scoring method, ${ }^{10,11}$ the common practice remains to ask experts to reach a consensus.

The Script Concordance Test (SCT) is a new tool of ctinical reasoning assessment ${ }^{12}$ that stems from current theories and empirical findings about clinical reasoning. ${ }^{13,14,15}$ The SC Test is an assessment technique which assesses how knowledge is arganized to make adequate decisions in the process of clinical reasoning in comparison to organization of knowledge observed among a group of experts. It does not focus on the outcome of the process, rather it assesses the micro decisions that are made within that process. From examinee scores, inferences are made on the degree of knowledge organization required to successfully address problems in the assessed domain.

The SC Test has a rich authentic context and is case-based. Items are made from the questions and actions physicians ask and make in clinical practice. Examinees are required to make diagnostic, investigative or therapeutic decisions, when specific elements of information are provided (see Figure 1). It is relatively easy to construct and to administer, and a series of empirical studies have documented it has a good reliability as well as good face and construct validity. ${ }^{16,17,18 .}$

\begin{tabular}{|c|c|c|}
\hline If you were thinking of & And then you find & This lyypothesis becomes \\
\hline (a diagnostic hypothesis) & $\begin{array}{l}\text { (a new clinical information, an } \\
\text { imaging study or a laboratory } \\
\text { test result) }\end{array}$ & $\begin{array}{lllllll}-3 & -2 & -1 & 0 & +1 & +2 & +3\end{array}$ \\
\hline
\end{tabular}

-3 Ruled out; - 2 Much less probable: -1 A little less probable: 0 No effect on this hypathesis; $+1 \mathrm{~A}$ little more probable: +2 Much more probable; +3 Certain.

Figure 1: Format of titems ised for diagnostic knowledge assessment.

The tool uses an aggregate scoring method..$^{10,11}$ It reflects the variability experts demonstrate when they answer complex questions belonging to clinical reasoning. Scores on each item are derived from the answers given by a criterion group of experts. The underlying principle is that the answer of any expert reflects a valid opinion that should be taken into account, and answers with poor agreement among experts should not be discarded. Each possible answer to an item re- 
ceives a partial credit that reflects the number of experts that have given that answer. The scoring process is described in detail below.

In this study, we compare the effect on scores obtained by students and experts with the aggregate method (A method) with the common method in which experts are asked to provide a consensus for each item ( $C$ method). The study bears on the gynecology-obstetric domain.

Our research questions are: (1) Do experts provide the same answer when they take the test individually and when they provide "the good answer" in-group meeting. (2) What is the distribution of scores and what are reliability coefficients with both methods? (3) Is a method better than the other to detect expertise among a sample of examinees?

\section{Method}

\section{Secting and subjects}

In the school in which the study took place, classes are made of approximately 90 students. Data were collected over a period of a year and a half. Hence the sample is made of 150 students. Students perform rotations during their clerkship in groups of 12 or 13 . At the end of each rotation in gymecology-obstetrics, they have an OSCE test. Students were asked to voluntarily take the SC test after the OSCE and all agreed. The seven staff members of the gynecology-obstetrics department of the school were asked to be the criterion group. Seven other experts (called hereafter "tested experts"), from another school were asked to participate in the study as subjects. All agreed to participate. Each of them completed the test individually. The performance of that second group of experts is compared with that of the 150 students.

\section{Construction of scale}

The original SC test was composed of 60 items (see Figure 2) grouped in three different clinical situations (first semester bleeding, abnormal uterine bleeding and request for a contraceptive method). Items were constructed according to the methodology described by Charlin ${ }^{12}$. An item analysis was done with the consensus scoring method. We used the iterative method of deleting items with negative or very small correlation and recalculating alpha coefficient until no more gain on reliability was observed. Fifteen items were removed, leading to a final test composed of 45 items. 
A woman is seen in the emergency room for a third semester of pregnancy bleeding.

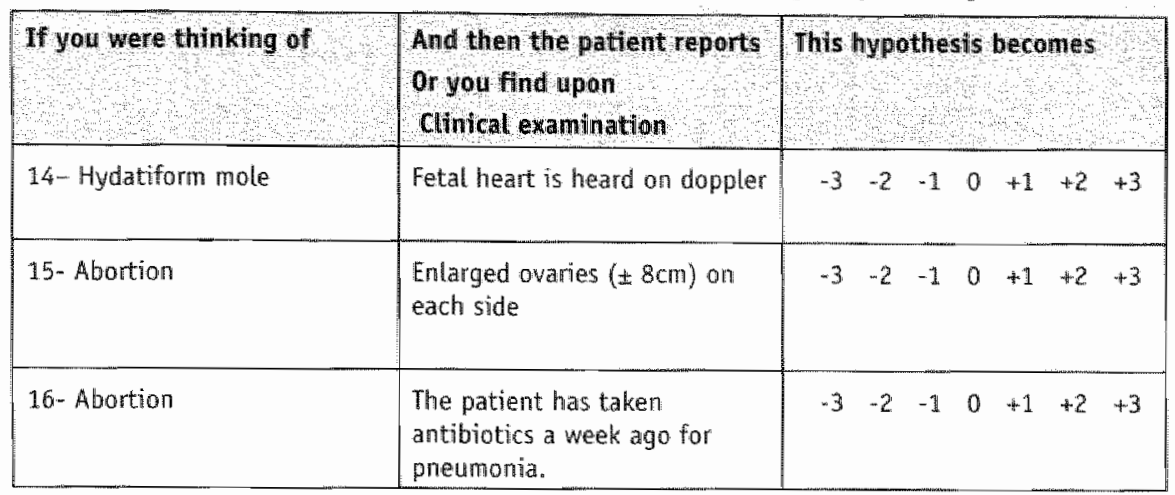

Figure 2: Example of items from the test.

\section{Clinical scenario}

\section{Construction of answer keys}

In a first step, experts from the criterion group were asked to complete the test: individually. Their individual answers were used to build the answer key of method A. In this study we modified the original scoring process used in previous research on SC Test. In the original scoring process items did not have the same maximum value. This was considered disturbing both by students and by assess. ment specialists. With the new method all items get a maximum score of 1 . For each item, answers are assigned a weight corresponding to the proportion of the experts who selected it. Credits for each answer are then transformed proportionally to get a maximum score of 1 for modal experts' choice (s) on each item, other experts' choices receiving a partial credit. Answers not chosen by experts receive zero. In the transformation all scores of an item are multiplied by the total number of experts and divided by the modat value for the item. For example (see Figure 3 ), if on an item 4 experts (out of 7) have chosen response 1 , this choice receives 1 point $(4 / 7 \times 7 / 4)$. If 2 experts have chosen response 2 , this choice receives $0.5(2 / 7 \times 7 / 4)$, and if 1 expert has chosen response 3 , this choice receives 0.25 point $(1 / 7 \times 7 / 4)$. The total score for the test is the sum of credit obtained on each item. Numbers are then transformed to get a maximum of 100 .

In a second step, one year later, members of the criterion group were asked to meet and provide the best answer by consensus for each item. This scoring method is called the consensus method ( $C$ method). Figure 3 illustrates the effect of the two scoring methods on five items of the test. 


\begin{tabular}{|c|c|c|c|c|c|c|c|c|}
\hline & s: & -3 & 2 & -1 & 0 & +1 & +2 & +3 \\
\hline \multirow[t]{3}{*}{ Iten 14} & Experis: & 2 & 5 & & & & & \\
\hline & A method & 0.40 & 1 & 0 & 0 & 0 & 0 & 0 \\
\hline & students $(\mathrm{N})$ & 118 & 20 & 4 & 1 & 1 & 1 & 5 \\
\hline \multirow[t]{3}{*}{ Item 32} & Experts & & & 1 & & 4 & 2 & \\
\hline & A method & 0 & 0 & 0.25 & 0 & 1 & 0.50 & 0 \\
\hline & Students (N) & & 4 & 9 & 1 & 52 & 79 & 5 \\
\hline \multirow[t]{3}{*}{ Item 49} & Experts & & & 2 & & 3 & 2 & \\
\hline & A method & 0 & 0 & 0.66 & 0 & 1 & 0.66 & 0 \\
\hline & Students (N) & 24 & 37 & 31 & 3 & 25 & 27 & 3 \\
\hline \multirow[t]{3}{*}{ Item 54} & Experts & & 1 & 3 & & 2 & 1 & \\
\hline & A method & 0 & 0.33 & 1 & 0 & 0.66 & 0.33 & 0 \\
\hline & Studens $(N)$ & 4 & 33 & 41 & 3 & 43 & 24 & 2 \\
\hline \multirow[t]{3}{*}{ Item 60} & Experts & 1 & 1 & 5 & & & & \\
\hline & A method & 0.20 & 0.20 & 1 & 0 & 0 & 0 & 0 \\
\hline & Students (N) & 16 & 33 & 35 & 58 & 5 & 3 & 0 \\
\hline
\end{tabular}

Figure 3: Examples of the scoring system, with the distribution of students ${ }^{t}$ answers. Darkened choices represent the consensus experts made one year later.

\section{Statistical analysis}

To answer the first research question we computed the percentage of answers given individually by criterion experts that differ from "the good answer" provided in a consensus meeting.

To answer the second research question (distribution of scores and reliability coefficients) scores obtained by examinees (i.e., students plus tested experts) with the two methods were studied with descriptive statistics. Cronbach's alpha coefficients were computed with the two answer keys. All statistical comparison are two-tailed and considered significant at $5 \%$ alpha level. A Pearson correlation coefficient was calculated to quantify the relationship between the two methods. A scatter-plot was drawn to visually detect the distribution of examinee scores.

To answer the third question (ability of each method to detect expertise among axaminas, we compared the means obtained by students and tested experts with Student $t$ tests in Effect sizes are calculated using the difference between the groups divided by the standard deviation of students groups. 


\section{Results}

\section{Research question I}

59 percent of answers given by experts from the criterion group when they answer individually differ from consensual answers (Figure 3 illustrates this variation).

\section{Research question 2}

Descriptive statistics of scores of the 157 examinees (students and experts, see Table 1) show that the range is greater for the $C$ method, with a lower minimum value. The maximum, and mean scores are higher with the A method. Skewness and kurtosis are in the normal range for both methods. With method $C$, the method used for optimization of items, ${ }_{r}$ Cronbach alpha is 0.63 . Its value is 0.52 with the A method. The value of the Pearson correlation coefficient for students $(0.72, p<0.001)$ indicates that the two methods induce differences in the classification of students. The scatter-plot of two sets of scores of students is graphed on Figure 4. Difference in classification is observed mainly for students in the center of the distribution. Ranking of students with more extreme scores shows fewer discrepancies.

\begin{tabular}{|c|c|c|c|c|c|c|}
\hline 1 & & dent & Teste & experts & & tal \\
\hline Statistics & A method & C method & A method & C method & A method & C method \\
\hline N & 150 & 150 & 7 & 7 & 157 & 157 \\
\hline Mean & 54.06 & 38.73 & 64.14 & 46.57 & 54.51 & 39.08 \\
\hline Std. Deviation & 8.02 & 10.79 & 3.29 & 6.16 & 8.14 & 10.7 .4 \\
\hline Range & 47.00 & 65.00 & 9.00 & 18.00 & 47.00 & 65.00 \\
\hline Minimum & 25.00 & 4.00 & 60.00 & 40.00 & 25.00 & 4.00 \\
\hline Maximum & 72.00 & 69.00 & 69.00 & 58.00 & 72.00 & 69.00 \\
\hline Kurtosis: & 0.84 & 0.56 & -0.95 & 1.03 & 0.75 & 0.60 \\
\hline Sikewness & -0.63 & -0.36 & 0.53 & 1.16 & -0.63 & -0.40 \\
\hline
\end{tabular}

Table 1: Descriptive statistics with the two methods (the maximum thearetical value for the test is 100)

\section{Research question 3}

Figure 5 depicts the differences obtained with the two methods for the groups of students and tested experts. The A method provides higher scores to tested experts and allows a better discrimination of scores among examinees. The mean difference is statistically significant $(t=10.1, p<0.001)$. With the $C$ method, the mean difference between groups is not statistically significant $(t=7.8, p=0.06)$. The effect size is also different between the two methods $(A=1.25, C=0.72)$. 


\section{8 chapter 4}

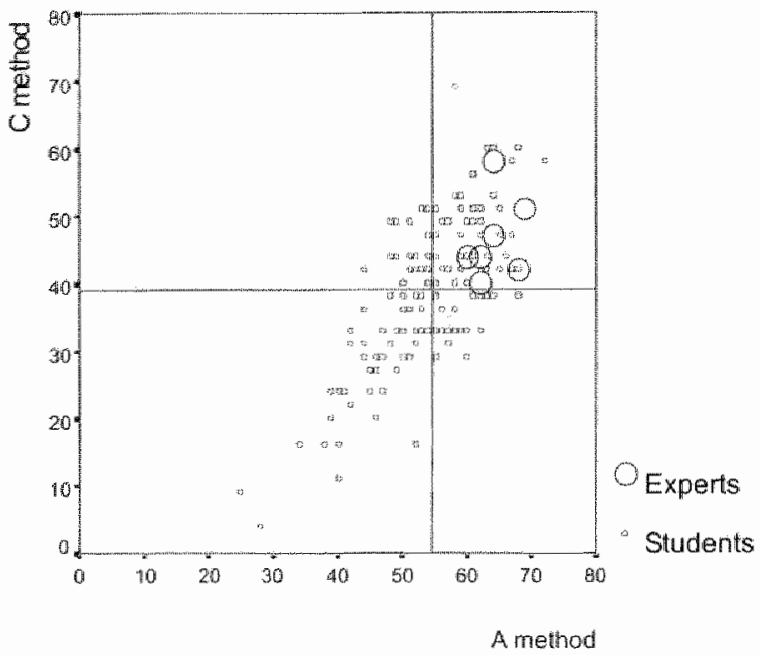

Figure 4: Scatter plot of $A$ and $C$ scores. Some students who are above the mean with a method are below the mean with the other, with sometime wide discrepancies.
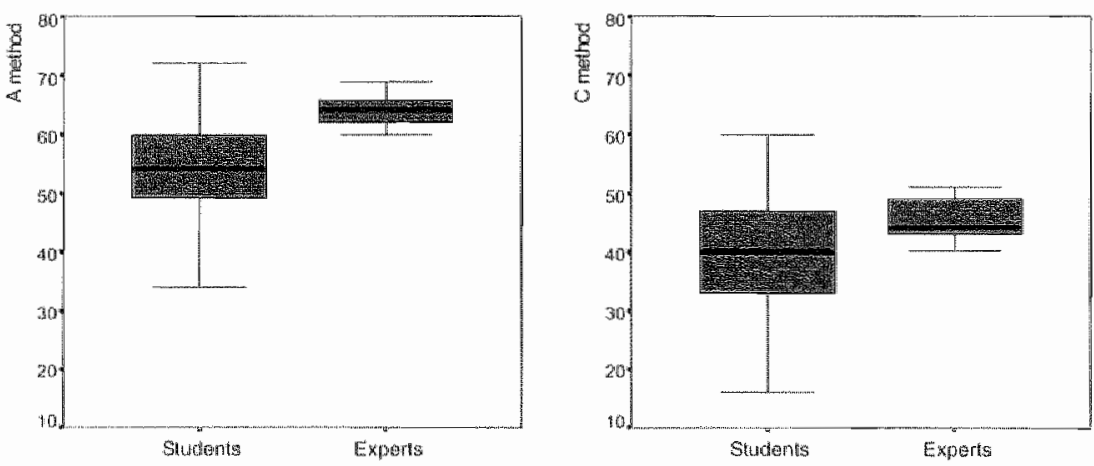

Figure 5: Boxaplot graphics with scares computed with the A rnethod (on left) and the C method (on righty. 


\section{Discussion}

In assessment practice there is a strong tendency toward more authenticity. The SC Test is in line with this tendency. It presents real life situations to examinees and uses an innovative format to ask them questions that experts ask themselves in those situations. The goal of the study is to compare two scoring methods. The $C$ method (C) follows the usual practice of asking a group of experts (criterion experts) to provide «the good answers on each itern. The A method considers that criterion experts should pass the test as examinees would do and that each answer given by an expert has an intrinsic value. For the construction of the final scale and in the analyses we made the optimization of items on the $C$ method. Hence we give an intrinsic disadvantage to the $\mathrm{A}$ method in subsequent analyses, but the reasoning for that approach is that if we find a superiority of method $A$, that finding will have more implications. This explains why the Cronbach alpha coefficient ( 0.63 for the $C$ method) drops with the A method (0.52). If optimization would have been done with the $A$ method the reverse might have been found.

We already knew that in similar dinical situations, physicians do not collect exactly the same data and do not follow the same paths of thought. "Thus the observation that experts' answers vary depending the context - individual response versus consensus response - is not a surprise. Another finding has potential strong implications. Fifty-nine percent of answers given by experts from the criterion group are different that those they give when they are placed in the consensus condition. Item number 49 in Figure 3 is an example of this behavior change. Experts' individual answers are distributed over minus 1 , plus 1 (modal answer) and plus 2, while in the consensus condition the common answer is plus 2. An explanation for this might be that the context for the tasks differs radically in the two conditions. When an expert is alone (as it is usually in practice), only the data provided by the case are used, while within a group the context is significantly modified by interactions with the other experts. Another argument might be that expertise lies in subtle differences in reasoning processes that disappear when experts are required to discuss among each other to reach a consensus.

From a psychometric perspective the scoring methods present some differences. The $C$ method produces very low scores, a wide range of answers and more variability. The $\mathrm{A}$ method provides higher scores and a higher mean because partial credits are given to several answers with this method, while with the $C$ method only one single best answer gives credit.

The Cronbach alpha coefficient obtained with the $C$ method $(0.63)$ is higher than the one obtained with the A method (0.52). This is a consequence of the optimization of the number of items made with the $C$ method. These coefficient values are moderate, but there are obtained on a test that had only 45 items. These values would improve with longer tests with similar item characteristics. 
The A method allows a better discrimination of tested experts and students. It is more sensible to detect expertise than the method that follows the usual practice of asking experts to provide a consensus on each answer. When experts are judged on a consensus build by ather experts their own expertise is difficult to detect. These findings suggest that the A method has a better construct validity than method $c$.

An interesting observation is the production of a different ranking of respondents. This is disturbing because with the method commonly used in most certification examination, the consensus method, some students who succeed would have failed with an aggregate scoring method, which seems to have more construct validity.

It is well known that humans combine probabilities badly in their mental tasks. ${ }^{19}$ The Bayesian madel of clinical reasoning is not a descriptive model of the real clinical reasoning process. It is a prescription of how clinicians should behave if they would use probabilities adequately. The Smith mode ${ }^{15.20}$ of categorization (diagnosis) is descriptive. It proposes a theory of how clinician knowledge might be organized to successfully address diagnostic clinical tasks. It suggests knowledge is organized in networks that contain expectations about values that are acceptable and not acceptable for each attribute of a clinical entity. The script concordance test is built around this assumption. The Likert scale of the test does not probe judgment about probabilities. It replicates the kinds of judgment clinicians are making in their reasoning process in respect to Smith's model.

One of the major criticisms of aggregate scoring is that when applied blindly, wrong answers will occasionally be given credit. Experts make divergent interpretations of data in ill-defined situations met in clinical encounters. The current study confirms that. We kept all answers as valid because we considered that in case-based rich context each person brings his own experience to the situation and make his own interpretation. Experts differ in the multiple decisions that are made in a clinical reasoning process while they usually converge toward a similar outcome. In the study we considered that if an expert make an interpretation, a student that makes he same interpretation should receive a partial credit. That position might be challenged. An alternative method would ask criterion experts what options should be considered correct. The aggregate weights can then be applied only to them. Deciding which method is best will be the object of further research.

In the study we set the weights of the most popular options (modal answer) to one. This has the effect of ensuring that all itemis contribute equally to the score (at least nominally). Another method would have been to allow the weights to vary naturally depending on the level of agreement among experts. This would give greater weight to those items where there is strong consensus among the experts and a lower weight where there is disagreement. We choose the first method 
because students have difficulties to accept that items might have a different maximum credit while they have no way of knowing which items provide more credit.

The study has several limitations. (1) Only three clinical situations are tested. (2) Only 7 experts are tested. (3) Correlation between the two methods is not very high; this may be attributable in part to the moderate reliability coefficients of both methods. (4) There is a one-year delay between the moments criterion group experts completed the test, once alone, and once in-group. Is it the delay that is responsible for the change in experts' answers or is it the context as we suggested above? These limitations will be addressed in subsequent research projects. Nevertheless, the study indicates that the method that is closer to the reality of clinical practice is richer and more productive to discriminate participants across their level of expertise. The consensus method seems to reduce information and validity.

This study confirms a fact found in research on clinical reasoning: in authentic tasks experts vary substantially on their way to progress toward the solution. Moreover, their actual performance (aggregate method) differs from what they expect from students (consensus method). This suggests that t $_{r}$ in assessment endeavors, the usual practice of asking experts to reach a consensus on each item reduces authenticity and hinders the detection of expertise. If these results are confirmed by other researches, this practice should be reconsidered, the aggregate method appearing as better for the assessment of complex performance in ill-defined situations.

\section{References}

1 Grant, J. \& Marsden, P. Primary knawledge, medical education and consultant expertise. Medical Education, 1988, 22, 173-179.

2 Barrows, H.S., Feightner, J.W., Neufeld, V.R. \& Norman, G.R. Analysis of the clinical Methods of Medical Students and Physicians. Final Report to the Province of Ontario Department of Health. 1978.

3. Elstein, A. 5., Shulman, L.S., Sprafka, 5.A. Medical Problem Solving: An Analysis of Clinical Reasoning. Cambridge, MA: Harvard University Press, 1978.

4 Kassirer, J.P. Teaching Clinical Medicine by Iterative Hypothesis Testing: Let's Prach What We Practice. New England Journal of Medicine, 1983, 309, 921-923.

5 Chamberland, M., Des Marchais, J.E. Chartin, B. Carfying PBL into the Clerkship: A Second Reform in the Sherbrooke Curriculum. Annals of Communitym Oriented Education, 1992, 5, 235-247.

6 Barrows, H.S. What your tutor may never tell you: a guide for medical students in problem-based learning. Southern Illinois University School of Medicine: revised edition, 1996. (15BN - 0 $931369-29-0) 40$ pages

7 Swanson, D.B., Norcini, J.J., Grosso, L.J. Assessment of Clinical Competence: Written and Computer-Based Sinulations. Assessment and Evaluation in highep Education, 1987, 12: 220-246.

8 Sedlacek, W.E. \& Nattress, L.W. A Technique for Determining the Validity of Patient Management: Problems. Journall of Medical Education, $1972,47: 263-266$.

9 Mazzuca, S.A.. \& Cohen, 5.J. Scoring Patient Management Problems: Externat Validation of expert Consensuls. Evaluation of Health Professionals, $1982,5: 210-217$. 
10 Norman, G.R. Objective Measurement of Clinical Performance. Medical Education, 1985, 19: $43-47$.

11 Norcini J.J., Shea, J.A., Day, S.C. The Use of the Aggregate Scoring for a Recertification Exarnination. Evaluation and the Health Professions, 1990, 13: 24:1-251.

12 Charlin B, Roy L. Brailowsky CA, Wan der Vleuten CPM. The Script Concordance Test: A Tool to Assess the Reflective Clinician. Teaching and Leaming in Medical Education, 2000; 12: 189-195.

13 Feltowich, P.J. \& Barrows, H.S. Issues of Gemerality in Medicall Problem Solving. In H.G. Schmidt \& M. L. De Volder (Eds.), Tutorials in Problem-Based Learning: A new Direction in Teaching the Health Professions. Assen. Holland: Wan Gorcum, 1984.

$14_{4}$ Schmidt, H.G. Whorman, G.R. and Boshuizen, H.P.A. A Cognitive Perspective on Medical Expertise: Theory and Implications. Academic Medicine, 1990, 65, 611-621.

15 Charlin B, Tardif J, Boshuizen HPA. Scripts and Medical Diagnostic knowledge: Theory and Apphications for Climical Reasoming Instruction and Research. Academic Medicine 2000;75:182-190

16 Charlin B, Brailousky CA, Brazeau-Lamontagne L, Samson L, Leduc C. Script Questionnaires: Their Use for Assessment of Diagnostic Knowledge in Radiology. Medical Teacher 1998; 20: 567-571.

17 Charlin B, Brailowsky CA. Leduc C, BLouin D. The Diagnostic Script Questionmaire: A New Tool to Assers a Specific Dimension of Clinical Competence. Adwances in Heath Sciences Education, 1998 ; 3: $51-58$.

18 Brailowsky, C, Charlin, B., Beausoleil, 5., Coté, S., van der Wleuten, CPM. Measurement of Clinical Reflective Capacity Early in Training as a Predictor of Clinical Reasoning Performance at the End of Residency: An Exploratory Study on the Script Concordance Test. Medical Education, 2001; 35: $430-4.36$.

19 Kahmeman D, Slowic P, Jwersky A (eds.) Judgement under uncertainty: Heuristics and biases. Cambridge: Cambridge University Press; 1.982.

20 Smith, E.E. Concepts and Induction. In Posner M.I.(Ed.). Foundations of Cognitive Science. Cambridge, MA: MIT Press; 1989. 


\section{Stability of the tool across cultures}

Published in Medical Teacher, 2002, 24;537-542

Stability of clinical reasoning assessment results with the script concordance test across two different linguistic, cultural and learning environments

Louis Sibert, Bernard Charlin, Jacques Corcos, Robert Gagnon, Philippe Grise, Cees van der Vleuten 


\section{Summary}

The Script Concordance (SC) test is designed to measure the organization of knowledge that allows interpretation of data in clinical reasoning. An originality of the test is that answer keys use an aggregate scoring method based of answers given by a panel of experts. Previous studies have shown that the SC test has good construct validity.

This study, done in urology, explores (1) the stability of the construct validity of the test across two different linguistic and learning environments and (2) the effect of the use of experts who belong to different environments.

An 80 items SC test was administered to participants from a French and a Canadian university. Two levels of experience were tested: 25 residents in urology (11 from the French university and 14 from the Canadian university) and 23 students (15 from the French faculty, 8 from the Canadian faculty). Reliability analysis was studied with Cronbach alpha coefficient. Scores between groups were compared by analysis of variance.

Reliability coefficient of the 80 items test was 0.794 for the French participants and 0.795 for the Canadian participants. Scores increased with clinical experience in urology in the two sites. Candidates obtained higher scores when correction was done using the answer key provided by the experts of the same country.

These data supports the stability of the construct validity of the tool across different learning enviromments.

\section{Introduction}

Until recently, the search for instruments to assess clinical competence was based on a traditional conception of the nature of clinical competence. The development of competence was considered as being equal to the development of each of its components. However, growth in competence appeared more capricious than expected. This empirical disillusion has stimulated cognitive psychological research into the development of expertise." Several authors have established that in mast clinical situations, medical reasoning is a hypothetico-deductive process ${ }^{2.3}$ characterized by early generation of hypotheses, oriented data collection and decision making judgment, using collected data to confirm or reject hypotheses. Expertise development of professionals appears to be strongly related to knowledge. However, the way in which knowledge is stored, used and retrieved characterizes differences between novices and experts. Experienced practitioners possess elaborated networks of knowledge fitted to the tasks they regularly do. ${ }^{4-6}$ These networks, named scripts, ${ }^{4,1,7}$ are organized to fulfill goals within tasks concerning diagnosis, strategies of investigation or treatment options. They begin to 
appear when students are faced with their first clinical cases and are later developed and refined during their entire clinical career. ${ }^{1,8}$ The script theory state that in diagnostic situations, clinicians fill their working memory with knowledge related to each relevant hypotheses. This activated knowledge is then used in a deductive process to actively seek information that will allow confirmation or rejection of respective hypotheses.

These cognitive psychological models have proven to be useful for new directions in assessment. A new written assessment tool, the Script Concordance ( $\mathrm{SC}$ ) test, was in fact designed to measure the richness of these networks. ${ }^{9}$ The test approach consists of presenting examinees with a series of patients problems and then asking examinees to make diagnostic, investigative or therapeutic decisions when specific elements of information are provided. It places examinees in written but authentic clinical situations where they have to interpret data to make decisions.

Contemporary assessment tools of clinical reasoning have repeatedly shown the puzzling fact that experienced clinicians score hardly better and sometimes worse than less experienced clinicians or students. ${ }^{10}$ This counterintuitive finding called "the intermediate effect, " indicates that most of these methods, especially written examinations, i.e. multiple-choice tests, measure clinical factual knowledge rather than clinical reasoning competence and are invalid indicators of the work clinicians actually do in a practice setting. ${ }^{11}$ In contrast to these findings, earlier studies have shown that SC tests have good construct validity with an increase in the mean scores of participants with different levels of clinical expertise. ${ }^{9}$ SC test was developed to explore the capacity of data interpretation when making clinical decisions, clearly a skill that belongs more to clinical competence than the simple recall of factual data.

The scoring process uses an aggregate scoring method. ${ }^{12,13}$ The principle is that any experienced clinician response is a reflection of expertise, and responses for which there is no agreement among experts should not be discarded. The test is submitted to a group of experienced clinicians and scoring is weighted by the degree of agreement between experts. This scoring is in no way artificial or arbitrary; but the cultural environment and the field of clinical activities of the reference panel could influence it.

In previous studies on the $S C$ test, ${ }^{9}$ candidates sat their examination in the same language (French) and were trained in one common medical culture. In the present study, we looked for arguments supporting the idea that the same test would be able to discriminate among participants across different countries according to their level of clinical experience, despite cultural, educational and institutional differences. The domain of assessment was urology. Two research hypotheses were tested: (1) The capacity of the test to discriminate among candidates with different levels of experience should persist even if the learning and cultural 
environment of the reference panel is different. (2) Candidates should obtain higher scores when they are assessed by experts from their own culture.

\section{Methods}

\section{Construction of the $\mathrm{SC}$ test}

Two clinicians belonging to the French faculty and the Canadian faculty were asked to describe clinical situations representative of urology practice and based on major educational objectives of Canadian and French urology training programmes. They were asked to specify for each situation a) the relevant hypotheses, investigation strategies or treatment options b) the questions they ask, physical examinations they perform, and tests they request to solve the problem; and c) what clinical information, positive or negative, they would look for in these inquiries. Test items were built with the material obtained from that inquiry. Great care was taken about the content validity of the test. The evaluation concerned urology residents as well as medical students, therefore, all the areas of clinical competence (i.e.: diagnosis, investigation, treatment) were assessed. Table 1 shows the blueprint of the test.

The clinical situations were presented in short vignettes, each of them followed by a series of related test items. Items were constructed according to the methodology described by Charlin. The item format differs with the objective of assessment (diagnosis, investigation, or treatment). Each item consists of three parts. The first part includes a diagnostic hypothesis, an investigative action or a treatment option. The second presents new information (e.g. a clinical data, imaging study or laboratory test result) that might have an effect on the diagnostic hypothesis, investigative action or treatment option. The third part is a 5-point Likert-type scale (see illustration of the 3 formats in Table 2). Each item was built so that a reflection was necessary to answer it. Clear instructions were also given that all items within each vignette were independent from each other. Hypotheses or options change for each question. Hence, a test of 12 clinical situations and 85 items was then constituted (see example of items form the diagnostic section in Table 3).

The test was administered in English to the Canadian subjects and in French to the French participants. Great care was taken in the translation process in order to avoid word substitution, word omission, word addition or different meaning for a word in the other language. ${ }^{14}$ Experienced urologists in their awm language then reviewed each version of the test. During their completion of the test, urologists were asked to identify the items they found confusing or not relevant. Five items were then discarded. Eighty items were retained for the calculation of scores and statistical analysis. 
Table 1: Bueprint of the Script Concordance test in urology.

\begin{tabular}{|c|c|c|c|c|c|}
\hline Clinical problems & context & Age & $\operatorname{sex}$ & NB & Assessed \\
\hline \multicolumn{6}{|l|}{ components } \\
\hline Scrotum enlargernent & $\mathrm{C}$ & 42 & M & 5 & DG \\
\hline Scrotal trauma & E & 27 & $M$ & 5 & $\pi$ \\
\hline Renal colic & E & 63 & $\mathrm{~F}$ & 10 & DG, I \\
\hline Pelvis trauma & $E$ & 25 & M & 10 & DG. TT \\
\hline Infertility & c & 31 & M & 5 & DG \\
\hline Uninary incontimence & $c$ & 57 & $\mathrm{~F}$ & 5 & $D G$ \\
\hline Urimary lithiasis & E & 35 & $M$ & 10 & DG. TT \\
\hline BPH, Prostate cancer & c & 58 & $M$ & 10 & $I, \pi$ \\
\hline Erectile dysfunction & c & 66 & M & 5 & DG \\
\hline Obstructive renal failure & $E$ & 73 & $\mathrm{~F}$ & 5 & $\pi T$ \\
\hline Urinary retention & E & 71 & M & 5 & $\pi$ \\
\hline Kidney tumpour & $\mathrm{C}$ & 79 & $\mathbb{F}$ & 5 & DG \\
\hline
\end{tabular}

Notes: $N B=$ mumber of questions, $C=$ Consultation, $E=$ emergency, $M=$ male, $F=$ female, $D C=$ Diagnostic, $I=I n v e s t i g a t i o n . ~ T T=$ Treatment, $B P H=$ Berign Prostatic hypertrophy.

\section{Participants}

The test was submitted to two groups of participants from the urology departments of McGill University, Montreal, Canada (14 residents, 8 medical students), and Rouen University Hospital, France (11 residents, 1.5 medical students). Two groups of certified urologists made the reference panels: 10 French urologists and 12 Canadian urologists. French urologists were representative of different areas of practice (faculty members, general and private practices). Canadian urologists were exclusively faculty members. Each urologist had a minimum of 5 years clinical experience. All the Canadian participants were English speaking. All subjects asked to participate volunteered. Criteria for inclusion were, for urologists to be certified according to the rules of their country; for residents, to belong to the urology programme at McGill or Rouen University Hospital; and for students to have had a rotation in a urology department in the last. 6 months. All students had spent from 4 to 6 months on urology attachments. In this exploratory research, the two groups of urologists were successively considered as the reference panel for the construction of answer keys. 
Table 2: llustration of questions and answering grids format.

For diagnostic knowledge assessment

\begin{tabular}{|l|l|l|l|}
\hline If you were thinking $0 f$ & And then you find & This hypothesis becomes \\
(A diagnosis hypothesis) & $\begin{array}{l}\text { (A new clinical information, an imaging } \\
\text { study or a laboratory test result) }\end{array}$ & -2 & $-1 \quad 0 \quad+1$ \\
\hline
\end{tabular}

-2 the hypothesis is almost ellumated

- the hypothesis becomes less probable

0 the information has no effect on the hypothesils

+1 the hypothesis is becoming more probable

+2 it can only be this hypothesis

For inwestigation knowledgle assessment

\begin{tabular}{|c|c|c|c|c|}
\hline $\begin{array}{l}\text { If you were considering: } \\
\text { to ask }\end{array}$ & And their you find & $\begin{array}{l}\text { This inve } \\
\text { becomes }\end{array}$ & fation & \\
\hline (A diagno & $\begin{array}{l}\text { (A new dinical information, an imaging } \\
\text { study or a laboratory test result) }\end{array}$ & $\begin{array}{lll}-2 & -1\end{array}$ & +1 & +2 \\
\hline
\end{tabular}

-2 contra-indicated totally or almost totally

-1 not useful ar aven detrimental

0 nor less nor more useful

+1 userut

+2 absolutely necessary

For treatment knowledge assessment

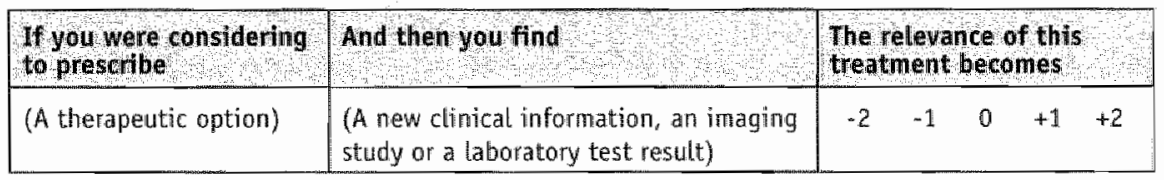

-2 contramindicated totally or almost totally

-1 not useful or even detrimental

0 nor less nor more wseful

*1 useful

*2 mecessary or absolutely necessary

\section{Scoring process}

For each item, answers were assigned a weight corresponding to the proportion of the members of the reference panel who selected it. Credits for each answer were then transformed proportionally (division of all scores by the modal value on the item) to obtain a maximum score of 1 for modal experts' choice (s) on each item, other experts. choices receiving a partial credit. Answers not chosen by any experts received zero. For example, if on an item, 6 experts (out of 10 ) have chosen response +1 , this choice received 1 point $(6 / 10 \times 10 / 6)$, if 4 experts have chosen response +2 , this choice received $0.64(4 / 10 \times 10 / 6)$. The total score for the test 
Table 3: Example of items from the diagnostic section of the SC test in urology.

Clinical Vignette: A 25 yearmold male patient is adnitted to the emergency room after a fall from a motorcycle with a direct impact to the pubis. Vital signs are normal. The $X$-ray reveals a fracture of the pelvis with a disjunction of the pubic symphysis.

\begin{tabular}{|c|c|c|c|c|c|c|}
\hline If you were thinking of & And then you find & \multicolumn{5}{|c|}{ This hypothesis becomes } \\
\hline Urethal rupture & Urethral bleeding & -2 & -1 & 0. & *1 & +2 \\
\hline $\begin{array}{l}\text { Retroperitoneal bladder } \\
\text { rupture }\end{array}$ & Bladder distension & -2 & -10 & $0+$ & +1 & +2 \\
\hline Urethral rupture & $\begin{array}{l}\text { Upward and bulging prostatic apex at } \\
\text { the digital rectal examination }\end{array}$ & -2 & -1 & $0+$ & +1 & +2 \\
\hline $\begin{array}{l}\text { Intra-peritoneal bladder } \\
\text { rupture }\end{array}$ & $\begin{array}{l}\text { Spontaneous micturitionafter the } \\
\text { accident }\end{array}$ & -2 & $-1<$ & 0 & +1 & +2 \\
\hline Urethral rupture & Perineal haematoma & -2 & -1 & 0. & +1. & +2 \\
\hline
\end{tabular}

$-2=$ the hypothesis is almost eliminated; $-1=$ the hypothesis becomes less probable; $0=$ the information has no effect on the hypothesis; $+1=$ the hypothesis is becoming more probable; $+2=$ it can anly be this thypothesis.

is represented by the sum of the scores obtained at each item. The French reference panel scored French candidates and Canadian reference panel scored Canadians candidates. This procedure was later reversed.

\section{Statistical analysis}

Descriptive statistics of the participant's' scores on the SC test were performed, followed by an univariate analysis of variance to test the differences between groups' means according to the composition of reference panel. Variations of scores obtained by students and residents with the two different reference paneis were compared with Student $t$ test. The homogeneity of group variances was estimated with the Levene's test in order to interpret the results of the previous analysis. When variances were unequal, adapted test was used. To evaluate the presence of a significant statistical difference, a $p<0.05$ value was considered as significant. Reliability of the examination was assessed through the Cronbach alpha internal consistency coefficient.

\section{Results}

The first analyses compared the scores obtained by candidates grouped by level of experience in urology, according to the composition of the reference panel. These results are summarized in table 4 . Mean global scores were $48.33 \pm 5.64$ for the students and $55.15 \pm 4.21$ for the residents when experts were the Canadian urol- 
Table 4: Comparison of mean scores by groups according to the composition af reference panets.

\begin{tabular}{|c|c|c|c|}
\hline Comp po sition of the treterence panel & $\begin{array}{l}\text { pesoms } \\
(h-25)\end{array}$ & $\begin{array}{l}5 \text { tudents } \\
(N=23)\end{array}$ & p-value \\
\hline French urologists $(N=10)$ & $53.16 \pm 4.68$ & $46.67 \pm 5.60$ & 0.0001 \\
\hline Canadian urologists ( $N=12$ ) & $55.15 \pm 4.21$ & $48.33 \pm 5.64$ & 0.0001 \\
\hline
\end{tabular}

Motes: "Size of groups; " pe0.05 was considered as significant (univariate analysis of variance):

: Values atre nean \pm 50 .

Table 5: Variatioms of mean scores according the learning enwironment of groups of candidates and reference panels.

\begin{tabular}{|l|l|l|l|l|}
\hline $\begin{array}{l}\text { Composition of the reference } \\
\text { panel }\end{array}$ & $\begin{array}{l}\text { French } \\
\text { students }\end{array}$ & $\begin{array}{l}\text { Canadian } \\
\text { students }\end{array}$ & $\begin{array}{l}\text { French } \\
\text { residents }\end{array}$ & $\begin{array}{l}\text { Canadian } \\
\text { residents }\end{array}$ \\
\hline Frencin urologists & $46.95 \pm 6.80^{\circ}$ & $46.16 \pm 2.33$ & $56.18 \pm 1.73$ & $50.78 \pm 4.94$ \\
\hline Canadian Urologists & $46.51 \pm 4.71$ & $51.74 \pm 5.95$ & $54.62 \pm 2.58$ & $55.57 \pm 5.22$ \\
\hline p-value & 0.68 & 0.0001 & 0.001 & 0.0001 \\
\hline
\end{tabular}

Notes: a: Values are mean $\pm 50 ;{ }^{\text {b}}: p<0.05$ was considered as significant (Student $t$ Test).

ogists. Mean global scores were $46.67 \pm 5.60$ for the students and $53.16 \pm 4.68$ for the residents when French urologists were considered as the reference panel. The univariate analysis of variance showed significant differences between students, residents and urologists. These observations were similar with the two different reference panels $(p<0.0001)$, indicating that the scores increased with the clinical experience of group participants, independently of the medical culture of the reference panel.

The second analyses compared the variations of candidates' scores according their Learning environment (see Table 5). Performance of French students did not vary with the wo reference panels $(46.51 \pm 4.71$ versus $46.95 \pm 6.80, p=0.68)$. Canadian students obtained higher scores with Canadian reference panel ( $51.74 \pm 5.95$ versus $46.16 \pm 2.33, p<0.0001$ ). French residents performed significantly better when French urologists were considered as the reference panel $(56.18 \pm 1.73$ versus $54.62 \pm 2.58, p<0.001)$. Canadian residents' scores significantly increased when Canadian urologists were the experts $(55.57 \pm 5.22$ versus $50.78 \pm 4.94$ x $p<0.0001)$

The Cronbach alpha reliability coefficients were similar for the French participants and the Canadian participants: 0.794 , and 0.795 respectively. 


\section{Discussion}

Cross-cultural research in the field of clinical competence assessment is not common. ${ }^{15}$ Rare existing data were obtained from bilingual. medical communities but with candidates trained in one common medical culture. ${ }^{16}$ Dur results showed variations of scores among groups of candidates with the same level of experience in urology, whatever the composition of the reference panel. Globally, Canadian candidates obtained better scores when Canadian urologists assessed them; and French candidates performed better when French urologists were considered as the reference panel.

To translate the examination we followed the process as described by Marshall. ${ }^{15}$ This process was effective for minimizing translation errors and assure equivalency of the English and French versions of the SC test. We believe that the differences observed are not biases of candidates. language but reflect medical and cultural differences between the two sites. Variance in urological practice patterns in the two communities influenced the performance of candidates in the $5 \mathrm{C}$ test. In North America, urology practice is currently specialized and restricted to a specific field of urology. In comparison, French urologists have a general as well as specialized urology practices. For example, male infertility and urinary incontinence are very specialized patterns, these specific cases could be rare in some Canadian urologists daily practice. In contrast, most of the French urologists are theoretically able to be effective in the initial care of these patients. Differences in areas of practice between the two panels of experts (Canadian urologists were exclusively faculty members, French urologists were from different areas of practice) could also explain the different levels of familiarity with the problems depicted in the test. This could also influence the performance of candidates.

However, despite the fact that students and residents are trained in two different medical cultures, their performances on the $S C$ test were remarkably similar. our results show an increase in the mean scores on the SC test of groups with different clinical experience, with the students receiving lower scores than the residents. These observations were similar in two sites with different languages and learning environments. This may mean that the SC test measures a dimension for which, as one should expect, experienced climicians get better scores than less experienced subjects. This supports the construct validity of the instrument. The study also showed that this test developed in urology has a relatively high reliability. The consemsual effect of this kind of examination, in term of construct validity and reliability across learning enviromments, across cultures and ways of practice is impressive and underlines the advantages of the SC test.

In SC test, examinees have to answer questions belonging to real medical problem solving that experts consider of crucial importance to the process. It is well known that assessment has a strong impact on learning. Students and residents adapt what they learn to what they believe will be tested. ${ }^{17} 5 \mathrm{C}$ test could reflect 
professional reality and is problem solving oriented; hence it should influence the adaptation of students and residents learming activities in that direction.

Our data demonstrate (1) that the $\mathrm{SC}$ test could assess candidates with good construct validity and reliability even if the reference panel belongs to a different medical culture: (2) scores are globally higher when the scoring system is established with a reference panel from the same environment than candidates.

The current need for medical training programme harmonization throughout European Union faculties favor the development of cross-cultural research in the field of clinical competence assessment. In this context, the SC test appears promising and warrants further investigation to confirm its value as a multi-linguistic and multi-cultural assessment tool of clinical reasoning.

\section{Conclusions}

These results showed an increase in the mean scores on the SC test of groups with different clinical experience in urology. The same effect was observed in two different learning and cultural environments. The variations of scores between groups of candidates with the same clinical experience could reflect the cultural difference among the groups of experts. These data present another argument in favor of the construct validity of the tool and the stability of its psychometric properties when it is administered in different learning enviromments. Most of the national medical associations are currently sensitive to the need for harmonizing traiming throughout the European Union. In this context, our findings warrant consideration and further research.

\section{References}

1 Schmidt, H.G., Norman, G.R. \& Boshuizen, H.P.A. A cognitive perspective on medicall expertise: Theory and inplications, Academic Medicine, 1990, 65: 611-621.

2 Elstein, A.S., Snulman, L.S. 8 Sprakka, 5. A. Medical problem-solving: An analysis of clinical reasoning. Cambridge, MA, Harward University Press, 1978.

3. Barrows, H.S., Norman, G.R., Neufeld, V.R. \& Feightner, J.W. The clinical reasoning of randomly selected physiciams in medical general practice, Clinical and Investigative Medicine, 1982,5 : $49 m 55$.

4 Feltovich, P.J. Expertise: Reorganizing and refining knowledge for use, Professions Education Research Notes, $1983,4: 5-9$.

5 Custers, J.F.M., Regher, G. \& Norman, G.R. Mental representations of medical diagnostic knowledge: a review, Academic Medicine, 71, 1996, pp. S55-61.

6 Zeitz, C.M. Some concrete advantages of abstraction: how experts' representations facilitate rea soning, in: P.J. Feltowich, K.M. Ford \& R.R. Hoffman RR (Eds) Expertise in Context: Human and machine. Memlo Park, CA, AAAI press, 1997, pp. 43-65.

7 Charlin. B., Tardif, J.\& Boshuizen, H.P.A. Scripts and medical diagnostic knowledge: theory and applications for clinical reasoning instmuction and research, Academic Medicine, 2000, 75: $182-190$ 
8 Bordage, G. Elaborated knowledge: A key to successful diagnostic thinking, Academic Medicine, $1994,69: 883-885$

9 Charlin, B., Brailovsky, C.A., Roy, L. \& van der Vleuten, C.P. The script concordance test: A tool to assess the reflective physician, Teaching and Learning in Miedicine, 2000, 12: 189-195.

10 Van der Vleuten, CPM The assessment of professional competence: development, research and practical implications, Advances in Health Sciences Education, 1996, 1: 41-67.

11 McGaghie, W.C. Evaluating competence for professional practice, in: L. Curry \& J.F. Wegin (Eds) Educating Professionals. Responding to new expectations for competence and accountability. San Francisco, Jossey-Bath, 1993, pp. 229-261.

12 Norman, G.R. Objective Measurement of Clinical Performance. Medical Education, 1985, 19: $43-47$.

13 Norcini, J.J., Shea, J.A. \& Day, S.C. The use of the aggregate scoring for a recertification examination, Evaluation and the Health Profession, 1990, 13: 241-251.

14 Ferland, J.J., Bordage, G., Loiselle, J-M. The effect of item translation on the psychometric status of a medical examination, Annals of the Royal College of Physicians and Surgeons of Canada, 1983. 16: 641-646.

15. Marshall, K.G., Brailovsky, C.A. \& Grand'Maison, P. French-English, English-French Translation process of an Objective Structured Clinical Examsination (OSCE) Used for Licensing family Physicians In Quebec, Teachingand Learning in Medicine, 1995, 7: 115-120.

16 Brailovsky, C.A. \& Grand'Maison, P. Using Evidence to Improve Evaluation: A Comprehensive Psychometric Assessment of a SP-Based OSCE Licensing Examination, Advances in Health Siciences Education, 2000, 5: 207-219.

17 Friedman Ben-David M. The role of assessment in expanding professional horizons, Medical Teacher, 2000, 22: 472-477. 



\section{CHAPTER}

\section{The growth of skill measured with the SCT A study in radiology}

Submitted to Radiology, August 2002

Measurement of competence in radiology: Evolution of knowledge elaboration and perception skill scores along training

Lucie Brazeau-Lamontagne, Bernard Charlin, Robert Gagnon, Louise Samson, Cees van der Vleuten

This study received funding from the Association of Canadian Medical Colleges and the Medical Research Council of Canada. 


\begin{abstract}
Purpose: Competence in visual clinical specialties implies (1) a perceptual component, which is most non-analytic, rapid and largely beyond consciousness and (2) an analytic component characterized by a conscious search for diagnostic features to be processed into a clinical decision. Search and processing are made possible by way of elaborated knowledge. This study assessed elaboration of knowledge by means of a script concordance test (SCT), while perception was assessed with a test of visual perception of radiological signs. Both tests were drawn from the same radiology domain: plain chest $x$-ray interpretation.
\end{abstract}

The first research hypothesis concerned acquisition of the two components. We expected a progression of scores on both SCT and perception tests paralleling training. The second hypothesis focused on differentiating between the two components. We assumed that both tests measure essential yet distinct dimensions of film reading competence. Therefore, we expected to find a positive Pearson correlation coefficient between the two tests, granted of a moderate magnitude.

Material and methods: Groups representing three levels of radiological training were tested: clerkship students (20), junior residents (R1 to R3; 20), and senior residents ( $R 4$ and $R 5 ; 20$ ). The perception test (Cronbach alpha: 0.79 ,) was composed of 38 items based on 4 radiological problems represented by 4 sets of chest $x$-rays. The SCT (Cronbach alpha: 0.81) was composed of 29 items related to the same problems presented on 4 other sets of chest $x$-rays. Answer keys were constructed from what was given by 11 current chest radiologists, according to the aggregate scoring method. Statistical analyses included descriptive statistics, ANOVA, regression analysis, and Pearson correlation coefficient.

Results: (1) The progression of scores was statistically significant in both tests. Both scores had a positive slope. Perception scores tended to increase more rapidly than knowledge elaboration scores, in global scores and in three out of four problems. (2) The Pearson correlation coefficient was found positive and of moderate magnitude. The two tests demonstrated large effect size, 2.2 (perception test) and $1.6(\mathrm{SCT})$

Conclusion: Study confirmed two distinct yet correlated components of film reading competence. Knowledge elaboration and perception skill scores increase both linearly, although at their own progression pace. The use of both tests is suggested to assess film reading learning during radiology training.

\title{
Introduction
}

Clinical reasoning, including radiology , is characterized by early generation of hypotheses, oriented collection of data and practical judgment based on these data 
to confirm or reject those hypotheses. ${ }^{1}$ According to Schmidt, ${ }^{2}$ clinical competence is acquired by developing specialized knowledge structures named scripts. These structures are tailored down to meet the demands of clinical tasks. ${ }^{3}$ Script theory ${ }^{2,4,5}$ implies that, in diagnostic situations, clinicians bring to their working memory blocks of networked knowledge relevant to the situation. Each script contains clues (clinical signs, for instance) associated with the illnesses as well as the nature of connections clues have with illnesses (clues could be linked positively, negatively or irrelevant to clinical hypotheses).

During residency training (radiology or else) building competence implies creating connections among bits of clinical knowledge. Scripts need to be progressively created to achieve clinical proficiency. The process is called elaboration of knowledge and is considered a key aspect of clinical learning ${ }^{6,7}$ In Bordage's studies on diagnostic thinking, ${ }^{89}$ best performing diagnosticians do not rely on linear lists of signs, symptoms, and illnesses, but on a rich network of knowledge held together by numerous connections. These connections are used to process incoming clinical data. Each processing reinforces or weakens the likelihood of hypotheses up to the final wrap up in a firm diagnosis and clinical management. We define elaboration of knowledge as the organization of knowledge that allows appropriate decisions in professional context. It is expected that elaboration of knowledge increases with training, from novice to experienced practitioner.

The Script Concordance Test (SCT), developed from those theories and from empirical finding ${ }^{10}$ probes mental associations connecting signs with illnesses in clinical knowledge networks. SCT requires data interpretation in authentic clinical problem setting, either diagnostic (investigative) or therapeutic. For diagnostic problems, examinees assess how new data effect the working hypotheses, which requires connections between clinical features and illnesses well anchored in a clinical knowledge base. The test allows score inferences about the degree of knowledge elaboration required to successfully handle problems in the assessed domain with good reliability, face, construct and predictive validity. ${ }^{11,12} \mathrm{~A}$ previous experience with SCT in radiology used written clinical scenarios to detect variations of elaboration of knowledge along with increasing levels of training in radiology. ${ }^{13}$ In the present study, actual $x$-rays are substituted to written scenarios in order to test with more authentic stimuli.

Competence in visual clinical specialties implies (1) a perceptual component, which is most often mon-analytic, rapid and largely "beyond" consciousness and (2) an analytic component characterized by a conscious search for diagnostic features and the processing of those features into a clinical decision. ${ }^{1 / 5}$ Such search and processing are made possible by way of elaborating clinical knowledge. With training, in radiology for instance, perception skills and elaboration of knowledge should both increase. This study assessed elaboration of knowledge by a SCT, while perception skill was assessed with a test on visual perception of radiological 
signs. Both tests were drawn from the same radiology domain: plain chest x-ray interpretation.

The study goal was to outline the relationship between those two components of the global competence of film interpretation. Our first hypothesis concerned acquisition of the two. We expected increasing scores an both (SCT and perception tests) with increasing training. The second hypothesis focused on the distinctivity between the two components. We assume that both tests measure essential yet different dimensions of film interpretation competence. Therefore, we expected to find a positive Pearson correlation coefficient between the two tests. granted of a moderate magnitude.

\section{Method}

\section{Subjects}

The study was carried in the teaching radiology department from two different universities. Trainees, sorted from three different levels of training, were asked to participate: clerkship students (20), junior residents (R1 to $R 3 ; 20$ ), and senior residents ( $R 4$ and $R 5 ; 20$ ). Clerkship students had to have completed a pre-graduate ratation in general radiology to be included. All students and residents invited to participate consented knowing that no retribution for participation was affered. Recruitment stopped when 20 subjects in each category were enrolled. Eleven staff members in University departments, all currently appointed to chest reading were asked to be the panel of reference. All agreed, again with no retribution.

\section{Interpretation test: Nodule}

\section{Answers grid (circle the right answer)}

- The dag nosis ts excluded

2 The diagnosis 15 a lot less probable

1 The tiagnosis 4 abit less probable
Whe diagnosis 13 a bit more probable

\$2 The dagnosis is a lot more probable

+3 The diagnosis Is the only one posstble

0 No feffect on hypothesis

On this $x$-ray, a pulmonary nodule is seen in the anterior segment at the left upper lobe. The following diagnoses are included.

- Lung cancer

- Histoplasmosis

- Solitary metastasis 
- Rheumatoild nodule

- Pulmonary abscess

On The $x$-ray, the following signs are also seen: 1. No calcification is seen in the nodule. What effect this finding has on the diagnostic
possibilities?

$\begin{array}{llllllll}\text { Primary lung cancer } & -3 & -2 & -1 & 0 & +1 & +2 & +3 \\ \text { Histoplasmosis } & -3 & -2 & -1 & 0 & +1 & +2 & +3 \\ \text { Solitary metastasis } & -3 & -2 & -1 & 0 & +1 & +2 & +3\end{array}$

2- The nodule is not cavitary

Solitary metastasis

Rheurnatoind nodule

Pulmonary abiscess

$\begin{array}{lllllll}-3 & -2 & -1 & 0 & +1 & +2 & +3 \\ -3 & -2 & -1 & 0 & +1 & +2 & +3 \\ -3 & -2 & -1 & 0 & +1 & +2 & +3\end{array}$

Figure 1: Examples of items from the first set of $x$-rays in the SC Test

\section{Material}

The tests used plain chest $x$-rays. Four common problems were selected from the training objectives of the radiology programs (shared by both pre-graduate and post-graduate programs): coin lesion, atelectasis, interstitial infiltrate, and mediastinal mass. Four sets of PA and lateral films were used in each test (SCT and perception test). Sets were different in the two tests. All were representative exemplars of each problem.

\section{SCT}

Any assessment method is composed of three elements, a stimulus format (examinees' task), a response format (how examinees' performances are recorded) and a scoring system (the transformation of performances in scores). ${ }^{25} \mathrm{SCT}$ is peculiar in every elements (see figure 1). The stimulus consisted in challenging films, even for an expert. Since the assessing focus with SCT is sign interpretation and not sign perception, actual signs were clearly specified on test sheets. The introducing paragraph was the following: «0n this film, there is a nodule in the anterior segment of the left superior lobe. Four hypotheses are relevant: primary neoplasm, histoplamosis, metastatic nodule, necrobiotic nodule, and pulmonary abscess. There are other signs on the films. What effect each of them has on the hypotheses you consider?) Positive signs (e.g., there are calcifications in the nodule), or negative (e.g., the nodule is not cavitated) were presented. The task was to decide what effect each sign had on the current hypotheses (see Figure 2). The format for answers was a 7 point Likert scale with value ranging from «the hypothesis is absolutely eliminated» to «it can only be that hypothesis», the middle 


\begin{tabular}{|l|c|c|c|c|c|c|c|}
\hline & -3 & -2 & -1 & 0 & +1 & +2 & +3 \\
\hline Hat of experts' answer & 0 & 3 & 6 & 0 & 2 & 0 & 0 \\
\hline Maw score & 0 & $3 / 11$ & $6 / 11$ & 0 & $2 / 11$ & 0 & 0 \\
\hline Transformed score & 0 & $3 / 6$ & $6 / 6$ & 0 & $2 / 6$ & 0 & 0 \\
\hline Situdent credit for the tem & 0 & 0.5 & 1 & 0 & 0.33 & 0 & 0 \\
\hline
\end{tabular}

Figure 2: Method of score transformation

point corresponding to athis information has no effects. The SCT was made of 29 items.

Scores on each item were extracted from answers given by a criterion group of experts ( 11 in this study). The following principle underlies the SCT scoring process: each answer of any expert reflects a valid opinion that should be taken into account; even the answers with poor agreement among experts should not be discarded. The aggregate scoring method. ${ }^{16,17}$ reflects the variability experts usually demonstrate when answering complex questions. ${ }^{13}$ Therefore each given answer to an item received a credit that reflects the number of experts answering that way. Experts were asked to complete the test individually. Their individual answers were used to build the answer's key. For each item, answers were assigned a credit of point corresponding to the proportion of the experts who selected it. For example in Figure 2, on an item, 3 experts (out of 11) chose response minus 2, 6 chose minus 1 (where 6 represents the modal answer) and 2 chose plus 1 . Raw scores would be $3 / 11$ of a point for answer minus $2,6 / 11$ of a point for answer minus 1 and $2 / 11$ of a point for answer plus 1 . The answers not chosen by experts received zero point.

Since all items should offer the same maximum credit, raw scores were further proportionally transformed to get a maximum score of 1 for modal experts' choice (s) on each item, other experts" choices receiving a partial credit. Scores were transformed, by dividing them by the modal value for the item. In this example, any student answering minus 2 will got .5 point, minus 1 got 1 point, plus 1 got .33 point and any other answer would get 0 point. The total score for the test was the sum of credits obtained on each item. Numbers were then transformed in order to get a maximum score of 100 .

\section{Perception test}

The test was based on the 4 problems pictured on four sets of chest $x$-rays. For each $P A$ and lateral set of chest $x$-rays, a series of radiological signs was provided. Each participant had to decide if the sign was present or not on the films (see Figure 3). Answer options were yes (the sign is present), no (the sign is not present), artefact (it is an artefact) or I don't know. Eleven experts completed the test. In 


\section{Perception test: Nodule}

\begin{tabular}{|c|c|c|c|c|}
\hline Is there & Yes. & Ho. & Artefact & Don't know \\
\hline A nodule in the rigint upper lobe? & $\square$ & $\square$ & $\square$ & $\square$ \\
\hline A nodule in the left upper lobe? & $\square$ & $\square$ & $\square$ & $\square$ \\
\hline A mass in the aortic pulmonary window? & $\square$ & $\square$ & $\square$ & $\square$ \\
\hline
\end{tabular}

Figure 3: Example of items from the first. set of $x$-rays in the perception test

spite of a choice of representative films, opinion of experts on the presence or absence of features on films was far from unanimous. Therefore we used two scoring methods. The first considered an answer to be right when at least $8 / 11$ gave the same answer. The second used the aggregate method. Both ended up with similar results. For coherence purposes, we chose the aggregate method as the common scoring method for both the perception and the interpretation tests.

\section{Statistical analysis}

Analyses on the SCT were first done at the level of signs to prevent artificial boosting of reliability coefficients by items dependence related to a single sign ( 5 sub questions for each sign). Data were analyzed at two levels: the problems ( 4 levels) and the whole test (summation of all 4 problems scores). All global scores (cases and total) were plotted to common denominator of 100 points to be easily comparable. Statistical analyses included descriptive statistics, ANOVA, and linear regression analysis. Scales reliability was evaluated by standard Cronbach alpha coefficient without any form of optimization. One way analysis of variance was used to test the differences between the three groups on global score, cases and signs. Simple regression analysis was used to compare "progression" of scares with increased level of training and to estimate the slope of the regression line (unstandardized regression coefficient). A Z test was used to compare the two regression coefficients (Kanji, 1993, 100 Statistical Tests, Sage Publications). The relationship between SCT and visual perception test was assessed with the Pearson correlation coefficient. Effect size was calculated using differences between mean of extreme groups and standard deviation of the lowest mean group. All tests were two-sided with an alpha level of $5 \%$.

\section{Results}

Data were obtained from three groups of 20 trainees. The alpha coefficient on 38 items of the perception test was 0.79 , while it was of the same order $(0.81)$ for the 29 items of the SCT. Tabie 1 and table 2 show the mean scores obtained for each of the four problems by the three groups with the perception test and the SCT. In the perception test, all differences between groups are highly significant 
Table 1: Performance of groups on the perception test

\begin{tabular}{|c|c|c|c|c|c|}
\hline 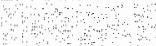 & Case $A$ & Case $B$ & Casec & Casse D & Total test \\
\hline Students & $66.9(1.5)$ & $65.7(15.1)$ & $59.6(16.9)$ & $53.0(15.7)$ & $6.1 .0(10.2)$ \\
\hline$R 1-R 3$ & $74.5(12.7)$ & $21.6(14.7)$ & $74.1(13.4)$ & $63.8(12.8)$ & $73.4(8.8)$ \\
\hline$R 4,-185$ & $82.1(8.0)$ & $93.6(0.1)$ & $85.4(7.2)$ & $70.8(9.6)$ & $83.0(4,0)$ \\
\hline Anova $\quad F$ & 8.5 & 24.3 & 19.3 & 9.6 & 36.8 \\
\hline$p$ & $<0.001$ & $<0.001$ & $<0,001$ & $<0.001$ & $<0.001$ \\
\hline
\end{tabular}

Table 2: Performance of groups on the SCT

\begin{tabular}{|c|c|c|c|c|c|}
\hline & Case A & $\mathrm{Ca}=\mathrm{Be}$ & casec & Case $D$ & Total test \\
\hline Studerints & $56.5(8.8)$ & $4.5 .7(11.8)$ & $53.3(7.9)$ & $55.5(10.3)$ & $52.9(7.1)$ \\
\hline$R 1-R 3$ & $69.5(11.6)$ & $50.4(9.9)$ & $54.6(9.9)$ & $59.7(11.4)$ & $59.3(7.9)$ \\
\hline$R 4-R 5$ & $76.2(8.2)$ & $57.6(10.9)$ & $58.8(7.9)$ & $50.9(10.4)$ & $64.4(6.2)$ \\
\hline Ariova $F$ & 21.6 & 6.1 & 2.3 & 1,4 & 13.0 \\
\hline$p$ & $<0.001$ & 0.004 & 0.11 & 0.26 & $<0.001$ \\
\hline
\end{tabular}

$(<0.001)$ for each of the four problems and for the test as a whole. In the case of the SCT, significant differences between the three groups are found for the two first problems and for the whole test. Smaller differences between groups were noted for problem $3(F=2.3 ; p=0.112)$ and for problem $4(F=1.4 ; p=0.215)$. In both tests, with all four problems, all the means showed a constant progression from the lower level of training (students) to the higher level (R4-R5).

The slope of the relationship between level of training and the mean scores on the four problems and on the whole test were estimated using the unstandardized regression coefficients. In general, the slope is steeper in the perception test (case $A=7.6$; case $B=13.9$; case $C=12.9$; case $D=8.9$; total $=10.9$ ) than in the $S C T$ (case $A=9.8$; case $B=5.9$; case $C=2.8$; case $D=2.7$; total $=5.7$ ). It should be noted that case $A$ is the exception, as the slope is steeper in the $5 \mathrm{CT}$ test. On the other hand, regression coefficients for each case of the perception test and of the $\mathrm{SCT}$ are not statistically significant $(p>0.12)$. Figure 4 illustrates the regression lines for both tests in the four problems.

Correlation coefficients between the two techniques show moderate correlations for case A $(0.44 ; p<0.01)$; case B $(0.42 ; p<0.01)$; case $C(0.21 ; p=0.08)$; case $D$ $(0.11 ; p=0.42)$ and for global score $(0.58 ; p<0.01)$.

Effect size is very large for both test, 2.2 (perception test) and 1.6 (SCT). 


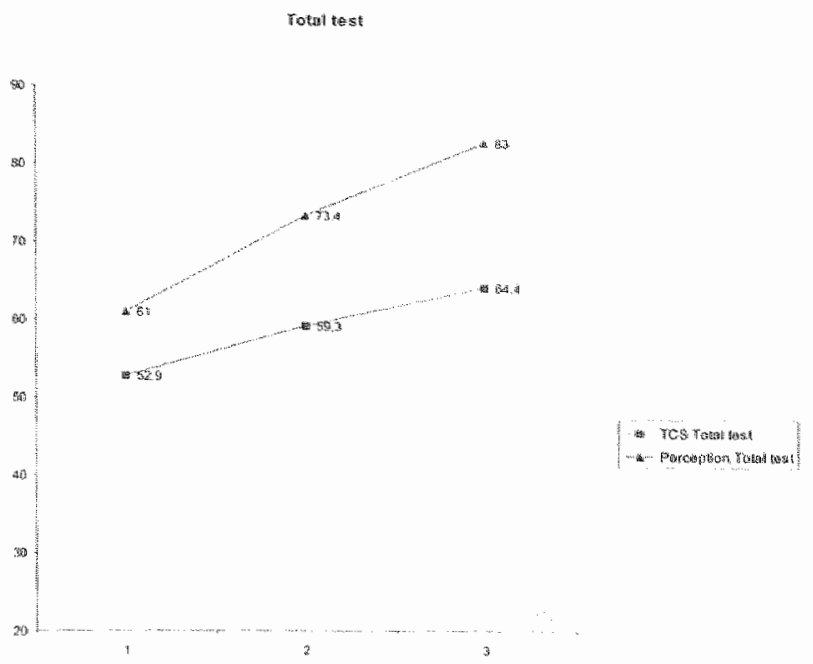

Figure 4: evolution of perception and interpretation scores

\section{Discussion}

Assessment of clinical competence with most written tools is doomed to a severe limitation. Experienced clinicians score hardly better and sometimes worse than senior residents. ${ }^{19}$ This corresponds to the intermediate effect, ${ }^{20}$ of the current tools of assessment. An explanation for this limitation may come from the nature of problems examinees have to solve with written exams.

Problems that professionals handle in their practice are of two kinds: ${ }^{21}$ technical and professional. First the technical ones. These problems are solvable by applying known reasoning strategies, in defined and stable contexts, for clear and predictable goals. They are called well-defined problems. On the other hand, each patient is imbedded in a particular context, made of somewhat imperfect, inconsistent, or even inaccurate information. Even radiological features are not always clear. Hence, clinicians are often challenged with the second kind of problems, called ill-defined problems. ${ }^{22}$ According to Schön the needed knowledge to solve ill-defined problems differs from the technical knowledge handling well-defined problems. He called it professional knowledge. He stated that professional schools emphasize on learning and assessing technical knowledge too much and often neglect the essence of the professions i.e., professional knowledge. Professional judgment and decision making both require reflective practice and excellent reasoning skills. ${ }^{21}$

When professionals are reasoning on complex problem, they follow different paths in their way to the solution. That was shown by clinical reasoning research 
repeatedly. ${ }^{1.12}$ Despite this finding, most of cument assessment practice is based on the following dogma: members of juries are required to provide uthe good answers that examinees should give on each test item. Therefore examinees are submitted to problems sufficiently well defined to allow clear-cut right answers, and almost never submitted to ill-defined problems real clinical experts deal with in daily practice.

SCT is proposed as an answer to this difficult issue. It differs from common exams on three ways: the nature of the tasks requested, the way it captures answers and its scoring process. Tasks are derived from real practice, including its complexity. In radiology for instance real $x$-rays are used. The stimulus is authentic film set presenting a diagnostic challenge, even for an expert. Usual exams such as MCas would ask for the most probable diagnosis which is the outcome of the clinical reasoning process. Instead SCT probes the process itself. It asks what effect a new information has on one of the working hypotheses. The way SCT captures answers (a Likert scale) replicates the way ${ }^{4,5}$ clinicians process data in their clinical reasoning. Since experts do not unamimously agree, there variability should be taken into account, which the aggregate scoring process does.

Both tests used in the study demonstrate good metric qualities. SCT is reliable with a good alpha coefficient despite a limited number of items $(29)$. It is well accepted by examinees, especially those who are fan of real clinical tasks. It is rather easy to build. It is made of authentic questions that experienced clinicians currently ask themselves to solve a problem. It has also the advantage of standardized scoring process. The other test (perception test) also shows good reliability with few items (38). It discriminates examinees efficiently as shown by high F values, large effect size and steep slopes for regression lines. Both instruments carry high discriminative power as effect size is very large in both tests, 2.2 (perception test) and 1.6 (SCT). Therefore it is possible to detect variations between small groups of examinees.

Study confirms existence of two distinct yet correlated components of film reading competence. Knowledge elaboration and perception skill scores are predictors of levels of training. Both increase linearly, although with their own progression pace. Perception is acquired soomer and more rapidy than elaboration of knowledge.

\section{Conclusion}

The use of both tests is suggested to assess film reading competence in radiology training. By using real life stimuli and tracking answers with standardized methods, SCT allows follow up of knowhedge organization with increasing training. Its use might be beneficial to probe problem solving expertise in radiology interpretation settings. Low scores on SCT might help sorting thase students or residents 
who would benefit from special educational assistance in organizing their knowledge, while the use of a perception test would permit to sort out residents in need of perceptual remedies.

\section{References}

1 Elstein, A.S., Shutman, L.S., Sprafka, S.A. Medical Problem Solving: An Analysis of Clinical Reasoning. Cambridge, MA: Harvard University Press, 1978.

2 Schmidt, H.G., Norman, G.R. and Boshwizen, H.P.A. A Cognitive Perspective on Medical Expertise: Theory and Implications. Academic Medicine, 1990; 65: 611-621.

3 Feltovich, P.J. Expertise: Reorganising and refining knowledge for use. Profession Education Research Notes, 1983; 4: 5-7.

4 Smith, E.E. Concepts and Induction. In Posner M.I.(Ed.). Foundations of Cognitive Science. Cambridge, MA: MIT Press. 1989.

5 Chartin, B., Tardif, J., Boshuizen, H.P.A. Scripts and Medical Diagnostic Knowledge: Theory and Applications for Clinical Reasoning Instruction and Research. Academic Mediche 2000; $75: 182-190$.

6 Coles, C.R. Eläborated learning in undergraduate medical education. Medical Education, 1990; 24:14-22.

7 Bordage, G. Elaborated Knowledge: A key ta Successful Diagnostic Thinking. Academic Medicine, 1994; 69: 883-885.

8 Bordage, G., \& Lemieux. M. Some cognitive characteristics of students with and without diagnostic reasoning difficulties. Proceedings of the twenty-first Annual Conference on Research in Medical Education of the American Association of Medical Colleges, Washington. DC, 1986; pp. $171-176$.

9 Bordage, $G_{n}$ et Lemieux, M. Semantic Structures and Diagnostic Thinking of Experts and Novices. Academic Medicine, 1991; 66: \$70-572.

10 Charlin, B., Roy, L., Brailovsky, C.A., Van der Vleuten, C.p.m. The Script Concordance Test: A Tool to Assess the Reflective Clinician. Teaching and Learning in Medical Education, 2000: 12: $189-195$.

11 Brarlovsky, C., Chartin, B., Beausoleil, S., Coté, S., van der Vleuten, C. Measurement of Clinical Reflective Capacity Early in Training as a Predictor of Clinical Reasoning Performance at the End of Residency: An Exploratory Study on the Script Concordance Test. Medical Education, 2001; 35: $430-436$.

12 Charlin B., Desaliniers $M$, Gagnon R, Blouin D, van der Vleuten $C$. Comparison of an aggregate scoring method with a consensus scoring method in a measure of clinical reasoning capacity. Teaching and Leaming in Medicine, 2002,14: 148-154.

13 Charlin, B., Bralovsky. C.A., Brazeau-Lamontagne, L., Samson, L., Leduc, C. Script Questionnaires: Their Use for Assessment of Diagnostic Knowledge in Radiology. Medical Teacher, 1998: 20: $567-571$.

14 Norman, G., Coblentz, C, Brooks, L., et Badcook, C. Expertise in Visual Diagnosis: A Review of the Literature, Academic Medicine, 1992: 67:578-583.

15 Norman G, Swanson DB, and Case SM. Conceptual and methodological issues in studies comparing assessment formats. Teaching and Learning in Medicine, 1996: 8: 208-216.

16 Norman, G.R. Objective Measurement of Clinical Performance. Medical Education, 1985: 19: 43-4?.

17 Norini 3.J., Shea, J.A., Day, 5.C. The Use of the Aggregate Sconing for a Recertification Examina tion. Evaluation and the Health Professions, 1990: 13: 241-251.

18 Grant, J. \& Marsden, P. Primary knowledge, medical education and consultant expertise. Medical Education, $1988,22: 173-179$. 
96 Chapter 6

19 Van der Wleutten CPM, Newble D, Case S, Holsgrove G, McCann B, MeRiae C, Saunders N. Methods of assessment in certification. In Mewble, D., Jolly, B. \& wakeford, $R$ (Eds) The certification and recertification of doctors: Issuess in the assessment of clinical competence. Cambridge: Cambridge University Press, 1904 .

20 Schmidt HG, Boshuizen HPA, Hobus PPM,; Transitory Stages in the Development of Medical Expertise: The "Intermediate Effect" in Clinical Case Representation Studies. In Proceedings of the 10th Annual Conference of the Cogitiwe Science Society. Hillsdale, N.J.: Erlbaum. 1988

21 Schön, D. A. The reflective Practitioner: How Professionals Think in Action. New York: Basic Books, 1983.

22 Harris, I. New Expectations for Professional Competence. In L. Curry \& J.F. Wegin (Eds), Educating Professionals. Responding to new expectations for competence and accountability. San Francisco: Jossey-Bath Publishers, 1993: pp. 17-52. 


\section{Conclusion}

This dissertation is built around a general research question:

Is it possible to conceive a clinical reasoning assessment tool that may be congruent with recent developments in cognitive psychology and assessment sciences?

Several. sub-questions stem from the general question.

Research question 1: what is the theoretical validity of the tool? In what way can we corroborate the choices that were made in the design of the tool with theoretical considerations and research outcomes in assessment?

In chapter 1, we have recalled that Bordage and Williams propose a practice-theory-practice approach for research in medical education, in which questions pertinent to educational practice are built in the context of existing theory, and results are interpreted to confirm, or refute, these theories. The endeavor, advisable for developments of models of instruction is advisable as well for the development of assessment tools.

We have also recalled that in cognitive research on medical expertise, according to Elstein et al (1990), there has been a shift from the search for a generic problem-solving skill toward a focus on memory organization, knowledge use, problem representation, and how they change with experience. These authors underline that in the testing and evaluation domain, this change of focus has not had many applications. In this perspective, they suggest that evaluation should concentrate on judging the quality of a set of cognitive operations or knowledge structures by comparing a student's problem representations, judgments, and choices to those of the experienced group. The Script Concordance test is developed within this framework. 
As described in the dissertation introduction, Schön makes an interesting distinction between the kinds of problems clinicians encounter in their practice. In well-defined problems, all data necessary to solve them is present, the goals to reach are clear and there are known solutions to reach goals. These problems can be solved using knowledge and skills belonging to the domain of technical rationality, and a significant part of clinical reasoning competence rests on the capacity of applying well known solutions to well defined problems. Written tests with excellent reliability and validity such as Multiple Choice Question (MCO) formats allow the successful assessment of the «technical rationality» part of clinical reasoning. But many clinical situations are made of ill-defined problems. All data necessary to solve the problem is not present, data must be gathered in order to formulate the problem, and some problems are characterized by imperfect, or inconsistent information. The capacity to solve these kinds of problems is an important part of clinical competence. Some evaluation tools, oral exams for example, can assess the knowledge (that Schön terms professional knowledge), which is required to solve ill-defined problems. Nevertheless, these tools have their limitations such as difficulty of standardization or feasibility of administration for large group of students. The Script Concordance Test (SCT) is designed to assess the ability to solve ill-defined problems. In fact, it assesses the extent to which examinees" knowledge is organized to efficiently solve that kind of problem.

Physicians can be defined as professionals that make decisions in the context of uncertainty. We know from research that in similar clinical situations, physicians do not collect exactly the same data and do not follow the same paths of thought, even if they obtain the same diagnostic outcome. They show substantial variation in performance on any particular real or simulated case. In chapter 2 , we have argued that current assessment practice has not yet incorporated these research findings. We continue to behave as if there were a unique right solution to all clinical problems, a unique right weight to give to the data processed while reasoning toward problem solutions. Therefore, we ask examination jury members to agree on a unique right answer on each item, and when then are unable to reach it, the item is removed from the examination. This impairs, assessment of ill-defined problems, and so of many of authentic clinical life situations.

In chapter 2, we have argued that, in order to assess ill-defined problems, it is necessary to take in account the variability that is inherent among practitioners while they are reasoning through ill-defined problems. A method to achieve that, named the aggregate scoring method, exists in medical education literature but has curiously been neglected since its description by Norman in 1985 and by Norcini in 1990. The work presented in this dissertation provides evidence in favor of its usefulness.

Mast current instruments of clinical competence assessment, either performance-based methods (e.g. OSCEs) or instruments assessing the solutions found to well-defined problem (e.g. MCQs) are measures of behavior. At a time where 
cognitive psychology has become the major conceptual framework in medical education (Irby, D. Academic Medicine, 72:116, 1997), it is mecessary to add to these instruments a way to assess clinical reasoning cognition. We should measure its process instead of its outcome. To measure this we need to have a theory of clinical reasoning process. Chapter 1 presents an adaptation of cognitive psychology script theory to the characteristics of clinical reasoning.

We explained that during the data collection process, physicians are systematically comparing incoming information to the values that are acceptable or unacceptable for each of the script attribute. For each attribute, if unacceptable values are found, the script is rejected, and other scripts that accept that value are activated or reinforced. Among acceptable values for an attribute, some bring more weight to a hypothesis than others. According to theory, clinical reasoning is therefore made of a series of qualitative judgments. Each of these judgments can be measured. This provides a method of clinical reasoning process assessment.

Chapter 2 describes how the script concordance test (SCT) is conceived to achieve this. The principle is to describe rich authentic clinical contexts in which there is not enough data to make a diagnostic or management decision. Therefore, the situation represents a problem, even for an expert of the domain. Items are made from the questions experienced physicians ask and the actions they take in these contexts. The SCT is innovative in the three components any assessment tool has: the stimulus format (examinees' ${ }^{\prime}$ task), the response format (how examinees" performances are recorded), and the scoring system (the transformation of performances into scores). The stimulus consists of a challenging clinical task. The response format is in accordance with what is known from clinical reasoning processes: a Likert scale, measuring the judgments that are constantly made within the clinical reasoning process, capturing examinees' answers. The scoring method, an adaptation of the aggregate scoring method, takes into account variation of answers among a criterion group. With these characteristics, stemming from the described theoretical frameworks, the SCT allows in the context of a series of clinical tasks, to compare examinees' scripts to those of a panel of experienced clinicians (hence the name of the test).

Through its theory and through the careful theory-based choices that were made in constructing the instrument, we can conclude that the SCT has theoretical walidity. We believe that the SCT is a good assessment illustration of Bordage and Williams"s conceptualization of educational research in general. 
Research question 2: What is the construct validity of the SCT? The SCT is ained at assessing the quality of scripts i.e., knowledge structures that theory purports to develop with clinical experience. Is the SCT able to discriminate among examinees across differing levels of experience? Furthermore, does the SCT allow us to overcome the intermediate effect described as a limitation of current clinical reasoning assessment methods?

One of the limitations of current clinical assessment tools is the intermediate effect i.e., the puzzling fact that experienced clinicians score little better and sometimes worse than less experienced clinicians or students. An explanation might be that most of the written tools measure clinical factual knowledge rather than clinical reasoning competence. They are invalid indicators of the work clinicians actually do in practice setting (Mc Gaghie, 1993). Tools that provide contexts close to those of the practice setting, such as simulations and practice-based exams, have their own difficulties, many of them concerning scoring issues. The intermediate effect is present for them as well.

The SCT probes script development i.e., the development of specialized knowledge structures that contain the clinically relevant information that clinicians use in their clinical activities. It also explores the capacity for data interpretation when making clinical decisions, clearly a skill that belongs more to clinical competence than the simple recall of factual data. The SCT has therefore by design the potential to overcome the intermediate effect.

Chapter 3 is a report of an early study (1998) that shows an increase in the mean scores of groups of different clinical expertise, the less experienced getting the lower results. This supports the construct validity of the instrument, indicating that the SCT measures a dimension for which, as one should expect, experienced physicians get better scores than less experienced subjects. However, the study presented a methodological limitation. The group of tested experienced clinicians made also the criterion group used to make the answer grid. Their performance was therefore artificially boosted. This methodological flaw has been avoided in subsequent studies on the SCT.

Four studies presented in the dissertation are applications for different goals of the SCT in different disciplines. We found a disappearance of the intermediate effect in all four applications / contexts. We conclude that these results represent an argument in favor of the SCT construct validity. This kind of validity can never be completely affirmed. Other studies in the future will seek to strengthen it.

\section{Research question 3: What are SCT reliability and feasibility?}

A test is often considered to be reliable when Cronbach alpha coefficient reaches a value of 0.80 . In three of the dissertation studies values reached (or almost reached) 0.79 (urology, chapter 5), 0.81 (radiology, chapter 6) and 0.82 (gyne- 
cology, chapter 3) with relatively small numbers of items $(80,29$ and 50 respectively). Experience shows that an 80-item test can be passed in an hour or less. This compares very favorably with the time required by other examination formats to reach the 0.80 value.

A good assessment tool should have a series of qualities in terms of feasibility. It should be relatively easy to build, easy to administer, easy to score. At first glance, it might appear simple and rapid to construct script concordance tests. A few experts of a domain are asked to describe some clinical situations that are characteristic of the domain to assess. The experts are then asked to specify the questions they would ask and the action they would take in the situation to arrive at a diagnosis or to decide on the adequate management of the patient. Vignette items are then built with this material. In reality, writing items for the SCT requires some familiarity with the tool. For instance, the situation described must be complex enough to be challenging for the level of training that has to be assessed, and with not enough data to "solve" it, even for an expert. Data provided in items related to the vignettes are data an expert will seek to progress toward a solution. Construction of the SCT is nevertheless simpler than construction of good quality MCas. Subsequent phases of validation of the test by experts and elaboration of the answer key are well accepted. These phases are not time consuming and physicians that constitute panels of reference generally like to complete a test that is close to real clinical reasoning. The sometimes lengthy discussions required, in other testing formats, to get consensus answers on all items are not required. Test administration can be paper or computer-based, without particular difficulty. Scoring system is simple, if examinee performance is entered in computer and transformed in scores by a program.

Data obtained in the studies described in the dissertation and day-to-day experience in test construction and administration teach us that the SCT is reliable and convenient for testing in different settings and different levels of training and experience.

Research question 4: What is the validity of the scoring method used in the SCT? The aggregate method has been proposed by Norman and by Norcini in the late 1980s, but has hardly been used and studied in the medical education literature. In what way is this method superior to conventional methods?

In the study presented in chapter 4 , members of the criterion group in two different contexts constructed answer keys. For the aggregate scoring method, they passed the test as if they were examinees (individual responses) while for the consensus method they were required to decide, by group discussion, on a single right answer one year later. 
Research has shown that physicians do not collect exactly the same data, do not follow the same paths of thought, and vary in patient management on ill-defined problem-solving tasks. So our finding that criterion group answers vary depending the context - individual response versus consensus response - is not a surprise. It was the magnitude of the difference that was a surprise. Members of the criterion group changed their responses on $59 \%$ of items. We explain this magnitude by the radically different context in which these responses were obtained. When a physician is alome (as he / she is usually in practice), only the data provided by the case are used, while within a group the context is significantly madified by interactions with the other physicians. This has major consequence for assessment of ill-defined problems. It appears important to obtain criterion group responses in a context that is simitar to the one examinees will have.

Another important aspect is the variability of responses obtained from criterion group members in individual responses (aggregate method), even for items that did not appeared at first glance very ambiguous. We also found this phenomenon in the study presented in chapter 6 . On a perception test, made of films considered by an expert as prototypical of some classical pathologies, we have surprisingly discovered that radiologists specialized in chest imaging differed in their perception of what was present and not present on films. This is consistent with the finding in the cognitive psychology and medical education literature that in real life clinical tasks we should not expect unanimity of interpretation and detection by expert clinicians. This is a strong argument in favor of the use of the aggregate scoring method.

Finally, another argument in favor of the aggregate scoring method is its superiority in the detection of experienced physicians in a group of examinees. The method appears more sensitive to detection of expertise than the typical consensus method. When experts are judged on a consensus-based scoring scheme built by other experts, their own expertise is difficult to detect.

Through the results of that study, we conclude that the aggregate method is valid. It is superior to the more conventional consensus method. It also offers an objective scoring process for the assessment of complex performance in ill-defined situations. That method opens a wide field of research for the future. It may be applied in several other exam formats and thus greatly improve professional competence assessment.

Research question 5: What is the applicability of the SCT in different dinical contexts? Is it useful at all different levels of medical clinical training (clerkship, residency, and physicians in practice)? Is the tool useful in different disciplines? Does the tool keep its psychometric qualities when applied in different cultural and learning environments? Does the tool help to detect the growth of essential components of clinical competence? 
Studies presented in chapters 3 to 6 show that the SCT can be used in disciplines as diverse as gynecology, radiology or urology and that it is able to discriminate examinees across their level of experience in the three disciplines. They also indicate that, probably because the test is made with authentic clinical situations, same tools can be used for students, residents and physicians in practice. With all, the tool is well accepted and found interesting to pass, without excess of facility for a group and excess of difficulty for another. The difficulty and content of the SCT can nevertheless be adapted to the testing situation when clinical vignettes and items are constructed.

In the urology study, the same test was administered in English to the Canadian subjects and in French to the French participants. The test was able to discrimimate among participants of the two countries according to their level of clinical experience, despite linguistic, cultural, educational and institutional differences. This was true even when examinees were judged with the criterion group of the other culture, although there was a slight difference in that examinees obtained higher scores when criterion groups from their own culture assessed them.

The study described in chapter 6 was conducted in a visual dornain, radiology. We wanted first to verify if the SCT could be used as a test of X-ray interpretation skills, with actual films as stimuli. The perception skills of radiological signs were assessed with a specific perception test. It is interesting to notice that as described above, radiology experts often provided different opinions on what was and wasn't present on films. The use of the aggregate scoring method improved the psychometric qualities of the test in this context also. With that study we brought other evidence in favor of the construct validity of the SCT by showing that the test is able to detect a dimension of competence that progresses along training at a different speed than the perception skill.

This confirms that we measured two dimensions of competence and that the SCT is an effective measure of one of them. The use of these two tests opens large avenues of improvement in training for visual domain specialties. Educators perceive intuitively that some residents have perception or interpretation problems, but up to now they have had no test providing an objective measure of the deficiency that had to be addressed by specific educational measures.

With data provided by these 4 studies it seems that the SCT can be efficiently used in very different clinical settings, at all levels of experience and for very different kinds of professional practice.

\section{Future research and development avenues}

The answers given to our five research questions bring a series of arguments in favor of the reliability and validity of the tool. The SCT remains nevertheless at the 
beginning of its development. Many issues warrants investigation, and among them:

- The stimuli for the tasks examinees have to complete can be very diverse. They can be paper-based or computer screen presentations of written clinical problems. They can be actual material, such as X-rays (like in chapter 6 study), or tissue slides presented under a microscope, video-clips of patient signs (tremor, stepping, etc) or audio-taped sounds (cardiac murmurs for instance) that have to be interpreted in the perspective of relevant hypotheses.

- The use of the SCT at different stages of medical training, for selection goals, basic sciences examination (interpretation of patha-physiologic events), during clerkship or residency, either as a formative or certification i.e., summative examination. Its use in continuing medical education as pre and post-test or as a method to detect areas participants need to focus on represents other areas that are important to explore.

- While the Likert scale appears as a good means of capturing the micro-decisions constantly made in the reasoming process, its conditions of use (number of points in the scale, anchoring of their signification for instance) require more precision.

- A comparison of cognitive processes used in different examination formats, such as matched rich context MCQ test and SCT; would open a field of research that is not sufficiently addressed up to now.

- The scoring process is a wide field of experimentation in itself. Numerous questions can be asked: what is the optimal number of members in a criterion group to get stable examinee results? What effect does the variability of answers within the criterion group have on the detection of the most experienced people in samples of examinees? What effect has variation of composition of the criterion group reference on students' scores and ranking? With the aggregate method, we consider that if a student makes the same interpretation than a member of the criterion group he should receive a partial. credit. That position might be challenged. An alternative method would ask criterion experts what options should be considered correct and the aggregate weights can then be applied only to them.

- Standard setting is an important and not easy issue, because of the variation of answers among the criterion group and because of the variation of weights given to examinee answers.

- The SCT can be administered on the Internet. Students and residents can pass khe test at their convenience and get immediately their scores with outlines of their areas of deficiencies. Very large pools of experienced physicians can also be used to constitute countrywide criterion groups. This offers other large avenues of research and developments.

- The SCT use is not limited to the medical profession. Other profession can use it, in the health professions, or in fact in any profession where decisions are made in context of uncertainty. 
We are already investigating several of these issues, with the help of co-investigators within Canada and abroad, and with funds obtained from granting agencies in Canada, USA and France.

\section{The place of the SCT in a strategy of clinical competence assessment}

We will end this dissertation on the script concordance test in examining the place the SCT could hold in a strategy of clinical competence assessment. Clinical competence is a multidimensional entity. No single instrument allows us to assess it globally. The use of several instruments is necessary to validly assess it. OSCES, and other performance-based tests will, for instance, allow valid and reliable measures of clinical and technical skills. Nevertheless, those tests do not provide optimal measures of clinical reasoning because observation holds only on observable behaviors. Even with very strict instruction, it is notoriously difficult to get reliable measures of clinical reasoning with think-aloud instructions. Beside those two components, competence rests also on knowledge of established rules, laws and procedures. All of them are well assessed with MCQ type of tests. Therefore a credible strategy of assessment could be made of a combination of MCas, SCTS and OSCEs (without excluding other instruments to measure other dimensions of competence). All three present the advantage of being standardized and objectively scored. These two qualities are essential in high stake contexts such as certification or selection exams. We therefore see the SCT as a promising tool that may occupy a specific place within the range of assessment tools of clinical competence. 
106 


\section{Summary}

The dissertation is built around a general research question:

Is it possible to conceive a clinical reasoning assessment too that may be congruent with recent developments in cognitive psychology and assessment sciences?

In cognitive research on medical expertise, there has been a shift from the search for a generic problem-solving skill toward a focus on memory organization, knowledge use, problem representation, and how they change with experience. In the testing and evaluation domain, this change of focus did not have yet many applications. The script concordance test (SCT) is conceived in the perspective of the recommendation of Elstein et al (1990). These authors suggested that evaluation should concentrate on judging the quality of a set of cognitive operations or knowledge structures by comparing a student's problem representation, judgments, and choices to those of the experienced group.

Theoretical validity of the tool is the theme of the first research question. In what way can we corroborate the choices that were made in the design of the tool with theoretical considerations and research outcomes in assessment?

Chapter 1 presents an adaptation of cognitive psychology script theory to the characteristics of clinical reasoning. We explain that during the data collection process, physicians are systematically comparing incoming information to the values that are acceptable or unacceptable for each of the script attributes. For each attribute, if unacceptable values are found, the script is rejected, and other scripts that accept that value are activated or reinforced. Among acceptable values for an attribute, some bring more weight to a hypothesis than others. According to theory, clinical reasoning is therefore made of a series of qualitative judgments. Each of these judgments can be measured. This provides a method of clinical reasoning process assessment.

Chapter 2 describes how the script concordance test (SCT) is conceived to achieve this. The principle is to describe rich authentic clinical contexts in which there is 
not enough data to make a diagnostic or management decision. Therefore the sitwation represents a problem, even for an expert of the domain. Items are made from the questions experienced physicians ask and the actions they take in these contexts. The SCT is innovative in the three components any assessment tool has: the stimulus format (examinees' task), the response format (how examinees ${ }^{\prime}$ performances are recorded), and the scoring system (the transformation of performances into scores). The stimulus consists of a challenging clinical task. The response format is in accordance with what is known from clinical reasoning processes: a Likert scale, measuring the judgments that are constantly made within the clinical reasoning process, capturing examinees" answers. The scoring method, an adaptation of the aggregate scoring method, takes into account variation of aniswers among a criterion group. With these characteristics, stemming from the described theoretical frameworks, the SCT allows in the context of a series of clinical tasks, to compare examinees' scripts to those of a panel of experienced clinicians (hence the name of the test).

The second research question concerns the construct validity of the SCT. One of the limitations of current clinical assessment tools is the intermediate effect i.e., the puzzling fact that experienced clinicians score little better and sometimes worse than less experienced clinicians or students. The SCT probes script development i.e., the development of specialized knowledge structures that contain the clinically relevant information that clinicians use in their clinical activities. It also explores the capacity for data interpretation when making clinical decisions, clearly a skill that belongs more to clinical competence than the simple recall of factual data. Four studies presented in the dissertation are applications for different goals of the SCT in different disciplines. We found a disappearance of the intermediate effect in all four applications / contexts. We conclude that these results represent an argument in favor of the SCT construct validity.

The third research question explores the reliability and feasibility of the SCT. In three studies, Cronbach alpha coefficient value was in the 0.79 to 0.82 range, with relatively small numbers of items ( 29 to 80 ). These values indicate a good reliability of the test, especially when interpreted in comparison with the time required by other examination formats to reach the 0.80 value. In terms of feasibility, in light of the experienced acquired with the studies described in the dissertation, SCT appears relatively easy to build, to administer and to score.

The fourth research question concerns the validity of the scoring method used in the SCT, the aggregate method. The fourth chapter of the dissertation is a comparison of that method with the usual consensus method in which jury members (criterion group) are required to decide, by group discussion, on a single right answer. The study showed a change of answers on $59 \%$ of items. This magnitude of change, if confirmed by other studies, has important consequence for the assessment of ill-defined problems. It suggests that criterion group responses should be obtained in contexts that are as similar as possible to those examinees will have. 
The study provides another argument in favor of the aggregate scoring method. The method appears more sensitive to detection of expertise than the typical consensus method. When experts are judged on a consensus-based scoring scheme built by other experts, their own expertise is difficult to detect. The aggregate method appears superior to the more conventional consensus method. It offers an objective scoring process for the assessment of complex performance in ill-defined situations.

The fifth research question examines the applicability of the SCT in different clinical contexts. Studies presented in chapters 3 to 6 show that the SCT can be used in disciptines as diverse as gynecology, radiology or urology and that it is able to discriminate examinees across their level of experience in the three disciplines. They also indicate that same tools can be used for students, residents and physicians in practice. The tool is well accepted and found interesting to pass. In the study presented in chapter 5, the same test was administered in English to the Canadian subjects and in French to the French participants. The test was able to discriminate among participants of the two countries according to their level of clinical experience, despite linguistic, cultural, educational and institutional differences. This was true even when examinees were judged with the criterion group of the other culture, although there was a slight difference in that examinees obtained higher scores when criterion groups from their own culture assessed them. The study described in chapter 6 was held to verify if the SCT could be used as a test of $X$-ray interpretation skills, with actual films as stimuli. The perception skills of radiological sigms were assessed with a specific perception test. The study shows that SCT is able to detect a dimension of competence that progresses along training at a different speed than the perception skill.

In the light of the presented studies, the SCT appears as a simple and direct approach to test organization and use of knowledge. It has the strong advantage for a testing method of being relatively easy to construct and use and to be machine-scorable. It can be either paper or computer-based and can be used in under-graduate, post-graduate, or continuing medical education. The dissertation ends with a description of the research and development avenues SCT offers, and with a proposition for the place SCT may occupy in a strategy of clinical competence assessment. 
110 


\section{Samenvatting}

De onderzoeksvraag die centraal staat in dit proefschrift heeft betrekking op de mogelijkheid om een toetsinstrument voor klinische redeneervaardigheid te ontwikkelen dat aansluit bij de actuele ontwikkelingen in de cognitieve psychologie en de wetenschappelijke inzichten over toetsing.

In het cognitief onderzoek naar medische expertise is de aandacht verschoven van algemene probleemoplossingsvaardigheden naar de organisatie van het geheugen, de toepassing van kennis, probleemrepresentatie en de veranderingen die zich hierin voordoen met het toenemen van de ervaring. Deze verplaatsing van het zwaartepunt is nog niet tot uiting gekomen in veel toepassingen op het gebied van toetsing en evaluatie. De script concordance test (SCT) is ontwikkeld vanuit het perspectief van de aanbeveling gedaan door Elstein et al. (1990). Deze auteurs stelden voor om evaluatie te richten op het beoordelen van de kwaliteit. van een aantal samenhangende cognitieve handelingen of kennisstructuren door een vergelijking te maken tussen de probleemrepresentatie, oordeelsvorming en keuzen van studenten en die van een groep ervaren deskundigen.

De eerste onderzoeksuraag gaat in op de theoretische validiteit van het toetsinstrument. Gekeken is naar de theoretische onderbouwing van de keuzes die gemaakt zijn bij het ontwerpen van het instrument en naar de mate waærin het instrument aansluit bij de resultaten van onderzoek over toetsing.

In hoofdstuk 1 wordt beschreven hoe de scripttheorie uit de cognitieve psychologie aangepast is aan de kenmerken van het klinisch redeneren. Beschreven wordt hoe artsen tijdens het proces van gegevensverzameling nieuwe informatie voor elk s.criptkenmerk systematisch toetsen aan de waarden die voor dat kenmerk aanvaardbaar of niet aanvaardbaar zijn. Als de gevonden waarden niet bij een bepaald kenmerk passen, wordt het script verworpen en worden andere scripts waar de nieuwe waarde wel bij past geactiveerd of ondersteund. Sommige waar- 
den die in overeenstemming zijn met een bepaald kenmerk, vormen een krachtiger ondersteuning voor de hypothese dan andere. Volgens de theorie bestaat klinisch redeneren uit een reeks kwalitatieve oordelen. Elk van deze oordelen kan gemeten worden. Met deze overwegingen als uitgangspunt kan een toetsmethode voor klinische redeneervaardigheid ontwikkeld worden.

Het onderwerp van hoofdstuk 2 is de ontwikkeling van de script concordance test (SCT), een instrument om klinische redeneervaardigheid te toetsen. In de SCT worden rijke authentieke klinische situaties beschreven die onvoldoende aanknopingspunten bevatten om beslissingen over diagnose en beleid te kunnen nemen. Dit betekent dat de situatie ook een expert op het betreffende terrein voor een echt probleem stelt. De toetsitems bestaan uit de vragen en handelingen van een ervaren arts in een vergelijkbare situatie. De SCT bevat vernieuwingen op de drie belangrijke onderdelen van toetsinstrumenten: de stimulus (de opdracht die de kandidaat moet uitvoeren), het antwoord (de manier waarop de prestatie van de kandidaat wordt geregistreerd) en de scoring (het omzetten van de prestatie in een waardering). De stimulus wordt gevormd door een uitdagende klinische opdracht. De antwoordvorm sluit aan bij wat we weten over klinische redeneerprocessen. De kandidaat kan de antwoorden aangeven op een Likertschaal, die de oordelen meet die tijdens het klinisch redeneerproces voortdurend worden gevormd. De toets wordt gescoord met behulp van een aangepaste versie van de aggregatiemethode. Deze methode maakt het mogelijk om verschillende antwoorden die in een criteriumgroep naar voren komen, in de waardering te betrekken. Bovengenoemde kenmerken, die voortvloeien uit de beschreven theoretische kaders, maken de SCT tot een instrument waarmee de scripts die kandidaten ontwikkelen naar aanleiding van een reeks klinische opdrachten vergeleken kunnen worden met de scripts van een panel ervaren clinici (vandaar de naam van de toets).

De tweede onderzoeksvraag gaat in op de constructvaliditeit van de SCT. Een van de beperkingen van de gangbare toetsmethoden voor klinische vaardigheid is het intermediërende effect, dat wil zeggen het verwarrende verschijnsel dat ervaren clinici niet veel beter en soms zelfs slechter scoren dan minder ervaren clinici of studenten. De SCT onderzoekt hoe de kandidaat een script ontwikkelt, met andere woorden de ontwikkeling van specialistische kennisstructuren waarbinnen de klinisch relevante informatie gevonden kan worden die door clinici bij het klinisch handelen wordt toegepast. De SCT onderzoekt ook het vermogen om gegevens te interpreteren bij het nemen van klinische beslissingen, een vaardigheid die duidelijk eerder thuishoort bij klinische competentie dan bij het alleen maar reproduceren van feitenkennis. In dit proefschrift worden vier onderzoeken beschreven waarin de SCT voor verschillende doeleinden en in verschillende disciplines is toegepast. Het intermediërende effect bleek te verdwijnen bij alle vier de toepassingen/contexten. De conclusie lijkt gerechtvaardigd dat deze resultaten de constructvaliditeit van de SCT ondersteunen. 
De derde onderzoeksvraag betreft de betrouwbaarheid en de haalbaarheid wan de SCT. In drie onderzoeken, warin het ging om toetsen met een betrekkelijk gering aantal items (29 tot 80 ), bleek Cronbachs alfa te varièren van .79 tot .82. Deze resultaten vormen een aanwijzing dat de SCT een betrouwbare toets is, vooral in vergelijking met andere examenvormen die meer toetstijd vereisen om een betrouwbaarheid wan .80 te bereiken. Wat haabaarheid betreft lijken de ervaringen uit de onderzoeken die in dit proefschrift beschreven worden erop te wijzen dat de SCT een toets is die eenvoudig is samen te stellen, af te memen en te scoren.

De vierde onderzoeksvraag betreft de validiteit van de scoringsmethode van de SCT, de aggregatiemethode. In het vierde hoofdstuk van dit proefschrift wordt een vergelijking gemaakt tussen deze methode en de gebruikelijke consensusmethode waarbij panelleden (criteriumgroep) door middel van discussie consensus over het enig juiste antwoord moeten bereiken. In het onderzoek bleek dat het antwoord bij $59 \%$ van de toetsitems gewijzigd werd. Als wijzigingen van een vergelijkbare omwang ook in ander onderzoek gevonden worden, heeft dat ingrijpende gevolgen voor de toetsing van onduidelijk omschreven problemen. Deze bevinding zou erop wijzen dat de criteriumgroep de vragen moet beantwoorden in omstandigheden die vergelijkbaar zijn met de omstandigheden waarin het examen wardt afgenomen. Het onderzoek levert nog een argument op dat de aggregatiemethode ondersteunt. De aggregatiemethode blijkt een gevoeliger methode te zijn voor het identificeren van expertise dan de conventionele consensusmethode. Het is moeilijk om de specifieke expertise van een expert te meten met een beoordelingsnorn die door andere experts met behulp van een consensusprocedure is vastgesteld. De aggregatiemethode blijkt: superieur te zijn aan de conventionele consensusmethode. Hij biedt een objectieve methode orn een complexe prestatie in een onduidelijke situatie te beoordelen.

De vijfde onderzoekswraag heeft betrekking op de bruikbaarheid van de SCT in verschillende klinische contexten. De onderzoeken die in hoofdstuk drie tot zes beschreven worden, laten zien dat de SCT geschilkt is woor uiteenlopende disciplines, zoals gynaecologie, radiologie of urologie en dat de methode in de drie disciplines verschillen in ervaring tussen kandidaten kan meten. De beschreven onderzoeken wijzen ook uit dat dezelfde instrumenten gebruikt kunnen worden voor toetsing van studenten, assistenten en praktiserende artsen. Kandidaten vinden de SCT een acceptabele toets. Ook vinden zij het een interessamte toets om te doen. In het onderzoek dat beschreven wordt in hoofdstuk 5 werd een Engelstalige toets afgenomen bij Canadese proefpersonen en een Franstalige versie van dezelfde toets bij Franse proefpersonen. Ondanks de verschillen tussen

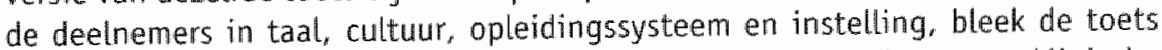
onderscheid te kunnen maken tussen de deelnemers in het niveau van klinische expertise. Dit was zelfs het geval als de kandidaten beoordeeld werden met behulp van de criteriumgroep uit de andere cultuur. Wel was er dan een gering 
verschil: de kandidaten behaalden namelijk hogere scores als zij beoordeeld werden aan de hand van de criteriumgroep uit hun eigen cultuur. Het onderzoek dat in hoofdstuk 6 wordt beschreven had tot doel te onderzoeken of de SCT ook toegepast kan worden om het beoordelen van röntgenfoto's te toetsen, waarbij echte röntgenfoto's als stimulus gebruikt werden. De vaardigheid om radiologische verschijnselen waar te nemen werd beoordeeld door middel van een speciale waarnemingstoets. Het onderzoek wees uit dat de SCT een dimensie van competentie kan meten die tijdens de opleiding in een ander tempo toeneemt. dan de waarnemingsvaardigheid.

De beschreven onderzoeken laten zien dat de SCT een eenvoudige en directe benadering biedt voor het toetsen van de organisatie en toepassing van kennis. Het grote voordeel van de methode is dat toetsconstructie en -afname betrekkelijk eenvoudig zijn en dat automatische scoring mogelijk is. De SCT kan schriftelijk of via de computer afgenomen worden en is zowel in de basisopleiding, de specialistenopleiding als voor nascholing bruikbaar. Het proefschrift wordt afgesloten met aanbevelingen voor verder onderzoek naar en ontwikkeling van de SCT. 0ok wordt een voorstel gedaan betreffende de plaats van de SCT als onderdeel van een methode voor het toetsen van klinische competentie. 


\section{Curriculum Vitae}

Bernard Charlin was born on January 26, 1949 in Rabat, Morocco. He obtained a M.D. degree in the University of Montpellier (France) in 1975, then a certificate of Ear, Nose and Throat specialist in the University of Montpellier in 1981. He went to Canada in 1983, and became a fellow of the Royal College of Physicians and Surgeons of Canada in 1985. He has exerted his head and neck surgery specialty in Sherbrooke, Quebec. He held the positions of ENT program director, then chair of the ear, nose and throat department of Sherbrooke University. He was nominated full Professor in 1992. He moved to the University of Montreal in 1998 to become Head of the Unit of research and Development in Health Sciences Education. He obtained a Master degree in Education (MA) in the University of Sherbrooke in 1993, a Certificate of Advanced Studies in Human Development and Psychology at the Harvard Graduate school of Education (Concentration in Methodology) in 1994. He began his PhD in Maastricht in 1997. 